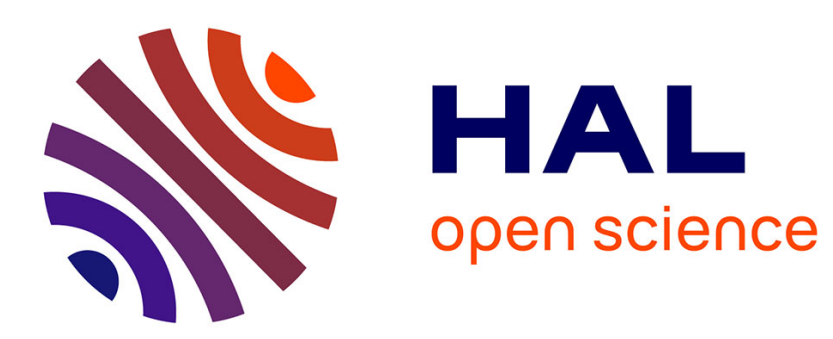

\title{
Global archaeomagnetic data: The state of the art and future challenges
}

\author{
Maxwell C Brown, Gwenaël Hervé, Monika Korte, Agnès Genevey
}

\section{To cite this version:}

Maxwell C Brown, Gwenaël Hervé, Monika Korte, Agnès Genevey. Global archaeomagnetic data: The state of the art and future challenges. Physics of the Earth and Planetary Interiors, 2021, 318, pp.106766. 10.1016/j.pepi.2021.106766 . insu-03280044

\section{HAL Id: insu-03280044 https://hal-insu.archives-ouvertes.fr/insu-03280044}

Submitted on 7 Jul 2021

HAL is a multi-disciplinary open access archive for the deposit and dissemination of scientific research documents, whether they are published or not. The documents may come from teaching and research institutions in France or abroad, or from public or private research centers.
L'archive ouverte pluridisciplinaire HAL, est destinée au dépôt et à la diffusion de documents scientifiques de niveau recherche, publiés ou non, émanant des établissements d'enseignement et de recherche français ou étrangers, des laboratoires publics ou privés. 


\section{Journal Pre-proof}

PHYSICS

OF THE EARTH

AND PLANETARY

INTERIORS

Global archaeomagnetic data: The state of the art and future challenges

Maxwell C. Brown, Gwenaël Hervé, Monika Korte, Agnès Genevey

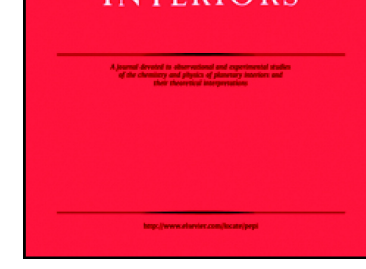

PII: $\quad$ S0031-9201(21)00124-2

DOI: $\quad$ https://doi.org/10.1016/j.pepi.2021.106766

Reference: PEPI 106766

To appear in: $\quad$ Physics of the Earth and Planetary Interiors

Received date: $\quad 7$ January 2021

Revised date: $\quad 17$ June 2021

Accepted date: $\quad 29$ June 2021

Please cite this article as: M.C. Brown, G. Hervé, M. Korte, et al., Global archaeomagnetic data: The state of the art and future challenges, Physics of the Earth and Planetary Interiors (2021), https://doi.org/10.1016/j.pepi.2021.106766

This is a PDF file of an article that has undergone enhancements after acceptance, such as the addition of a cover page and metadata, and formatting for readability, but it is not yet the definitive version of record. This version will undergo additional copyediting, typesetting and review before it is published in its final form, but we are providing this version to give early visibility of the article. Please note that, during the production process, errors may be discovered which could affect the content, and all legal disclaimers that apply to the journal pertain.

(C) 2021 Published by Elsevier B.V. 


\title{
Global archaeomagnetic data: the state of the art and future challenges
}

\author{
Maxwell C. Brown ${ }^{\mathrm{a}, \mathrm{b}, *}$, Gwenaël Hervé, ,d,e $^{\text {, }}$ Monika Korte ${ }^{\mathrm{f}}$, Agnès Genevey ${ }^{\mathrm{g}}$ \\ ${ }^{a}$ Institute for Rock Magnetism, Department of Earth and Environmental Sciences, University of \\ Minnesota, 150 John T. Tate Hall, 116 Church St SE, Minneapolis, MN 55455, USA \\ ${ }^{\mathrm{b}}$ Institute of Earth Sciences, University of Iceland, Sturlugata 7, 101 Reykjavík, Iceland \\ ${ }^{c}$ Université Bordeaux Montaigne, 33607 Pessac, France \\ ${ }^{\mathrm{d}}$ Université Rennes 1, 2 rue du Thabor, 35065 Rennes, France \\ ${ }^{\mathrm{e}}$ Laboratoire des Sciences du Climat et de l'Environnement/ $\mathrm{P}_{\mathrm{T}}^{\top}$ CEA, CNRS, UVSQ, Université \\ Paris-Saclay, Orme des Merisiers, Bat. 714, 91190, Gif-sur Yvette, France \\ ${ }^{\mathrm{f}}$ GFZ German Research Centre for Geosciences, Teleg ${ }^{\prime}$ dfe. herg, 14473 Potsdam, Germany \\ ${ }^{\text {g} S o r b o n n e ~ U n i v e r s i t e ́, ~ C N R S, ~ L a b o r a t o i r e ~ d ' A r c h ~} 1$ Jg 2 Molculaire et Structurale (LAMS), \\ F-75005 Paris, France
}

\begin{abstract}
Archaeomagnetic data are funda ne. ${ }^{+}$al for our understanding of the evolution of Earth's magnetic field on centennial to millennia ${ }^{1}$ tımescales. From the earliest studies of the Thelliers, Aitken, Nagata and others in the 1 y ¿s and 1960s, archaeomagnetic data have been vital for extending our knowledge of the field th times prior to observational measurements. Today, many thousands of archaeomagnetic data alıow us to explore the geomagnetic field in more detail than ever before. Both regional time series of archaeomagnetic data and the inclusion of archaeomagnetic data in time-varying global spherical harmonic field models have revealed a range of newly discovered field behaviour. More sophisticated approaches to developing regional curves and global models have allowed us to resolve the field in certain regions more robustly and with greater resolution than previously possible. In this review we give an overview of the widely used global
\end{abstract}

\footnotetext{
${ }^{*}$ Corresponding author

Email address: mcbrown@umn. edu (Maxwell C. Brown)
} 
archaeomagnetic database GEOMAGIA50, discuss the methods used to obtain archaeomagnetic data, their challenges, and explore progress over the past twenty years in developing regional secular variation curves and global spherical harmonic models of the archaeomagnetic field. We end the review by covering what we see as the "grand challenges" in archaeomagnetism, including which regions of the world should be focussed on with regards to data acquisition.

Keywords: archaeomagnetism, GEOMAGIA50, global models

\section{Introduction}

Archaeomagnetism is the study of the past direction ar : : ₹wnsity of Earth's magnetic field recorded by any type of manmade artefact or fired mate ${ }^{-}$al.. in is dependent on archaeological discoveries and advances that lead to a better descript on i nd understanding of our history and heritage. Although it was recognized at the end of the 29 th ı entury that fired materials can record Earth's magnetic field (Folgheraiter, 1899), it 'va $n$ 't until the pioneering work of Émile and Odette Thellier beginning in the 1930s th? th phy sical principles, methods and instrumentation necessary to accurately obtain the past directio. and intensity of the geomagnetic field recorded by archaeological materials were devel ${ }_{r}{ }^{\circ}$ (Thellier, 1938, 1941; Thellier and Thellier, 1959). Reviews by Thellier (1977), Le C ff at al. (2006) and Dunlop (2011) give excellent English language overviews of the Thel ${ }^{1}$ ers 'most important contributions to the subject.

Archaeomagnetism estat 's shed itself as a research field through the 1950s and 1960s, with proponents of the subject sbtaining data from fired materials from locations globally. Studies from these decades reported u ta from Europe (e.g., Burlatskaya, 1961; Aitken and Weaver, 1962; Belshé et al., 1963; Chelidze, 1965; Bucha, 1967; Kovacheva, 1969), Northern Africa (Athavale, 1969), India (Athavale, 1966), China (Deng and Li, 1965), Japan (Watanabe, 1958; Nagata et al., 1963; Sasajima, 1965), North America (e.g., Watanabe and Dubois, 1965; Schwarz and Christie, 1967) and South America (e.g., Nagata et al., 1965; Kitazawa and Kobayashi, 1968). Research continued though the 1970s, but it was not until the 1980s that there was a general increase in the number of studies reporting new archaeomagnetic data each year (Fig. 1); a trend that continued through to the 2010s. This has resulted in a large compilation of global data that has greatly improved our understanding of how Earth's magnetic field has varied spatially and temporally on centennial to millennial timescales. 
To date close to 700 studies reporting archaeomagnetic data have been published. The majority of studies have concentrated on specific regions, with data from Europe, the Middle East, China, Japan and North America dominating the global database (see section 2.3). A peak in productivity in the 2000s coincided with the successful European Commission funded Archaeomagnetic Applications for the Rescue of Cultural Heritage (AARCH) research and training network. Data from Europe vastly outweighs that from any other region (section 2.3). Since the early 2000s the development of temporally continuous global spherical harmonic models of the geomagnetic field (see section 4.2) and an interest in the development of the South Atlantic Anomaly on archaeomagnetic timescales has led to a number of stuun $-s$ focussed on obtaining data from archaeological sites in the Southern Hemisphere and equat rial cegions (e.g., Tarduno et al., 2015; Hartmann et al., 2019). Significant new studies hare been published for Africa

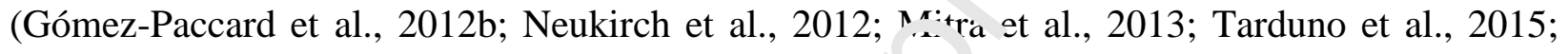
Donadini et al., 2015; Hare et al., 2018; Kapper et al. 2 . 1 , 2020; Tchibinda Madingou et al., 2020), South America (e.g., Hartmann et al., 20 0, 2011, 2019; Goguitchaichvili et al., 2011, 2015, 2019; Poletti et al., 2016; Capdepont é.1., ?019; Cejudo et al., 2019; Gómez-Paccard et al., 2019) and West Oceania (Stark et al., 2010; ; rner et al., 2020). These areas are ripe for expanding our global data set. However, there are li nitations on the availability of archaeological materials for analyses from these areas. As arch af or adgnetism is a destructive method (artefacts must be cut and often heated), there can be res ictiuns on the materials available for laboratory analyses.

Figure 1: Histogram of the "mber of archaeomagnetic studies published per year in the GEOMAGIA50.v3.4 w. taine that contain data dated to the past 10,000 years (accurate as of December 2020). The al number of studies is 685. This excludes studies that employed archaeomagnetic dating as the sole dating method. NB (1) there are additional studies that have published data in non-tabulated form, which have not been added to the database and do not contribute to the total number of studies reported here (e.g., Aitken and Weaver, 1965; Aitken et al., 1989); (2) not all archaeomagnetic studies from Japan have been fully integrated in the current version of GEOMAGIA50 (see section 2.3).

The majority of archaeomagnetic data have been dated to within the past 3000 years, with the number of data on the whole decreasing with increasing age (section 2.4). This has led an 
increasing number of studies to focus on obtaining archaeomagnetic data from materials between 6000 BCE (Before the Current Era) and 1000 BCE (e.g., Kovacheva et al., 2009a; Fanjat et al., 2013; Gallet et al., 2014, 2015; Shaar et al., 2016, 2020; Cai et al., 2020); however, almost all data are from Eurasia, limiting our global knowledge of the field at older archaeological times. Extending archaeological time series to older ages is an exciting direction of research for the coming years. Although, as with improving the global distribution of data, limitations on the materials available for analysis impact the time periods that can be studied further.

The usefulness of compiling regional and global archaeomagnetic data for understanding the evolution of the geomagnetic field was recognized early on in w- development of the subject (e.g., Cook and Belshé, 1958; Watanabe, 1958; Aitken and We ver 1965; Kawai and Hirooka, 1967). This has continued through today, with country or reg ions 1 specific archaeomagnetic data compilations (e.g., Thellier, 1981; Márton, 2003; Tema _: १ı., 2006; Márton, 2010; Carrancho et al., 2013; Hervé et al., 2013a; De Marco et al., 2014; K - acheva et al., 2014; Batt et al., 2017; Molina-Cardín et al., 2018; Goguitchaichvili et al., 2r 17; Schnepp et al., 2020b,a; Rivero-Montero et al., 2021). Such regional data sets have r.’n sed to develop secular variation (or reference) curves (see section 4.1), using evermore sop' sticated mathematical approaches (recent examples include Lodge and Holme, 2009; Thébau' ${ }^{1+}$ and Gallet, 2010; Hellio et al., 2014; Batt et al., 2017; Livermore et al., 2018; Genevey et r1., 2021; Kapper et al., 2020). Compilations of global archaeointensity data have alsn heeı used to infer global dipole moment evolution (e.g.,

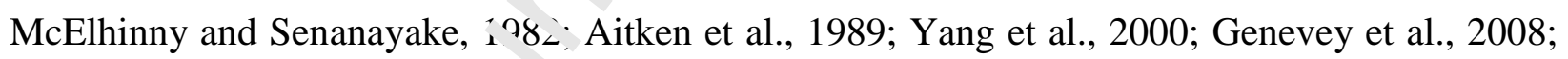
Knudsen et al., 2008; Usocl'in ^t al., 2016).

Over the past 21 s (alongside the construction of direction and intensity curves), has been the development $\mathrm{c}^{\mathrm{c}}$ emporally continuous global palaeomagnetic field models (see section 4.2). These data-based inverse models employ spherical harmonic methods initially developed to analyze and depict the present day field (e.g., Bloxham and Gubbins, 1985; Bloxham and Jackson, 1992) and the historical field (from 1590 CE onwards, based on shipboard and ground based measurements) (Jackson et al., 2000). They have been adapted to suit archaeomagnetic and palaeomagnetic data to produce maps of the geomagnetic field at Earth's surface and the core-mantle boundary (CMB). The earliest global models were developed by Hongre et al. (1998), Constable et al. (2000), Korte and Constable (2003) and Korte and Constable (2005) and combined a variety of data sources (archaeomagnetic, volcanic and sediment data). Global models 
based on primarily archaeomagnetic data (but also including volcanic data) were not developed until the construction of ARCH3k.1 (Korte et al., 2009) (a three thousand year model), which was recently updated to a 10,000 year model (Constable et al., 2016). Spherical harmonic cap approaches using archaeomagnetic data have also been used to create regional models (e.g., Pavón-Carrasco et al., 2008; Pavón-Carrasco et al., 2009). Varying approaches to modelling the archaeomagnetic field have been applied since, including Licht et al. (2013), Pavón-Carrasco et al. (2014), Sanchez et al. (2016), Hellio and Gillet (2018), Arneitz et al. (2019) and Mauerberger et al. (2020).

Concurrent to regional compilations of data and the develup nent of global models there have been continued efforts to create global databases of archac om r gnetic data. The first global archaeomagnetic databases were paper lists of results, the First likely being the historical and archaeointensity compilation of Smith (1967). With the development of digital database structures, archaeomagnetic data could be compiled a. : updated more easily. Early efforts included those of Burlatskaya et al. (1986), Liritzi ; s a' Lagios (1993) and Daly and Goff (1996), although the data were not available in a di a that was easily accessible was the Plymout . trchaeomagnetic directional database (ARCHEO97 and ARCHEO00) compiled by Don Ta ${ }^{1}{ }^{1}$ ing and last released in 1999. This was one of seven International Association of Geomagie is $\_$and Aeromony (IAGA) databases available online to download as stand-alone program. Tw $\checkmark$ major efforts to compile all global archaeomagnetic data have been the ArcheoInt dat ha (Genevey et al., 2008) and the GEOMAGIA50 database (Donadini et al., 2006; Krnu. al et al., 2008; Brown et al., 2015b). Although GEOMAGIA50 largely subsumes the ${ }^{2}$ l. . vithin ArcheoInt, ArcheoInt contains additional fields that place archaeomagnetic resul in their archaeological context and provides greater descriptive information regarding the acquisition of the data sets. The databases can be viewed as complementary. In addition, there is the HISTMAG database of Arneitz et al. (2017), which combines historical and archaeomagnetic data. There are also numerous archaeomagnetic data in the MagIC database (described in part in Tauxe et al., 2016); however, GEOMAGIA50 is currently the primary database for archaeomagnetic data. Unlike MagIC, GEOMAGIA50 includes only average data and is not designed to include results at the specimen level or raw measurements. The site level data from GEOMAGIA50 has been used in numerous studies. In addition to being used to construct secular variation curves and global and regional field models, it has been used to 
understand solar activity during the Holocene (Usoskin et al., 2016) and to calibrate cosmogenic nuclide production stacks through the use of intensity data (e.g., authigenic ${ }^{10} \mathrm{Be} /{ }^{9} \mathrm{Be}$ ratios, Simon et al., 2016).

An important consideration when using archaeomagnetic data for any purpose is the reliability of the data. This includes chronological controls and archaeomagnetic components (direction and intensity), which are most commonly determined from a thermoremanent magnetization (TRM): a magnetization acquired on cooling from firing temperature to room temperature. Archaeomagnetic directions can be influenced by post-cooling displacement and magnetic refraction (section 3.1.1) and obtaining reliable aru' 'eointensities requires that numerous factors are considered (section 3.1.2). These inc ide thermal alteration during palaeointensity experiments (section 3.1.3), the influence of ion-ideal magnetic remanence carriers (e.g., multi-domain (MD) grains, section 3.1.4), - Ya.ence anisotropy (section 3.1.5) and differences between natural and experimental cooling , ies (section 3.1.6). All chronological determinations have an associated uncertainty, wh th $\mathrm{tr}$ an archaeological age, determined through physical measurements (e.g., by radioca - in dating or luminescence methods), or by a combination of approaches (section 3.2). L umenting such uncertainties is a challenge (section 5.1.1) and uncertainties should be caret. ${ }^{1} \mathrm{y}$ considered in any study looking to investigate field behaviour.

In this review we cover the current status of the global archaeomagnetic database (GEOMAGIA50; section 2), $\mathrm{r}^{\mathrm{r}} \mathrm{v}$ : de an overview of archaeomagnetic procedures, data quality, uncertainties and chronoln ric.'1 controls (section 3) and explore advances in regional secular variation curve constru tic - and global archaeomagnetic field modelling (section 4). The review ends with a discussion $c^{n}$, he future challenges of the subject (section 5).

\section{Overview of the GEOMAGIA50 archaeomagnetic database}

In the following sections we give a brief history of the GEOMAGIA50 database (section 2.1), cover the abundance of archaeomagnetic data within the most recent version of the database (GEOMAGIA50.v3.4) (section 2.2), discuss the spatial and temporal distribution of data (section 2.3 and section 2.4), and provide an overview of the archaeological materials used to obtain archaeomagnetic data (section 2.5). The methods used to obtain archaeomagnetic and age data, as well as their uncertainties, are discussed in section 3. 
In this review we consider purely archaeomagnetic data. Data from volcanic materials (lava, volcanic ashes, obsidian) and speleothems (i.e. Latham et al., 1986; Trindade et al., 2018), although stored in GEOMAGIA50.v3.4, are neglected for the purpose of this study. We also restrict our analysis to materials dated between $8000 \mathrm{BCE}$ and today, and we do not include materials that have been dated using archaeomagnetic dating.

\subsection{History of GEOMAGIA50 and its most recent compilation}

Version 1 of GEOMAGIA50 primarily focused on compiling palaeointensity data and contained data from both archaeological materials and lava flows. Lirectional data were added only if they accompanied intensity data. Version 1 integrated the $4 \mathbf{r}$, heoInt database of Genevey et al. (2008) and the IAG A ARCHEO00 database (http://www.ngdc.noaa.gov/geomag/paleo.shtml) compite by Don Tarling. Data from other country- or region-specific compilations were also adr aa 'see Brown et al. (2015b) for a list of compilations). Further details of version 1 of the $c^{\dagger} a b$ ise can be found in Donadini et al. (2006), Korhonen et al. (2008) and Brown et $\%$. 2u:5b). After numerous updates since original publication, 2762 archaeomagnetic entries $1.7 m 109$ studies remain from version 1 in the most up-to-date version of the database.

No publication accompanied vers on 2 of the database; however, the data compilation is described in Donadini et al. (20)s; Around 100 archaeomagnetic entries from version 1 of the database were updated in ersion 2. Archaeomagnetic directional results were added independently of whether in $y$ uccompanied intensity data. This greatly increased the amount of data in version 2 of the c taudse, with 3072 data from 130 studies added at this time that remain in the most recent update oi the database (5834 entries from 240 studies in total).

The current version of the database is version 3, which was initially published in 2015 (Brown et al., 2015b). It marked a change from being hosted at the Scripps Institution of Oceanography, University of California-San Diego, to GFZ Potsdam (https://geomagia.gfz-potsdam.de/). Sediment data were also added in version 3 (Brown et al., 2015a). 1006 entries from 100 archaeomagnetic studies were added to version 3.1 of the database; 498 entries from 220 studies were added to version 3.2 (released in 2017); and 1717 entries from 109 studies in version 3.3 (released in 2019). GEOMAGIA50.v3.2 also incorporated a number of legacy studies (studies published prior to the inception of the database in 2004) that were missing 
in previous versions of the database. This included 141 studies from the UK, which was part of a major revision of all UK entries (Batt et al., 2017). It also included 75 UK studies published since 2004.

The most up-to-date version of GEOMAGIA50 (v3.4) was released in December 2020. To our knowledge, it includes nearly all archaeomagnetic studies with independent age constraints published to date, with the exception of a large number of entries in the Japanese archaeomagnetic database (http://mag.center.ous.ac.jp/en) and some entries from HISTMAG (Arneitz et al., 2017), which have not yet been integrated into GEOMAGIA50. In total 1188 archaeomagnetic entries from 29 studies were added to GEOMAGIA50.v3.4 in 2020 and se current database contains 9981 archaeomagnetic entries from 685 studies. This is $87 \%$ of a' 1 en ries within the database as a whole. This includes 528 French directional entries determin ' $d$ ir the Thellier laboratory at Saint Maur over the past 25 years (Le Goff et al., 2020) and . - - valuation of the French directional compilations of Thellier (1981) and Bucur (1994) (170 e e : . Ies). It also contains a significant new compilation of central European archaeomagnet c scta, both directional data (Schnepp et al., 2020b) and intensity data (Schnepp et al., $\curvearrowright \bumpeq u_{c}$ ) (188 new entries and 18 updates). Data from China have also been significantly increa d with 64 entries published in Cai et al. (2020). Improvements to the Southern Hemisphe \%/equatorial compilation were made, with new data from Kenya (Tchibinda Madingou et al., $2 Y^{\top} 0$, Burkina Faso and Ivory Coast (Kapper et al., 2020), Ecuador (Herrero-Bervera et al.. 2720, Colombia (Cejudo et al., 2019), Uruguay (Capdepont et al., 2019) and New Zealand (Tur. ar et al., 2020). Changes in the distribution of data with each version of GEOMAGIA5n ho: $h$ globally and for Europe, are shown in Fig. 2 and Fig. 3.

\subsection{Overview of a, haeomagnetic data}

Out of the 9981 archaeomagnetic entries in GEOMAGIA50.v3.4, 5931 archaeomagnetic entries contain either declination or inclination and 4528 entries have both. The majority of entries that only have inclination are from the Russian school (e.g., Burlatskaya et al., 1986) (85\% of inclination only entries). Although 5231 entries contain archaeointensity, only 651 entries contain full vector information (declination, inclination and intensity); 533 entries report intensity and inclination without declination; and 4047 entries list intensity without accompanying directions.

In addition to archaeomagnetic results, GEOMAGIA50 contains age and age uncertainty information (see section 3.2) and a variety of meta data that outline the directional, intensity and 
dating methods used. It also includes the number of samples/specimens and specimen types investigated, and the types of archaeological materials the data were obtained from (section 2.5). Full details of the fields within GEOMAGIA50 are given in Brown et al. (2015b).

\subsection{Spatial distribution of archaeomagnetic data}

Figure 2: Geographical distribution of archaeomagnetic sites given in the six versions of GEOMAGIA50 to date (date range from $8000 \mathrm{BCE}$ to $2000 \mathrm{CE}$; archaeomagnetically dated sites are excluded). Colours denote when the data were added to the datab a ${ }^{2} e$. (a) sites with directional data; (b) sites with intensity data. Some version 1 (v1) sites we ie updated with directional information and are shown in (a) as belonging to v1, altho ga th $\pm y$ were updated after the initial release of $\mathrm{v} 1$. If sites were removed during revisions of $\mathrm{s} \wedge \mathrm{Ds}$ ' quent versions, they are not shown on the figure.

Figure 3: Geographical distribution of 2.ch ne nagnetic sites given in the six versions of GEOMAGIA50 to date for Europe and surru 'nding regions (date range from 8000 BCE to 2000 CE; archaeomagnetically dated sites are ‘vcluded). (a) sites with directional data; (b) sites with intensity data. See Fig 2 for legend and of ler details.

There is a large disparı, in the global distribution of archaeomagnetic data (Fig. 2). Data from Europe dominates th _ 'aluvase (Fig. 3 and Fig. 4a-c): 59\% of all entries (including Russia), $51 \%$ without Russian da. ?. File UK (10\% of entries), France (9\%), Russia (8\%) and Georgia (5\%) contribute to a significant portion the European entries (Fig. 3 and Fig. 4b). Many European countries individually contribute between $2 \%$ and $4 \%$ of the total number of entries. The UK comprises the largest number of all entries (961), which are primarily directional data (905). See Batt et al. (2017) for further details on the UK contribution. France is the second largest contributor with 890 entries ( 770 with directions, 162 with intensity). A large amount of data was added (520 entries) following the publication of Le Goff et al. (2020).

Figure 4: Pie charts of the number of archaeomagnetic entries (in brackets) in GEOMAGIA50.v3.4 by region (a-c) and by country (d-f) by data type: (a,d) directional and 
intensity, $(\mathrm{b}, \mathrm{e})$ directional, and $(\mathrm{c}, \mathrm{f})$ intensity. Country plots list the top nine countries by number of entries, with all other entries grouped into a single pie segment.*The data within GEOMAGIA50.v3.4 does not contain all known Japanese data, which total around 800.

It is worth noting that although $72 \%$ of directional entries come from Europe (omitting Russia), this region covers only 1-2\% of Earth's surface (depending on the definition of Europe) (Fig. 4b). Data from regions adjacent to Europe are also dense, with the Levant (Israel, Syria, Jordan), Egypt and Iraq contributing significantly to the database. The distribution of data (directions and intensities) from Europe and these regions is shown - $^{-}$Fig. 3.

Outside of Europe the United States of America (7\% of , ntri ss), China (6\%), Japan (4\%) and Mexico (3\%) are the main contributors. All other nation. ma ke up 29\% of entries. Although the number of Japanese entries in GEOMAGIA50 $\operatorname{tot}^{-1} .3,9$, the Japanese archaeomagnetism database of T. Hatakeyama (Okayama University, Japar) 1 .tp://mag.center.ous.ac.jp/en) lists 744 directional data and 59 intensity data, placing it $\mathrm{b}^{\mathrm{i}} \mathrm{ic}$ in the list of country entries. We aim to integrate this significant contribution with $C=9{ }^{*}$ AGIA50 in the future.

Although there have been recent $e_{1}{ }^{c}$ irts to improve the global distribution of data, the Southern Hemisphere is currently pow. ${ }^{-1} \mathrm{v}$ represented, with only 400 entries or $4 \%$ of all archaeomagnetic entries. 76 entries cun alı a direction and 340 an intensity. The disparity in data distribution is stark when it is re ssidured that Africa and South America, which cover 9\% of Earth's surface when combin $1.2 \%$ of the land area), provide only $7 \%$ of the entries in the database (Fig. 4a). Howevar amount of Southern Hemisphere data continues to improve. In Fig. 2 we show the it wase of Southern Hemisphere data with each new version of GEOMAGIA50. Notab:- studies have that have obtained data from southern Africa are Neukirch et al. (2012), Tarduno et al. (2015) and Hare et al. (2018). Previously only one study had published data from this region (Henthorn et al., 1979) and this was not added to GEOMAGIA50 until version 3.3. A number of South American countries have garnered new data. In the first version of GEOMAGIA50, there were no entries from Brazil, Argentina, Uruguay and Chile. In the past 10 years data have been obtained from all four: Brazil, 49 intensity entries (Hartmann et al., 2010, 2011, 2019; Poletti et al., 2016), Argentina, 44 entries (e.g., Gómez-Paccard et al., 2019; Goguitchaichvili et al., 2019), Uruguay, 6 entries (Capdepont et al., 2019) and Chile, 1 entry (Roperch et al., 2015). In addition, data have been obtained from other South American countries 
south of the Equator. By far the most number of entries come from Peru, with 191 (e.g., Gunn and Murray, 1980; Yang et al., 1993). Smaller contributions come from Bolivia (13 entries) (e.g., Nagata et al., 1965; Kitazawa and Kobayashi, 1968) and Ecuador (23 entries) (Kitazawa and Kobayashi, 1968; Bowles et al., 2002; Herrero-Bervera et al., 2020).

The area between the tropics fairs better than the Southern Hemisphere, with nearly $10 \%$ of all entries coming from this latitude band. This includes the large and growing data set from Mexico (see, Hervé et al., 2019b,c; Mahgoub et al., 2019). New studies from India (Basavaiah et al., 2019; Deenadayalan et al., 2020), western Africa (Kapper et al., 2017, 2020) and eastern Africa (Osete et al., 2015) have contributed important intensity data from areas that are isolated from others globally. As we move closer to the equator the amount of i vail ible data shrinks with $<2 \%$ of database entries from between $\pm 10^{\circ}$ latitude. Six sturii $\mathrm{h}_{\mathrm{i}}$ ve produced new data in this latitude band over the past 10 years, with the first arch $\ldots$. nagnetic data from Kenya (Tchibinda Madingou et al., 2020) and the Ivory Coast (Kapper et a'., $\cdot 120$ ), and others building on small data sets from Ecuador (Herrero-Bervera et al., 2020) c nr. Colombia (Cejudo et al., 2019).

The spatial distribution of directiona' a ' d intensity data are distinctly different (Fig. 2, Fig. 3 and Fig. 4). Countries that produce num. rous directional data do not always produce large amounts of intensity data and vice vers. As stated already, the UK has the most directional entries, but few intensity entries. Curve sely, China has the most abundant intensity data by country, but does not make the trp ten countries for directional data. Russia, east of the Black Sea has abundant directional data, $\iota$ 't $\triangle$ parser intensity data. To a lesser extend the same is true for the Ukraine, which produces t... 5 . most directional data (5\% of all directional entries), but far fewer intensity data than oth $r$ cuntries. India and Brazil have no directional data, but numerous intensity data. This dispmity can be crucial in areas with sparse data coverage, where full vector data are particularly important for constraining field models, e.g., sites in West Africa, where few directional data have been obtained (Burkina Faso; Donadini et al., 2015), whereas intensity data are more plentiful (Mitra et al., 2013; Kapper et al., 2017, 2020). The greater abundance of intensity data can be related to the availability of material to study (see section 2.5).

\subsection{Temporal distribution of archaeomagnetic data}

There is a large variability in the temporal distribution of data in GEOMAGIA50.v3.4 over the past 10,000 years (Fig. 5). Both the number of archaeomagnetic directions and intensity in 
general decrease with age. This is most stark for BCE data, with $35 \%$ of all entries from this time. The number of BCE directions is substantially less (20\% of total directions) than for $\mathrm{CE}$ (Common Era) directions. The contrast is less abrupt for archaeointensity data. Although the number of BCE intensity entries per century is in general less than for CE entries, 54\% of all intensity data span $8000 \mathrm{BCE}$ to $1 \mathrm{BCE}$.

There are notable spikes in the number of directional and intensity entries for certain time periods. For directional data there are peaks in the number of directional data between $100 \mathrm{CE}$ and $300 \mathrm{CE}, 700 \mathrm{CE}$ and $900 \mathrm{CE}, 1100$ and $1400 \mathrm{BCE}$, and $1700 \mathrm{BCE}$ and 2000 (Fig. 5a). The most populous century for directional results is the 19th (410 entries froin 31 studies). Some peaks can be attributed to certain cultural periods, e.g., the high number of sntr es between $100 \mathrm{CE}$ and 300 $\mathrm{CE}$ are from the peak of the Roman Empire, with the data $s t^{+}$do ninated by entries from present

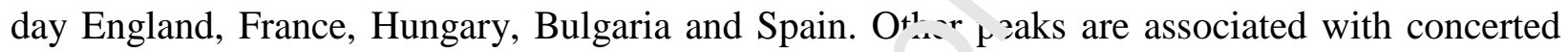
research initiatives in specific countries (or by certain r warch groups with dedicated focuses), e.g., the $700 \mathrm{CE}$ to $900 \mathrm{CE}$ peak is dominated by ( at $\mathcal{\imath}$ rom France for the High Middle Ages (Le Goff et al., 2020).

There is a peak in archaeointensity ge entries during the first millennium BCE, where there has been concerted efforts to chara terize the Levantine intensity spike (see section 4.1.2). There are notable minor peaks in the $1 . \mathrm{a} n \mathrm{nt} \sim \mathrm{r}$ of intensity entries during the Neolithic, with notable studies from the Neolithic and Brc. ze age from China (207 entries) (see Cai et al., 2020), Iraq (179 entries) (Sakai, 1980; Nachasc `a . nd Burakov, 1995, 1998; Yutsis-Akimova et al., 2018a,b) and the rest of the Middle Eas ${ }^{\prime}\left(14^{\circ}\right.$ _ntries) (e.g., Kawai et al., 1972; Gallet et al., 2014; Stillinger et al., 2015; Shaar et al., 20.4. Gallet et al., 2020), Bulgaria (136 entries) (e.g., Kovacheva, 1997; Kovacheva et al., 200。, 2014; Kostadinova-Avramova et al., 2020) and Spain (79 entries) (Nachasova et al., 2002, 2007; Carrancho et al., 2013).

Figure 5: Archaeomagnetic entries in GEOMAGIA50.v3.4 by age in 100 year bins. (a) directions, (b) intensity, (c) Northern Hemisphere data and (d) Southern Hemisphere data.

We note that there are very few BCE data from the Southern Hemisphere. There are only a few data per century back to 6000 BCE (Fig. 5d). In contrast the Northern Hemisphere (Fig. 5c) has 10 times or more data per century. 


\subsection{Overview of archaeological materials}

A wide range of archaeological materials and structures can be used to obtain directional and intensity information (Fig. 6). Almost all data from archaeological material $(\sim 99 \%)$ were recovered from baked clays that acquired a TRM roughly parallel and proportional to the ambient geomagnetic field at the time of their firing. A few other archaeological materials can carry a remanent magnetization acquired through different processes. In mural paintings, e.g., frescoes, red pigments with hematite can acquire a so-called pictorial remanent magnetization when paint is sufficiently liquid to enable hematite grains to orientate parallel to . he geomagnetic field (e.g., Chiari and Lanza, 1997; Zanella et al., 2000). Through a rela ${ }^{\circ}$ d process, lime-plasters (e.g., Hueda-Tanabe et al., 2004) and unburnt adobe bricks (e g., G.mes, 1977) can also acquire a remanent magnetization, when the plaster or the clay s is ixed with water. These materials are promising, even though experimental uncertainties are gen rally higher than for baked clays.

Fifty types of materials and structures are is ec in the current version of GEOMAGIA50; however, there are some that have been sam ste $1 \mathrm{n}$.re frequently than others. In Fig. 6 we list the 8 most commonly used. In some cases $(13 \%, f$ entries $)$ the type of material that was used is not given in the database. There are clear diftc:ences in the materials used for directional and intensity studies. For directional analysis, in-nlar e ',riented structures are necessary. Therefore kilns, ovens and hearths, bricks, and burnt stu tures are frequently used. For intensity the materials do not need to be in-situ, which allow a store diverse array of materials to be pooled from. Pottery and ceramics, owing to their w nudnce and ease of sampling are therefore the most common for intensity analysis. Ove reunt years copper slags have been used owing to their magnetically appropriate characteristıs for intensity experiments (Shaar et al., 2010).

Materials suitable for intensity are often easier to access, because the material has already been sampled and the collections they are from are well-studied. Sampling of these objects is also less invasive. For directional studies, it is necessary to be reactive to an archaeological excavation. In-situ structures are uncovered and maybe destroyed when working on rescue excavations. Sometimes kiln-type structures are preserved because of an obvious archaeological interest; however, sampling is invasive and possibly incompatible with heritage conservation. These issues may partially explain why the proportion of direction and intensity studies varies in different countries (section 2.3). 
Figure 6: Pie charts of the number of mentions (in brackets) of the archaeomagnetic materials used to determine (a) direction and/or intensity, (b) directions, (c) intensity. The eight most used materials are shown in each subplot, remaining material types are grouped under "Other". Note in (b), most inclination data only come from displaced bricks, making the assumption that they were fired on one of their sides. The number of directional and intensity entries do not match the number of materials given in the plots, as numerous entries were determined from multiple materials.

\section{Experimental considerations and data quaity}

In this section we outline the methods that have been $1>0:=$ obtain archaeomagnetic data and date archaeological materials. We discuss how experir enı.1 methods and practices affect the accuracy and precision of archaeomagnetic and chronol gic $\mathrm{ll}$ data and address how uncertainties are represented in the database. For intensity experime its v'e cover alteration during heating, the influence of multi-domain grains, remanence anisc ${ }^{+}$or $y$ and the effect of cooling rate.

Dating methods applied to archaeol jgi al in aterials are varied and we group them into two categories: those that directly or indirectly 'ate a material. We discuss the nuances of these methods when applied to archaeologinal naterials, how they can be combined to create a site chronology, and their age uncertain+ies.

\subsection{Archaeomagnetic me'surements}

\subsubsection{Directions}

Three approache have commonly been used to recover directional data from archaeological materials. The first two involve stepwise removal (demagnetization) of a TRM by either heating to increasing temperatures (thermal demagnetization) or by increasing the alternating current of a field coil (alternating field (AF) demagnetization). For some entries in the database both approaches have been used in conjunction. An alternative approach is to use viscosity cleaning. Developed by Émile Thellier (see, Thellier, 1981), viscosity cleaning has proven to be as effective as a complete demagnetization in isolating directions, when a sample records a single TRM component. See Le Goff et al. (2020) for an overview of this two-step method. Unfortunately, $56 \%$ of entries in the database do not report the demagnetization method used. Of entries that do list a demagnetization method, alternating field (AF) demagnetization is 
the most commonly used (33\%), followed by viscosity cleaning (28\%) (largely from entries from France, Le Goff et al., 2020), a mixture of AF and thermal demagnetization (23\%), and solely thermal demagnetization (16\%).

There are various factors that are likely to interfere with the accurate recovery of past field directions. First is the precision of the sampling and sample orientation, which is critical in archaeomagnetism where one tries to recover small directional variations. Conservation of structures and mechanical problems, such as the inward or outward sagging of the walls or a slight tilting of the kiln sole, can influence the precision and reliability of the archaeomagnetic direction. The direction recorded by a structure can be further perturbed by mas netic refraction, whereby the magnetization of a structure can distort the magnetic field $\mathrm{r}$ cor ed, in particular when the magnetization is strong (e.g., Aitken and Hawley, 1970; Hus $\epsilon^{\prime}$ al. 2004). This can also result from differential cooling as, for instance, may occur in large wures (Lanos, 1987). Understanding magnetic refraction requires dense sampling across all $\mu$. is of a structure. Too much localized sampling can lead to a precise but biased mean dir ect.ı $\mathrm{n}$.

Another factor that may bias remane ${ }^{\prime} \mathrm{c}^{\prime}$ 'rections is the anisotropy of TRM. For bricks or tiles used to mason all or parts of a kiln, this ifect results in a recorded direction that may deviate from the ancient field. Taking this effecı : nto account requires the determination of an anisotropy tensor (see details on the correction fo : n1, utropy effects in section 3.1.5). For baked clay ovens or hearths, the degree of anisotropy is usually considered to be weak, and does not impact the remanence direction, e.g., Ko ' $\mathrm{ch}$ 'va et al. (2009b) and Le Goff et al. (2020). However, it should be noted that a significant $\left.{ }^{+}{ }^{h} a_{1}\right\lrcorner$ wing of inclinations of up to $13^{\circ}$ was recently documented for thin oven soles (Palen: ${ }_{1}$ - _tas et al., 2017, 2021). We further note that the GEOMAGIA50 database does not yet li $\mathrm{k}$ ke it possible to assess whether or not the anisotropy effect has been evaluated and taken into account in the directional studies.

On the whole the precision of directional data within GEOMAGIA50.v3.4 is variable, but is in general of statistically good quality, with $80 \%$ of entries having $0^{\circ} \leq \alpha_{95} \leq 5^{\circ}$ (the cone of confidence at 95\%; Fisher, 1953) and 90\% with $0^{\circ} \leq \alpha_{95} \leq 10^{\circ}$ (Fig. 7). Some data have particularly low $\alpha_{95}$ (30\% of entries have $0^{\circ} \leq \alpha_{95} \leq 2^{\circ}$ ) and values of $k$ (the precision parameter; Fisher, 1953) into the thousands. Conversely, some $\alpha_{95}$ values are notably high and some $k$ are very low. The precision of directional data can be difficult to quantify for some 
entries as $\alpha_{95}$ is not specified for $6 \%$ of directional entries and $k$ is given for only $50 \%$. We also note that the method of calculating $\alpha_{95}$ is not always noted in publications. There are two forms of the $\alpha_{95}$ equation; the original equation in Fisher (1953) and an approximation for a large number of samples (see, e.g., Butler, 1992). These can result in different values of $\alpha_{95}$ if the number of samples is less than approximately 10 .

Less than $2 \%$ of entries are based on the successful analysis of only one or two samples and have no associated $\alpha_{95}$ or $k$. When the number of successfully measured samples is at least equal to $3, k$ is greater than 100 for $80 \%$ of the entries reporting $i$ ( $40 \%$ of the all directional results). Any study wishing to use directional data should asse ss $t$ le uncertainty that they are comfortable in incorporating into the analysis.

Figure 7: Measures of uncertainty and precision (Fisher. 1; ; 3) on archaeomagnetic directional and intensity entries within GEOMAGIA50.v3.4: (a) $9 j^{\prime}$, ) cone of confidence $\left(\alpha_{95}\right)$ (bin size $=1$ degree); (b) precision parameter $(k)$ (bir si $a=100 k$ ). Only $\alpha_{95}$ values $<20$ are shown, corresponding to 5542 entries or $99 \%$ of all en . ries with an $\alpha_{95}$ or $93 \%$ of all directional entries. Only $k$ values < 4000 are plotted, ot ${ }^{1}$ ling 2769 values (91\% of all entries with k; $47 \%$ of all directional entries). Whether $\alpha_{95}$ is alculated using the full equation of Fisher (1953) or an approximation (see, Butler, 199L) is not noted in the database as it is commonly not stated. (c) Uncertainty on archaeointensi $\mathrm{v}$; stimates expressed as a percentage of the archaeointensity value (bin size $=1 \%$ ). Note $h a$, th , uncertainties plotted here are those given by the author and result from different approaches io calculating uncertainty.

\subsubsection{Archaeointensity determinations}

The linearity at low fields $(<150 \mu \mathrm{T})$ between geomagnetic field strength and the intensity of a TRM acquired on cooling in this field is the physical basis for intensity estimates. A detailed description of the protocols is beyond the scope of this article as there are numerous approaches and derivatives that can be used (e.g., Dunlop, 2011; Tauxe and Yamazaki, 2015; Tauxe et al., 2018), but we give an overview of those used for archaeological entries in GEOMAGIA50 and review the different experimental strategies used to detect and/or possibly 
mitigate various effects that influence the intensity measurements.

GEOMAGIA50.v3.4 lists 25 palaeointensity methods and variants; however, these can be primarily classed into five main types, as listed in Fig. 8a. Thellier-type approaches that use double heating steps to impart a laboratory induced TRM as proposed by Thellier and Thellier (1959) make up $87 \%$ of all intensity entries in the database. Of the Thellier-type approaches, the original Thellier and Thellier (1959) method has been used more than any other method, followed by the Coe-Thellier approach (Coe, 1967). The IZZI protocol (Yu et al., 2004) has increasingly been used over recent years as the revised order of the in-field and zero-field steps during the experiment aids in the identification of non-ideal (MD) grains that can bias intensit, estimates (section 3.1.4). It currently makes up $11 \%$ of Thellier-type entries, but we anticipat it v ill be used increasingly over coming years. Other Thellier-type variants, such as that of A $i$. ken tt al. (1988), MT4 of Leonhardt et al. (2004), and the two specimen approach of Domen $(107$, , make up only a minor contribution to the database.

Figure 8: Pie charts of the number of entrier : $\eta$, rackets) within GEOMAGIA50.v3.4 associated with different palaeointensity methods. (a) ts' palaeointensity methods (note that the total number of entries exceeds 5231 as multiple palae intensity entries were derived from measurements using one or more methods). Thellier me.h' d, by type are given in (b): Original Thellier-Thellier method (Thellier and Thellier, 19 ) ), Coe-Thellier (Coe, 1967), Aitken (Aitken et al., 1988), IZZI (Yu et al., 2004), MT4 metho' (1 eonhardt et al., 2004), the two specimen approach of Domen (1977) and other non-specific , in sllier-based methods. Note that for three entries two Thellier-type methods were used for $h \in m$ an intensity given in the entry, therefore the individual mentions of Thellier-type methods $t^{+* .}$ s 4610 . Shaw methods include the original procedure (Shaw, 1974) and modified versions by Kono (1978), Rolph and Shaw (1985), Shaw et al. (1995), Tsunakawa and Shaw (1994), Yamamoto et al. (2003). Triaxe method is that of Le Goff and Gallet (2004). Microwave methods are based on versions of the Thellier-type approaches listed above (see, e.g., Hill and Shaw, 1999, 2007). The multispecimen entries include both Dekkers and Böhnel (2006) and Fabian and Leonhardt (2010) approaches. Other methods are the approach of Walton (1977) and the calibrated pseudo-Thellier method (de Groot et al., 2013).

The remaining $13 \%$ of palaeointensity estimates were determined by variants of the Shaw 
(1974) method (5\%), the Triaxe approach (Le Goff and Gallet, 2004) (4\%) (derived from a technique proposed by Wilson (1961)), microwave variants of Thellier-type protocols (Shaw et al., 1999; Hill and Shaw, 1999, 2007; Stark et al., 2010) (2\%) and the two variants of the multispecimen parallel differential partial TRM (pTRM) method (Dekkers and Böhnel, 2006; Fabian and Leonhardt, 2010) (1\%). The calibrated pseudo-Thellier method (de Groot et al., 2013) and the approach of Walton (1977) contribute less than 1\% of entries.

\subsubsection{Checking and/or correcting for thermal alteration}

As noted above, most archaeointensity data have been obuianed using protocols derived from the original Thellier and Thellier (1959) method. Its pri 'cip e is based on the stepwise thermal demagnetization of the natural remanent magnetizatic $~(~(~ R M$, assumed to be a TRM) and its progressive replacement by a new TRM acquired $\mathrm{i}^{\mathrm{r}}$. I I boratory field whose direction and intensity are controlled. The ratio between the remaining, $\mathrm{M}$ and the partial TRM acquired after each heating/cooling step, with data usually displi $y f \mathfrak{d}$ on an Arai-Nagata diagram (Nagata et al.,

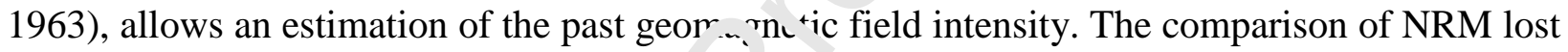
to TRM gained requires the magnetic miner a' gy of the specimen to remain unchanged during the thermal treatment. In order to assess alte tion, Thellier suggested as early as 1946 a partial-TRM check (a pTRM check) (Thellier, 19 1F). During the stepwise heating-cooling cycle, additional pTRM acquisition steps are adde Atter a number of heating steps, a lower temperature step is repeated and the pTRMs com art $^{-1}$ This is done multiple times throughout the experiment, e.g., after every three heating stans, $h \dot{t}$ first step of the three will be repeated. This alteration test is now common and always ${ }^{\circ} \mathbf{y}^{-i \mathrm{i}} \mathrm{d}$ for modern intensity studies using the Thellier method and derivatives (i.e. Coe, 15\%; Aitken et al., 1988; Yu et al., 2004). It is important to underline that different approaches have been used to calculate the degree of alteration at each pTRM check (commonly expressed as a percentage) and the associated cut-off values to accept or reject a check or an intensity determination. 44\% of Thellier-type intensity entries are accompanied by a pTRM check; however, this number hides the variability in the statistical cutoffs used (see Genevey et al., 2008; Paterson et al., 2014).

Monitoring magnetic susceptibility during heating has been used to check for the stability of the magnetic mineralogy; however, it must be noted that slight changes in susceptibility may not relate to changes in remanence carrying minerals or the formation of new remanence carriers 
(rather changes in the susceptibility of magnetic minerals that do not have the capacity to hold or acquire a remanence). This approach was for example used for the part of the Bulgarian data set acquired in the 70s and 80s (Kovacheva et al., 2014). Susceptibility monitoring was only used for $1.5 \%$ of intensity entries in the database.

Instead of rejecting samples for which alteration is judged too strong, another possibility is to correct for this effect. This was proposed by Burakov and Nachasova (1985), with a protocol that additionally takes into account anisotropy of TRM. Several sets of data were acquired using this protocol (26 studies spanning 1986 to the present day). This protocol which has not been used in other laboratories is viewed with caution.

For $\sim 30 \%$ of database entries listing the use of a Thellit -ty e protocol, no alteration test was performed to check or correct for alteration: the linearity of th 2 data points in the Arai-Nagata diagram over a large proportion of the unblocking tempe ..

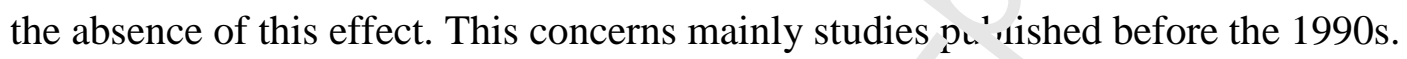

In the Triaxe method (Le Goff and Gallet, $2 \mathrm{~S} J$ ) measurements are made continuously in temperature, through successive series of he ...ng nd cooling, in zero field or laboratory field. The stability of the magnetic mineralogy is asse ed by checking the stability of the ratio between the demagnetized NRM fraction and the acy.ired TRM fraction at each increasing temperature step. This approach corresponds in a similai $N c y$ to testing the linearity in an Arai-Nagata diagram, but the steps are spaced only $5^{\circ} \mathrm{C}$ a a ${ }^{\circ}$ : the data are therefore numerous (e.g., 60 data for a $300^{\circ} \mathrm{C}$ temperature interval) and the ine. -ity is thus finely checked and also assessed through specific linearity tests (Le Goff an ${ }^{\prime}$. Fai...t, 2004).

To mitigate the $\therefore$. $\therefore$ magnetic alteration, alternative methods have been developed. From the oldest to the most ruent: the Shaw technique and derivatives (Shaw, 1974; Tsunakawa and Shaw, 1994; Yamamoto et al., 2003), the microwave technique (e.g., Walton et al., 1996; Hill and Shaw, 1999) and the multispecimen protocol and adaptations (Dekkers and Böhnel, 2006; Fabian and Leonhardt, 2010).

Most data obtained with the Shaw technique were acquired between 1975 and 1995 (e.g., Liritzis and Thomas, 1980; Shaw et al., 1995), but the method has seen a revival in recent years (Kitahara et al., 2018, 2020) in the form of the modified Tsunakawa-Shaw approach (Yamamoto et al., 2003). The Shaw method involves only one heating in which the sample is heated above its Curie temperature allowing the acquisition of a full TRM. Prior to heating the NRM is stepwise 
demagnetized using increasing alternating field (AF) steps. After heating the sample is again demagnetized using the AF steps as for the NRM. The linear relationship of the demagnetized NRM to TRM is then used to calculate an estimate of palaeointensity. Alteration is assessed through a comparison of coercivity spectra. Changes in an AF demagnetized anhysteretic magnetization (ARM) given before and after heating are compared. Later modifications to the method incorporated corrections to take into account alteration to the pre- and post-heating ARM spectra (Kono, 1978; Rolph and Shaw, 1985).

The microwave method follows the protocols of Thellier and Thellier and modified variants, e.g., the perpendicular single heating method (Hill aic Shaw, 2007), but thermal demagnetization is replaced by microwave demagnetization. 's the ationale is that microwave power should limit the rise in temperature of the sample $\mathrm{r}$ 'atri : and reduce the possibility of alteration. However, some conversion to thermal en a to heat the matrix is likely and pTRM-checks test are now integrated in the microwar technique. Recent studies have also included checks for evaluating the cooling rate e fe -t (e.g., Poletti et al., 2013; Ertepinar et al., 2020).

The multispecimen parallel differen ¿ ı partial pTRM method (Dekkers and Böhnel, 2006) started life as essentially a very simple $n_{1}$ thod. Multiple specimens from a site were heated at the same temperature (below the tempcrra $\lrcorner$ of alteration, but high enough for an appreciable decrease in NRM), but with a diff, rent iield for each specimen aligned with the specimens NRM. However, shortcomings in the ne:

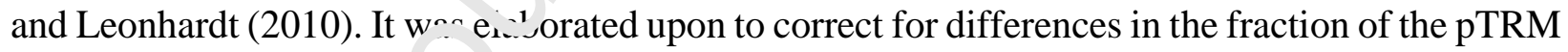
imparted in each spec1. $\bullet_{1}, \cdots$ specimen's domain state, and included a step to monitor alteration.

\subsubsection{Checking or correcting for the presence of multi-domain grains}

Another possible factor for the failure of intensity determinations is linked to the presence of MD grains for which the laws of reciprocity and additivity of the partial TRMs are not obeyed (Néel, 1949). Although the influence of MD grains on volcanic palaeointensity estimates has been investigated in detail, it has received less attention in archaeomagnetic studies. This is primarily a result of the different grain size distributions found in archaeomagnetic materials compared with volcanic rocks: archaeomagnetic materials are commonly dominated by pseudo-single domain grains, which are not effected by pTRM tails, whereas volcanic rocks frequently contain a MD 
fraction where pTRM tails are significant (where a pTRM-tail results from a non-reciprocity between the blocking and unblocking temperatures). The influence of MD grains can be recognized on Arai-Nagata diagrams as a concave-up curve, whose misinterpretation can lead to underestimates or overestimates of intensity depending on which portion of the curve was used to calculate palaeointensity (e.g., Levi, 1977; Dunlop, 2011). The linearity of the data in the Arai diagram was often considered as a sufficient criterion to, if not exclude, at least consider that the proportion of MD grains is too small to critically affect the intensity determination. The presence of MD grains is now more directly investigated with either rock magnetic measurements, such as hysteresis curves, backfield curves and first order reversal curves 'see, e.g., Day et al., 1977; Dunlop, 2002; Roberts et al., 2019), or through additional tests i. nplf mented during Thellier-type methods and microwave protocols, such as pTRM-tail checks (air ling at testing the independence

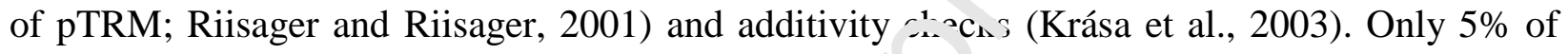
intensity entries in the database list an MD check.

The IZZI protocol (Yu et al., 2004), a va is at on the Thellier method, was designed to accentuate the influence of MD tails, evider.' 'y ronounced zig-zagging in the Arai-Nagata plot. However, this method is sensitive to the dir - ion of the laboratory field relative to the orientation of the NRM leading to over- or under- es : mation of the pTRM-tail and with the field aligned with the direction of the NRM, MD tails can of suppressed.

In comparison to other pre ncors, the MSP-DSC method of Fabian and Leonhardt (2010) has the advantage to (partially, $\mathrm{co}_{1}$ "ect intensities for domain state effect. The Triaxe protocol (Le Goff and Gallet, 2004) mitirals che spurious effect of large grains because the laboratory TRM is almost a full one, mm icirirg the acquisition of the original TRM. The Shaw derivative of Yamamoto et al. (2003) $\therefore$ ms to remove all MD contributions by incorporating a low-temperature demagnetization step after each remanence acquisition and prior to AF demagnetization.

\subsubsection{TRM anisotropy}

An important parameter that may affect intensity determinations when analyzing baked clay artefacts is anisotropy of TRM (already touched upon in section 3.1.1). This anisotropy arises from the stretching of clay during the process of shaping an object, resulting in a preferential alignment of magnetic grains in the clay matrix (e.g., Rogers et al., 1979; Aitken et al., 1981). This effect may be particularly intense for pottery fragments and thin tiles and to a lesser extent to thick 
bricks, with biases up to several dozens of micro Tesla (e.g., Genevey et al., 2008; Hervé et al., 2017; Gómez-Paccard et al., 2019). Conversely, it has been observed that this effect is generally less critical when analysing fragments made of clay, which are coarsely assembled, as they are usually taken from in situ structures (e.g., Kovacheva et al., 2009b).

Figure 9: Pie charts of the intensity entries in the GEOMAGIA5.v3.4 database noting (a) remanence anisotropy corrections and (b) cooling rate corrections. Number of uses of an approach are given in brackets. In (a) TRM = thermoremanent magnetization; $A R M=$ anhysteretic remanent magnetization; IRM = isothermal remanent magnetization; NRM $b_{l a}$ parallel = laboratory field applied parallel to specimen natural remanent magnetization $(\mathfrak{R} R \mathrm{R})$ direction during the palaeointensity method; other corrections are generally $a_{\mathrm{L}}$ nrr aches that were insufficiently defined in a publication). See more details in section 3.1.ว ، " Section 3.1.6,

For $38 \%$ of archaeointensity entries in the database remanence anisotropy was not investigated (Fig. 9a). In some cases data ve e ctained from less anisotropic materials and no measure of anisotropy was pursued. In a sma.' number of entries where anisotropy was estimated, a correction was not necessary. This is 1 . nst likely as the anisotropy was not considered to be significant. Different approaches ha e been proposed to evaluate remanence anisotropy. Determination of a TRM anisc tre $\urcorner y$ tensor for each analysed sample allows to evaluate the importance of this effect and to accurately correct the raw intensity determinations (Veitch et al., 1984; Selkin and Tauxe, $2 \pi$ ?). i his approach was used for $30 \%$ of entries considering anisotropy in the database. The d. wuack of this approach is the time-consuming multiple heating steps (usually six), which incıeases the risk of mineralogical alteration. Aligning the laboratory field direction with the original NRM (25\% of entries considering anisotropy) is an adequate alternative, as long as the degree of anisotropy is not too strong to bias significantly the direction (e.g., Aitken et al., 1981). Ideally, the laboratory field direction should be aligned with the ancient ambient field. This is achieved with the Triaxe protocol and MSP protocols where the direction of the laboratory field is adjusted so a TRM is imparted parallel to the primary TRM (see, Le Goff and Gallet, 2004). To minimize the effect of TRM anisotropy, Morales et al. (2009) proposed to average the intensity values obtained for 6 specimens from the same fragment: here the specimens are oriented in such a way that the TRM is acquired in 6 orthogonal directions relative to a fixed 
arbitrary orientation. However, Poletti et al. (2016) and Hervé et al. (2019b) demonstrated that this approach results in larger standard deviations and possibly significant inaccuracies as high as $10-15 \mu \mathrm{T}$.

As an alternative to the full determination of the TRM anisotropy tensor, it has been suggested to use other tensors to evaluate and correct for anisotropy; namely tensors of magnetic susceptibility (AMS; 14\% of anisotropy assessed entries), anhysteretic remanent magnetization (ARM; 8\%) or isothermal remanent magnetization (IRM; <1\%). These substitutes are often quicker and easier to implement and avoid the six additional heatings during the thermal protocol. However, the respective ellipsoids significantly differ in their shane and anisotropy degree from TRM ellipsoids (e.g., Chauvin et al., 2000). AMS can underestil'at $r$ TRM anisotropy by several dozens of percent (Gómez-Paccard et al., 2019). In 22\% c er tries other types of anisotropy corrections have been applied, but either a method was $n \pi{ }^{\circ}$ stud in the database or the method was not described in the publication.

\subsubsection{Cooling rate effect}

Another possible biasing factor for in ${ }^{n n s i t y ~ d e t e r m i n a t i o n s ~ i s ~ t h e ~ c o o l i n g ~ r a t e ~ d e p e n d e n c e ~}$ of TRM intensity (Fox and Aitken, 198?). Ideally, to avoid such systematic bias, the cooling duration used for the acquisition of tur li. boratory TRM should be chosen to be identical to the original one when the primary ? $\mathrm{M}$ was recorded by the archaeological object. This is rarely possible as the original cooling : $\mathrm{m} \iota$ is usually long, ranging typically from half a day to a few days (with the notable exceptir at ine slags, Shaar et al., 2010), while the laboratory cooling time is faster, generally from $\backslash 5$ up to 2 hours, depending of the type of oven and the size of the specimens.

For Thellier-Thellier data, the cooling rate effect can be evaluated through a comparison of the TRM acquired with a rapid cooling time (the one used routinely during the experiment) and a slow cooling time chosen to be close to the original one (e.g., Chauvin et al., 2000; Leonhardt et al., 2006; Poletti et al., 2013). This is performed for $28 \%$ of the intensity entries in the database and comprises $80 \%$ of entries that used a cooling rate correction (Fig. 9b). Precisely evaluating the duration of the past cooling is the main difficulty of the correction protocol. Experimental archaeology has provided constraints on this issue (e.g., Morales et al., 2011; Calvo-Rathert et al., 2019; Genevey et al., 2016; Schnepp et al., 2016; Hervé et al., 2019a; Jones et al., 2020). 
Archaeological information concerning, e.g., the estimated size of kilns, their morphology, and the type of firing (open or closed), may also help to assess the original cooling conditions. Another approach is to measure the cooling rate effect on TRM acquisition with increasingly slow cooling duration (therefore exploring different conditions of cooling) and to infer from this the error that would be made by under or over estimating the original cooling rate (Genevey et al., 2003; Hartmann et al., 2010).

A different possibility is to apply a fixed correction for all samples from the same archaeomagnetic site, usually $5 \%$ or $10 \%$. This "educated guess" concerns $7 \%$ of intensity data or $20 \%$ of entries which applied a cooling rate correction (Fig. 9b). 1.is approach is based on the assumption that all fragments of the same archaeological objec ${ }^{+}$sh w we same TRM intensity dependence on cooling rate. Experimental studies have, hnv eve ; pointed out that this effect is variable from one sample to another and (as predicted $b$ s. following a logarithmic law as a function of the ratio bet en an increasingly slow cooling time

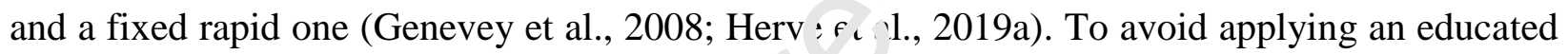
guess correction to all fragments, it has been .. gy sted to estimate at least for part of the collection the cooling rate effect and to apply in average correction to the other fragments (Kostadinova-Avramova and Jordanova, ?019).

Another important question is at $w_{\text {urat }}$ temperature to estimate the effect of cooling rate. In particular, Hervé et al. (2019a) sh. weu too high of a temperature could greatly overestimate this effect and therefore underesti nal the intensity value. This appears to depend on the magnetic mineralogy of the materia ${ }^{1} n_{a}{ }^{\prime} y^{\prime}$ ed (see also Kostadinova-Avramova and Jordanova, 2019).

The cooling ran $e_{1}^{c_{\alpha}, t}$ is a challenging parameter to estimate and many studies have not explored this question ( $\cdots$ er $70 \%$ of entries in the database). However, some of these data were obtained with a relatively slow cooling time as part of routine intensity experiments (for example for Bulgarian dataset; Kovacheva et al., 2014): the cooling rate effect is therefore expected to affect them less strongly.

Optimally, we would like to be able to dispense with the question of the cooling rate effect. It has been observed experimentally that the Triaxe protocol accounts for cooling rate (Le Goff and Gallet, 2004; Genevey et al., 2009; Hartmann et al., 2010; Hervé et al., 2017; Salnaia et al., 2017). The multispecimen parallel differential pTRM method also seems to be insensitive to cooling rate (e.g., Schnepp et al., 2016; Calvo-Rathert et al., 2019), possibly because in this technique all 
pTRMs are acquired at medium temperatures. However, this question still needs to be further explored (Schnepp et al., 2020a).

\subsubsection{Intensity uncertainties}

On the whole archaeomagnetic data within GEOMAGIA50.v3.4 have reasonably well constrained uncertainties (Fig. 7c). The majority of estimates have an uncertainty of less than $10 \%$ of the intensity estimate (60\% of intensity entries that report uncertainties), i.e. a few $\mu \mathrm{T}$ on most measurements. Some intensity measurements, however, have high uncertainties, ranging up to 40 $\mu \mathrm{T}$. They require careful evaluation prior to their inclusion in $\mathrm{r}$ ference curves or for field modelling.

A caveat to all intensity uncertainties in the databas $1_{\mathrm{s}}$ th ${ }_{\lrcorner}$they have been calculated in a variety of ways. Uncertainties may be reported as stat daı 1 deviations (to 1 or $2 \sigma$ ), standard errors or they could be weighted. The type of intensity $u_{1}$-ertainty is not noted in the database. Care must therefore be taken when using intensit, an ertainties when constructing field models and reference curves and using this field as a s lec: on criteria.

\subsection{Dating methods}

Dating and its accuracy and ${ }_{\mathcal{P}} e^{-}:^{*}$ on are key elements for any archaeomagnetic study. For archaeological artefacts, the $\mathrm{d}^{2}$ ing methods used and listed in GEOMAGIA50 are based on archaeological or historical cons raints, or chronometric methods involving mainly radioisotopic and physicochemical me tsu 'ments (Fig. 10). See Aitken (2014) for an overview of scientific dating methods. We briel:' describe the most salient aspects of these methods and their caveats in section 3.2.1.

The archaeological approach remains the most common and concerns almost $60 \%$ of the database. Behind the term "archaeological dating" is often hidden the use of a relative chronology, which itself is constrained by elements of absolute dating. The different types of dating methods are clearly complementary and the quality of the two approaches cannot be simply ranked, i.e. scientific dating does not always outrank archaeological observations, it depends on the specific context and an understanding of an archaeological site. The importance of sampling in close collaboration with an archaeologist is paramount for selecting materials whose TRM acquisition can be dated with the maximum precision and confidence. Two categories of methods to date 
TRM acquisition are distinguished here, either direct, i.e. directly concerning the analyzed material itself, or indirect, i.e. the material is dated by association with another dating element.

Figure 10: Pie chart of the 8 most commonly used methods to date archaeological materials in GEOMAGIA50.v3.4. Note, the numbers in brackets do not sum to the total number of entries in the database, as numerous entries have been dated using multiple methods. "Other" methods include whether accelerator mass spectrometry was used to obtain radiocarbon ages (133 entries, with frequent overlap with the calibrated and uncalibrated radiocarbon age entries), and if optically stimulated luminescence (OSL; 9 entries) or rehydroxylatı n (5 entries) were used.

\subsubsection{Direct dating of TRM}

One of the main sources to directly date TRM - re tocument archives. A well-known example is the eruption of Vesuvius first described by $\mathrm{P}_{11}$. the Younger, which destroyed the city of Herculaneum and Pompeii in 79 CE (Evan ;, 1n91; Evans and Hoye, 2005). But more commonly, these archives are used, for exa $\ldots_{\perp}$ le, to precisely date the edification of religious or civil buildings (e.g., Schnepp et al., 2003; C zte et al., 2015; Salnaia et al., 2017; Genevey et al., 2019) or short periods of activity of c -amics workshops (e.g., Genevey et al., 2009). Other objects, such as some amphoras, cai je precisely dated directly through the identification of stamps (Ben-Yosef et al., 2017).

Among the chronomer ic nethods used in archaeology, thermoluminescence (TL) and optically stimulated luminarce. above $400^{\circ} \mathrm{C}$ is time-zt. $7 u^{\circ}$. ne method as at above this temperature the electron traps in quartz or feldspar grains in bakeá -iays are emptied (Aitken, 1985). From this moment, traps progressively fill again under irradiation from the surrounding environment (mainly related to ${ }^{40} \mathrm{~K},{ }^{238} \mathrm{U},{ }^{235} \mathrm{U}$ and ${ }^{232} \mathrm{Th}$ radioactive isotopes). In spite of the advantage of dating the same instance as the TRM acquisition, luminescence methods constitute only $\sim 3 \%$ of entries in the database. However, this method has been used in recent studies (e.g., Gómez-Paccard et al., 2012a; Schnepp et al., 2003; Kondopoulou et al., 2015; Cai et al., 2015; Aidona et al., 2021). Accurate luminescence dating requires a careful reconstitution of the radioactive environment of the baked clay since the last firing. The resulting long measurement time limits the use of the techniques (Roberts et al., 2015). Another caveat of luminescence methods are age uncertainties of $\pm 5-10 \%(1 \sigma)$, corresponding 
to $\pm 100-200$ years for a $0 \mathrm{CE}$ baked clay for example. However, this can be reduced if multiple TL measurements are made. It is worth noting that OSL does not always provide a direct dating of the TRM acquisition because time-zero of this technique can also be the last exposure to sunlight, offering the possibility to date the deposit of sedimentary layers around the studied baked clays.

Another method to directly date baked clay artefacts was proposed by Wilson et al. (2009). It is based on the process of rehydroxylation (RHX) of fired-clay ceramics after production. Similar to luminescence methods, the principle is to start from a zero point by heating a sample up to $\sim 500^{\circ} \mathrm{C}$ (dehydroxylation) and then monitor precisely the sample's weight gain in known environmental conditions over several weeks (through rehydroxylatı $n$ ). This allows the kinetics of the rehydroxylation process to be determined. Although pros ' isi'g for archaeologists, and in turn for archaeomagnetists, the relationship between mass $\mathrm{g}$ :i. an'، time has proved more complex than initially thought, with kinetics that appear to depen'. w? lie nature and/or firing conditions of the ceramic (in addition to the environmental conditions), $a$ 'd the applicability of the RHX method appears clearly compromised (Bowen et al., 1971 Je Joff and Gallet, 2014, 2015). So far it has only been applied to two archaeomagnetir s. 1ains, both on Spanish ceramics (Nachasova and Burakov, 2012; Burakov and Nachasova, 2u: 3).

\subsubsection{Indirect dating of TRM}

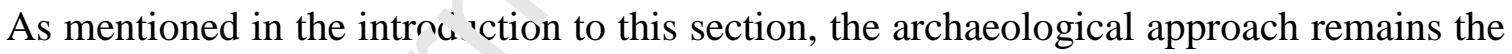
most used method of indirect 'atı. $\mathrm{g}$. Archaeological dating is however a very generic term that integrates many differen ${ }^{+}=e_{1}-n$ nts. The first is stratigraphy, which is essential for building chronologies for ancieı nt..'i-layered sites in the Middle East (Shaar et al., 2011; Gallet et al., 2020) and Eastern Eururu (e.g., Kostadinova-Avramova et al., 2014). Elements such as coins, fragments of ceramics or metallic artefacts (e.g., swords and fibulae) are also key for dating, if the evolution of their typology is well known. Together, these elements make it possible to define a post quem and ante quem terminus terminus (lower and upper age limit respectively) for an archaeological level or artefact. It is also important to understand whether there has been any nixing of the layers in the stratigraphy, which can limit chronological control.The central question is to precisely understand how the object analysed for archaeomagnetism is reliably related to these chronological constraints. This question is far from trivial, e.g., for settlements occupied over a long period. For intensity determination, one way to overcome this issue is to work directly 
on dated pottery fragments, i.e. those whose shape or decoration is recognized and can be linked to a known local/regional typo-chronology.

The relative chronology given by the stratigraphy is fixed to the calendar scale by historical events or chronometric methods. Their precision and reliability are mainly related to the state of the art of archaeological research in the region for a certain period. For example, in Western Europe, precise typo-chronologies are firm for the Roman period (0-500 CE), but are "floating" for the Neolithic period (6000-2000 BCE). These typo-chronologies, and more generally archaeological dating, are also likely to evolve according to the progress of knowledge. This is not a weakness insofar as the archaeomagnetic results remain accurate. 'Towever, it is important that dates associated with archaeomagnetic measurements reflect rev, ion ; to archaeological ages. For some regions there have been recent revisions to GEOM \GI 150 to accommodate new age information, e.g., Bulgaria (Kovacheva et al., 2014), Ur... Y...ingdom (Batt et al., 2017), Greece (De Marco et al., 2014), USA (Bowles et al., 2002; Jones ‘ al., 2020) and France (Le Goff et al., 2020). It must also be recognized that there are $1 \mathrm{k} / \mathrm{L}$ ages within GEOMAGIA50 that do not reflect advances in archaeological age deterr. ai ans for specific times, regions or sites. Work can continue on sites for years to decades and $\_$archaeomagnetic aspect of the excavation/project may not be the primary objective; new a res may come to light after the final publication of the archaeomagnetic work.

Another common methor 'sea to indirectly date archaeological materials is radiocarbon dating. Approximately $15 \%$ c f e.tries have used radiocarbon dating as the sole chronological control or in conjunction with ${ }^{\prime}$.er dating methods. Charcoals from carbonaceous or ashy layers that are related to the lia ${ }^{+} \mathrm{m} \cdot 0$ of a kiln/fireplace or located in different horizons of the stratigraphy have frequently been us d ior dating (e.g., Shaar et al., 2015), but other materials such as seeds and bones have also been used. In comparison to the typochronological approach, its advantage is to give a precise date bound by experimentally derived uncertainties. However, the significance of this date relative to the TRM acquisition is not guaranteed. For example, the date can be affected by an old carbon/wood effect. Radiocarbon dates the formation of the organic cell and dating charcoals from reused woods or central tree rings can result in earlier dates up to a few centuries. A preliminary anthracological study is useful to identify such samples and select, if possible, materials with a short lifetime as burnt twigs, grasses or seeds.

A limitation of the method is that the abundance of radiocarbon within a sample can not be 
simply related to a specimen's age, through comparison to a decay product, as for example in ${ }^{40} \mathrm{~K} /$

${ }^{39} \mathrm{Ar}$ dating; nitrogen produced by the decay of ${ }^{14} \mathrm{C}$ is not captured by the majority of materials (Reimer et al., 2020). Radiocarbon dating is based on measuring the amount of ${ }^{14} \mathrm{C}$ still present in the sample, but the initial concentration of atmospheric radiocarbon has varied through time and this variation must be accounted for in the calculation of a final radiocarbon age (also known as a calendar age). This process is called calibration and there has been a sustained effort by the radiocarbon community over the past 40 years to develop curves of atmospheric radiocarbon variations that can be used to transfer ${ }^{14} \mathrm{C}$ ages based on the meas urement of radiocarbon present in a specimen, expressed in years Before Present $\left(0 \mathrm{BP}=195 \mathrm{C}_{\mathrm{L}}\right)$ ) to an age on a calendar timescale in calibrated BCE/CE. The last versions of calibrat: $\sim \eta$ a.rves being (for the Northern Hemisphere; Reimer et al., 2020), SHCal20 (for the Southe n I. nisphere; Hogg et al., 2020) and Marine20 (for the oceans; Heaton et al., 2020). As atmo ohe ic radiocarbon variations vary rapidly and non-linearly, this leads to highly variable and complex alibration curves. This in turn results in calibrated radiocarbon ages that have a non-G. iss an error and in some cases result in very broad uncertainties with multiple age range s. $\mathrm{F}$ ateau effects at certain periods result in irreducible date intervals of several centuries, such as 8:'0-7600 BCE, 4300-4000 BCE, 3400-2900 BCE, 800-400 BCE or the past four centurier.

Finally, we underline that $t^{2} \sim b_{1} c^{t}$ way to minimize the risk that the true date of the TRM acquisition is not included in th $\epsilon \mathrm{g}_{1}$, en interval of age is to combine several chronometric and/or archaeological dates. This is ofte. done by an archaeologist who has an overarching understanding of the site and its positior ing in the regional fabric. More recently, mathematical techniques such as Bayesian chronologica' modelling (e.g., Bronk Ramsey, 2009; Lanos and Philippe, 2018) have brought additional insights into developing archaeological chronologies, especially for sites with complex stratigraphies (e.g., Shaar et al., 2011).

\subsubsection{Age uncertainties in GEOMAGIA50}

Age uncertainties (expressed here as age ranges to accommodate the multimodal age probability distributions of calibrated radiocarbon ages) vary widely within the database, ranging from 0 years for some historically and archaeologically dated entries (1.4\% of data) to 2900 years for an archaeologically dated oven from Germany (Schnepp et al., 2020b) (Fig. 11). Approximately $6 \%$ of data (627 entries) have an age range $\leq 10$ years; $\sim 30 \%$ have an age range 
$\leq 50$ years; and $\sim 50 \%$ of entries have age ranges of 100 years or less. Nearly all age ranges are less than 500 years $(\sim 90 \%)$. There are spikes in the age ranges, with ranges of 100, 200, 300, 400 and 500 being more populous than others (Fig. 11b). The majority of these ranges are from archaeological dated materials and are assignments to specific centuries or across multiple centuries. In general, there is no correlation between age and age range. It is important to note that age ranges can be reported at differing precisions (e.g., 1 or 2 standard deviations) and they do not have the same form. For example, some age distributions will follow a normal distribution (e.g., uncalibrated radiocarbon ages and luminescence techniques), some a multimodal distribution (calibrated radiocarbon ages) and others a uniform distribution (e.g., rchaeological ages assigned to a specific archaeological period). For a specific age within an $a_{c}$ re $r$ r nge, this means there will be differing probabilities of this age depending on the dating $m \in$ hoc used.

Figure 11: Archaeomagnetic age ranges within GEOMA_A50.v3.4, binned by (a) 100 year age ranges and (b) 10 year age ranges. (a) the full spc 1 'f age ranges; (b) truncated to age ranges $\leq$ 500 years.

\section{Archaeomagnetic field 1 ? constructions}

As described in section 2.3 ^nc sction 2.4 archaeomagnetic data are inhomogeneous in space and time. Furthermore, lit le $、$ in be garnered about the large scale geomagnetic field from individual data. Regional or gloial compilations of data are therefore necessary to gain a greater understanding of the temr ora. and spatial evolution of the field. This section will give an overview of the two main approac:es to reconstructing the geomagnetic field on centennial to millennial time scales: regional secular variation curves and global spherical harmonic models.

\subsection{Regional secular variation curves}

The potential to combine individual archaeomagnetic data from different locations into composite archaeomagnetic curves for dating purposes was recognized in the 1950s (e.g., Cook and Belshé, 1958; Watanabe, 1958) and a variety of reference curves have been obtained for several parts of the world since then (see Korte et al. (2019) for a detailed review). Because the geomagnetic field cannot be considered purely dipolar, field variations at one location (or in one region) are not representative of the evolution of the field as a whole. Smaller-scale non-dipole 
contributions lead to deviations from a dipolar geometry, resulting in variations in direction and intensity that can vary from one region to another. Combining all global archaeomagnetic data into composite curves will not fully capture the evolution of the field and may obscure regional field structures. Therefore it has been common to develop regional archaeomagnetic curves. It is generally assumed that data within a radius of several 100 to a few $1000 \mathrm{~km}$ reflect similar field variations and can be combined to form a reference curve for a region (e.g., Tarling, 1989; Tema and Lanos, 2020). A review by Korte et al. (2019) included an investigation of the spatial correlation length of geomagnetic variations and the possible influence of the distance to a curve for dating accuracy. However, strict guidelines cannot be given ow $\mathrm{h}_{\mathrm{g}} \mathrm{\sigma}$ to the complex spatial and temporal evolution of the geomagnetic field over short time scal $\varsigma$.

Archaeomagnetic reference curves of field diresions intensity, or all three field components have been developed over a number of dec. s's ior several European countries (e.g., Kovacheva et al., 2009a; Tema and Lanos, 2020; Schnepp ‘ al., 2020b,a), Japan (e.g., Watanabe, 1958; Nagata et al., 1963; Kitazawa, 1970; Sakai a id Arooka, 1986), China (e.g., Wei et al., 1982, 1986; Batt et al., 1998; Yang et al., 1993; ${ }^{*}$ ' ${ }^{\top} \mathrm{W}$ at al., 1995), and the United States of America (e.g., Watanabe and Dubois, 1965; Sternbe._. 1989a; Hagstrum and Blinman, 2010; Jones et al., 2020) (see Constable and Korte (2015) inr a more detailed list with comprehensive references). Several curves have been frequently u. $\mathrm{p}^{\prime}$ เal $\_$d with new data as they become available, e.g., France (e.g., Thellier, 1981; Bucur, 1994, Thauvin et al., 2000; Genevey and Gallet, 2002; Genevey et al., 2009, 2016; Gallet et al., 2002, Hє. vé et al., 2013a,b; Le Goff et al., 2020). With efforts to improve data coverage for other resinh. , here are now curves for China (Cai et al., 2017), the Near East (Gallet et al., 2015; Si.11 ${ }_{11}$ r $i$ et al., 2015; Shaar et al., 2020; Livermore et al., 2021), Mexico (Soler Arechalde et al., Ir 19; Mahgoub et al., 2019) and South America (Goguitchaichvili et al., 2019).

\subsubsection{Approaches to curve construction}

The first step to building a reference curve is to relocate the distributed data to a central location (also known a reference location) to eliminate differences that result in directions or intensity at different locations purely from a dipole field geometry. For directions, this is commonly done by using the conversion-via-pole (CVP) method, whereby a directional pair with one set of geographic coordinates is transformed to a virtual geomagnetic pole (VGP) and the 
subsequent VGP is then transformed to a new directional pair using the geographic coordinates selected for the reference curve (Shuey et al., 1970; Noel and Batt, 1990). Alternative approaches have also been used, which assume an axial dipole (a dipole aligned with Earth's rotation axis where the geographic and magnetic pole are coincident) (Aitken and Hawley, 1966; Thellier, 1981), though this method is no longer common. In addition, average curves have been calculated using VGPs and not relocated directions (e.g., in the USA; Sternberg, 1989b; Lengyel and Eighmy, 2002). It is important to note that the non-dipolar nature of the archaeomagnetic field means that all relocation methods have an associated uncertainty (Shuey et al., 1970; Casas and Incoronato, 2007).

For archaeointensities, curves are typically constructec usi ig intensity transformed to either a virtual dipole moment (VDM) or a virtual axial dipo e $m$ sment (VADM) (e.g., Daly and Goff, 1996; Yang et al., 2000). A VDM is analogous to * V CP, as it uses inclination assuming a tilted dipole. VADM assumes a geocentric axial dipole . nfiguration and allows intensity data lacking inclination to be compared. As with reloc tte $\mathfrak{d}$ directions, there is an intrinsic uncertainty when calculating a $\mathrm{V}(\mathrm{A}) \mathrm{DM}$ assuming a $\because \mathrm{O}^{2}$ - field configuration when the field can have noticeable non-dipolar components. This ca. esult in a dispersion between sites that is a reflection of non-dipolar field behaviour and not 1. a ated to issues with how estimates of archaeointensity were obtained.

Different data fitting and smouthing methods have been employed to derive regional secular variation curves. Son ${ }^{2}$ c.rly curves relied on hand drawn fits through the data (see, Thellier, 1981; Clark et al. 19ie). However, through time increasingly sophisticated mathematical approaches have been 'su' $\mathrm{d}$ construct curves, applying methods that not only derive single curves through time ( $0_{1}{ }^{+1}$.rough inclination and declination), but calculate uncertainties. Simple interpolation of individual field components (or means across time interval bins) with or without the estimation of curve uncertainties has been common (e.g., Sternberg, 1989a; Yang et al., 2000), but over the past thirty years a variety of mathematical approaches have been taken. Methods such as bivariate extensions of Fisher Statistics (Le Goff et al., 1992) continue to be used to produce curves for Europe, e.g., France (Hervé et al., 2013a; Le Goff et al., 2020). Recently bootstrap or Bayesian methods have been used to obtain curves, uncertainty estimates, and/or probability distributions (Thébault and Gallet, 2010; Hellio et al., 2014; Livermore et al., 2018). The Bayesian method of Lanos (2004) and Lanos et al. (2005) is notable as it produces consistent curves for all 
three field components and provides curve uncertainties that consider uncertainties on the archaeomagnetic data and ages, and the data distribution. This approach has been used in the creation of a number of archaeomagnetic curves across Europe, e.g., Austria and Germany (Schnepp and Lanos, 2005), and Bulgaria (Kovacheva et al., 2014). The method of Livermore et al. (2018), which is published alongside open source code, also produces curve uncertainties for intensity and the posterior sample age distributions as a direct output.

\subsubsection{Examples of regional field variations}

There are two features noticed in several regions that have :eceived attention in the last decades: archaeomagnetic jerks and intensity spikes. Rapid chan res n directional variations seen in Bauer plots (declination against inclination) associated w/ h a increase in intensity in French and Middle East data have been named "archaeomagnet; _ ali s" (Gallet et al., 2003, 2005, 2009). Gallet et al. (2005) suggested that if archaeomagnetic $\_$. Ks are global features, they could be associated with episodes of a tilted and enhanced c if $\mathrm{Jl}$. Later, Gallet et al. (2009) noted that they may correspond to maximum geomag .. ${ }^{\text {ic }}$ field hemispheric asymmetry, leading to most-eccentric dipole events, related to the ' vnamics of flux patches at mid- to high-latitudes. If

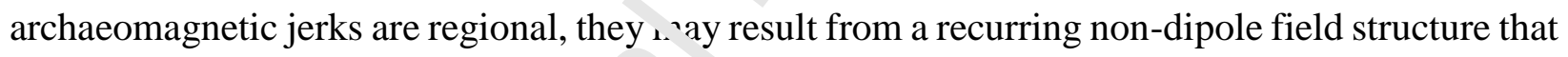
influences Western Europe. Using the gol al field model CALS7k.2 (Korte and Constable, 2005), Dumberry and Bloxham (2006) $i_{1}$ erred that archaeomagnetic jerks are associated with a change in the dominant azimuthal flov. dh sction at the top of the outer core below Europe. It is important to note that there is a clear $\gamma_{1}{ }^{f_{c}}$ rence in timescales between archaeomagnetic and geomagnetic jerks (e.g., Mandea $a_{\llcorner}+\mathfrak{C}^{1}$ en, 2009). Archaeomagnetic jerks do not appear unusually rapid compared to what we $\mathrm{k} \sim \mathrm{w}$ from the present field. An archaeomagnetic jerk may last 100-200 years, whereas a geomagnetic jerk lasts $\sim 1$ year.

In contrast, the intensity variations during geomagnetic intensity spikes during the Iron Age derived from archaeological materials in the Levant (e.g., Ben-Yosef et al., 2009; Shaar et al., 2011), are much faster than field changes observed for recent and historical times. The intensity of the field was also far greater than seen today, exceeding twice today's field strength (Shaar et al., 2016, 2018) (Fig 12). Livermore et al. (2021) suggest that six intensity spikes are required by the Levant data sets. Increases in intensity were also associated with a directional anomaly (most notably in inclination) and the combined directional-intensity anomaly is referred to as the 
Levantine Iron Age Anomaly (Shaar et al., 2018). As with archaeomagnetic jerks, it is currently unclear whether the Iron Age anomaly is regional or global in extent. Data from areas surrounding the Levant (e.g., Georgia, Turkmenistan, Uzbekistan, Cyprus, Greece, Bulgaria and Egypt) indicate there is some evidence of an increase in intensity at the same (or similar) times to the Levantine spikes; however, although intensity reaches twice the present day field's at these locations, the increase spans a broader time (a few hundred years) (Fig. 12). This maybe a true representation of the field behaviour during the Iron Age or it may reflect dating inaccuracies.

There is some evidence globally of an intensity increase coincident with the Iron Age anomaly and of spikes at other times (see, Korte and Constable, 2018). Their origin is under discussion (Livermore et al., 2014; Davies and Constable, 20 '7; Korte and Constable, 2018; Troyano et al., 2020) and difficult to explain given our curre.'t kr owledge of the geodynamo. To

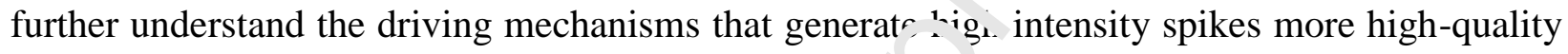
archaeomagnetic data from several regions are necessa, to fully characterize their regional or global behaviour.

Figure 12: Virtual axial dipole moment ( $\mathrm{JADM}$ ) for the Levant and surrounding regions calculated from data in GEOMAGIA50. 3.4. Note that the data shown in (a) do not reflect the most recent interpretations (compilatiur s) of Shaar et al. (2016), Shaar et al. (2020) and Livermore et al. (2021) as GEOMAGIA50 i in ludes all data and a data selection protocol is not applied. The reader is referred to the above $n_{1 .}$. ilations for rationales related to data selection.

\subsection{Global archai mingnetic field models}

Given its source in Earth's outer core, the geomagnetic field is a global phenomenon and any studies that aim to decipher its driving processes must consider the global evolution of the field. In addition, variations in global field strength, expressed as a dipole moment are also of interest, e.g., in the context of estimating geomagnetic shielding against solar wind, galactic cosmic ray production, atmospheric ionization and solar activity (e.g., Usoskin et al., 2006, 2008, 2010, 2016). A range of global archaeomagnetic field models have been derived over the past decades, from which maps of the field can be generated for Earth's surface (e.g., Fig. 13) and core-mantle boundary (CMB) (e.g., Fig. 14). In the following sections we give an overview of the history of global archaeomagnetic field models, how modelling approaches have evolved over the 
past twenty years, and the current state of the art. We discuss how data selection and data uncertainties influence global models and how these have been treated in the most recent models. We describe some of the major findings that global modelling has facilitated, but also note caveats to the modelling approaches.

\subsubsection{Dipole moment reconstructions}

According to the International Geomagnetic Reference Field (IGRF 13th generation; Alken et al., 2020) the present core field is dominated to about $93 \%$ by a dipole centered in the middle of the Earth and tilted with respect to Earth's rotation axis, al ${ }^{-1}$ to about $91 \%$ percent by an axial dipole, i.e. a dipole aligned with the rotation axis. For a pı rely axially aligned dipole field, the global dipole moment can be determined from a single in tens ity value and the latitude of the observation. For the moment of a tilted dipole, the inclin $:\urcorner n \cdot t$ the observation site is additionally required (see, e.g., Merrill et al., 1996). However, when nc -dipole field contributions are present, any dipole moment values determined in this way : re $0^{\circ}$ ased depending on the strength of the local non-dipole field. It is often assumed that no. ${ }^{\text {tip }}$ le field contributions average out when enough individual VDMs or VADMs are averaged 1 - space and/or time, so that such an average V(A)DM is considered a valid approximation on the actual dipole moment (e.g., Merrill et al., 1996). However, the validity of this assump.ir, in unclear and at least for short intervals or a strongly inhomogeneous global data distrii tion, the resulting averaged V(A)DM is likely biased.

Several V(A)DM rec nsu'lctions from archaeomagnetic data (which also in general include volcanic data) spar the rast 10 to $50 \mathrm{kyr}$ (McElhinny and Senanayake, 1982; Yang et al., 2000; Genevey et al., 公ר d, V.uudsen et al., 2008; Valet et al., 2008; Usoskin et al., 2016). Genevey et al. (2008) showed tha $\mathfrak{k}$ ased on the ArcheoInt database, VADM or mixed VADM/VDM curves from Eurasia differ notably from curves for the rest of the world and they constructed global curves for the past $3 \mathrm{kyr}$ using equally weighted regional curves to avoid biasing from a heterogenous data distribution. Knudsen et al. (2008) used GEOMAGIA50 (version 1) for a VADM reconstruction over the past $50 \mathrm{kyr}$, in time windows increasing from 500 years for the past $4 \mathrm{kyr}$ to $4 \mathrm{kyr}$ prior to $24 \mathrm{ka}$, and noted that field strength through the Holocene is higher than during the preceding $40 \mathrm{kyr}$.

\subsubsection{History of archaeomagnetic field models}


Although early attempts to construct global archaeomagnetic field models date back to the early 1970s (e.g., Márton, 1970; Braginskiy and Burlatskaya, 1979), they have only received considerable attention over the past 20 years, when the data basis had become large enough to allow for more spatial detail and temporally continuous reconstructions. The recent history of purely archaeomagnetic field models is closely linked to models including palaeomagnetic sediment records in addition to archaeomagnetic and also volcanic data. A surge of models spanning back to 2 to $12 \mathrm{ka}$ followed the publication of Hongre et al. (1998). This includes a series of 100-year snapshot models for the past 3000 years by Constable et al. (2000), and its first continuous equivalent (Korte and Constable, 2003). Several recent 1 'views include overviews of all these models (Constable and Korte, 2015; Korte and Constat 'e, 2 J18; Korte et al., 2019), and we focus on archaeomagnetic models (including volcanic d. ta, ut no sediment records) in the following discussion.

The first such models were ARCH3k.1 and ARC t.?."_cst.1 (Korte et al., 2009) for the time interval $1000 \mathrm{BCE}$ to $1990 \mathrm{CE}$. ARCH3k.1 was i lit a'ly based on all available archaeomagnetic and volcanic data that the authors were aw ${ }^{\prime} \iota^{f}$ (9605 values), with iterative outlier rejection. ARCH3k_cst.1 was based on a smaller data t (6211 values) with prior data selection, excluding data with directional uncertainty $\alpha_{95}>1 \mathrm{l}^{\circ}$ intensity uncertainty $\sigma_{V A D M}>2 \times 10^{22} \mathrm{Am}^{2}$, and age uncertainty $\sigma_{\text {Age }}>100 \mathrm{yr}$. Licht at i 1 (2013) presented model A_FM based on 9660 data, spanning $1000 \mathrm{BCE}$ to $2000 \mathrm{C}^{\mathbf{C}}$. S. nilar to the two ARCH3k models, this was part of a study comparing archaeomagnetic dat. only models to models including sediment records. A model derived with the main pu bosı of archaeomagnetic dating is SHA.DIF.14k (Pavón-Carrasco et al., 2014), spanning nearly thı past $14 \mathrm{kyr}$ based on 12779 data and following from a series of regional European models by the same group (e.g., Pavón-Carrasco et al., 2009). ARCH10k.1 was derived mainly as a starting model for a reconstruction including sediment records for $8000 \mathrm{BCE}$ to 1990 CE (Constable et al., 2016). A model with somewhat improved Southern Hemisphere data coverage due to recent efforts to improve the global data coverage and a data weighting scheme according to archaeomagnetic quality criteria, named SHAWQ2k, was presented by Campuzano et al. (2019). New modelling methods were explored for models AmR, spanning 1200 BCE to 2000 CE in 40-year snapshots (Sanchez et al., 2016), COV-ARCH, a continuous model for the past 3 kyr (Hellio and Gillet, 2018), BIGMUDI4k.1, an iterative approach simultaneously inverting palaeomagnetic, archaeomagnetic and historical records for the past 4,000 years (Arneitz et al., 
2019), and a proof-of-concept model for the past 1000 years (Mauerberger et al., 2020).

\subsubsection{Range of modelling approaches}

Most global geomagnetic field models, whether covering recent, historical, archaeo- or palaeomagnetic times, are based on series of spherical harmonic ( $\mathrm{SH})$ functions that are fit to the data by mathematical inversion techniques. The geomagnetic field is conveniently described by a series of coefficients that scale with field contributions that can be described by a (tilted) dipole, quadrupole, octupole and increasingly shorter wavelength parts. Moreover, when assuming that Earth's mantle is electrically insulating, the SH representation can be downward-continued to provide an image of the field morphology at the top of Eat th's outer core, the CMB. For continuous models over certain time intervals the cieffj ients are smoothly varying time-dependent functions, mostly based on cubic $\mathrm{B}-\mathrm{r}_{\mathrm{r}}{ }^{1}$ ins $\mathrm{s}$ when constructing historical to millennial scale models (see, e.g., Korte and Constable. $2 n, 3$; Korte et al., 2009).

As a result of uncertainties in data and age ( $\mathrm{se}_{\mathrm{S}}$-ection 3 ) a model cannot and should not fit all data exactly, and some form of smooth:... $c$ nstraint is implemented in the modelling. The simplest form is a truncation of the $\mathrm{SH}$ expa sion at low degrees to limit the spatial variability of the model and a temporal parameterisatı $~$ allowing only slow temporal changes. However, most

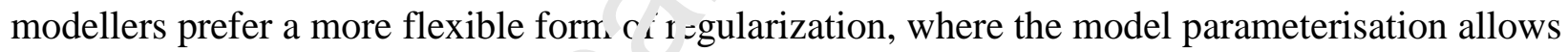
for more variability than expectec to bu resolved by the data, and the fit to the data is traded off against additional smoothness on traints in space and time.

Methodological diffart. es among most archaeo- and palaeomagnetic SH models mainly lie in the choice and st $n_{\xi}{ }^{\text {th }}$ of smoothing constraints, and the treatment of outlying data. Hellio and Gillet (2018) in a ne $*$ approach used statistical information about geomagnetic field evolution from satellite and observatory observations in temporal cross-covariance functions as a constraint in a Bayesian modelling frame. The method results in an ensemble of models with statistically coherent errors on the parameters. Arneitz et al. (2019) also used a Bayesian approach when directly combining archaeomagnetic data with historical observations.

Two recent studies investigate new methods for snapshots in time as a step towards improved continuous models. Sanchez et al. (2016) use statistics from a numerical dynamo simulation as mean and covariance background constraints, which avoids subjective choices of regularization parameters and provides an improved understanding what global spatial resolution 
can be retrieved from the data. Mauerberger et al. (2020) implemented a Bayesian non-parametric approach, assuming the geomagnetic potential to be a Gaussian process rather than using SH basis functions. The method provides realistic regional model uncertainties depending on data distribution.

New modelling approaches provide additional relevant information on model resolution and model uncertainties. Models in general agree for regions or parameters that are well constrained by data, as can be seen in the maps of Fig. 13 and Fig. 14, where the different models appear more similar (panels in a) and have smaller uncertainties (panels in b) in the Northern, than the Southern Hemisphere. This can also been seen in time series fic $\eta$ Europe and South Africa, where there is a better agreement of the models for Paris (densc dat $\iota$ ) than South Africa (sparse data) (Fig. 15). Differences in the data basis, outlier treatmen، anc how uncertainties are weighted have a stronger influence on the models than the methr. 'is:d (Sanchez et al., 2016; Korte and Constable, 2018). When creating a field model (and osessing site dependent output), the underlying data basis should be considered, esp ci cl'y how well a model is constrained for a certain region and time or for a certain $\mathrm{pu}_{\mathrm{r}}$ ss Moreover, all available models are smoothed representations of the actual field variability $: 1$ both space and time. The amplitudes of rapid field changes in field models are not fully resc.'ved and are likely underestimated.

\subsubsection{Influence of data selection ind distribution on global models}

Data selection, weighting ?nd distribution have a significant influence on the output of global models. Data selertion f fllows two philosophies. The first is to use all available data without any prior selec: ${ }_{11}$, roping that the signal to noise ratio will increase with the number of available data. The secc- - philosophy is to make a prior data selection by imposing a set of quality criteria. This makes sense when the quality of the data is well understood and the information is available in global databases, e.g., studies from France (Le Goff et al., 2020) or the Levant (Shaar et al., 2016, 2020). However, this is currently not the case in many other regions of the world, where results are sparse and/or many of the results have been obtained decades ago, before some of the modern laboratory methods and tests providing modern quality criteria existed. It is worth noting that Korte et al. (2009) performed a comparison of models with and without prior data selection based on data and dating uncertainties and found no notable improvement when data selection was imposed. 
Well distributed global data are the most relevant ingredient for an overall good global model. Recent models providing improved uncertainty estimates (Sanchez et al., 2016; Hellio and Gillet, 2018; Mauerberger et al., 2020) quantify what has been qualitatively stated before (Korte et al., 2009): with the presently available data distribution (more precisely the scarcity of Southern Hemisphere data) archaeomagnetic field models provide limited information about the Southern Hemisphere geomagnetic field.

In Fig. 13 and Fig. 14 we show intensity at Earth's surface and the radial field at the CMB for one snapshot in time. Models based on archaeomagnetic (and volcanic) data (ARCH10k.1, SHAWQ2k, AmR and COV-ARCH) and archaeomagnetic, vicanic and sediment data (CALS10k.2; Constable et al., 2016) and (COV-LAKE; Hellic an I Gillet, 2018) can produce models with some broad similarities in intensity at Earth's s'u 'ace and radial field for the Southern Hemisphere, e.g., lower intensity patches extending acrors the Indian Ocean and southern Atlantic ocean. However, the precise locations and morphologies intensity and radial field patches are different. This can be seen in the model COV $-A K E$, which incorporates sediment data and includes more Southern Hemisphere $d \ldots$ han its counterpart archaeomagnetic model $(\mathrm{COV}-\mathrm{ARCH})$; the use of sediment data . sults in different global intensity and radial field morphologies. Using sediment data in a'dition to archaeomagnetic data, but applying the same modelling approach, (e.g., COV-ARC $\mathrm{H}$ a ı COV-LAKE), results in reduced uncertainties on the model output for the Southern He ispıere (Fig. 13b).

Figure 13: (a) Maps of inten ${ }^{i+} y$ at Earth's surface at $900 \mathrm{CE}$ from six global field models: ARCH10k.1 (Constab: - + dl., 2016), SHAWQ2K (Campuzano et al., 2019), CALS10k.2 (Constable et al., 2016), ‘mR (Sanchez et al., 2016), and COV-ARCH and COV-LAKE (Hellio and Gillet, 2018). (b) Maps of intensity uncertainty for AmR, COV-ARCH and COV-LAKE.

Figure 14: Maps of (a) the radial field (Br) and (b) its uncertainty for the core-mantle boundary at 900 CE for different field models. See Fig. 13 for model references.

Figure 15: Time series of magnetic declination (D, top panels), inclination (I, middle panels) and intensity (F, bottom panels) for the past 3000 years at two locations as predicted by six different global magnetic field models. All models agree closely most of the time for Paris, where data 
coverage is good (a), whereas notable differences exist for South Africa, where there are limited data (b). The included models are the archaeomagnetic models ARCH10k.1 (brown), SHAWQ2k (yellow), AmR (red) and COV-ARCH (black), and the two models additionally including sediment records CALS10k.2 (green) and COV-LAKE (blue). We note that owing to the regularization applied in global modelling, all curves are reduced in temporal resolution in comparison to regional curves, e.g., intensity curves for Paris (Livermore et al., 2018).

The lack of Southern Hemisphere data was explicitly considered by earlier versions of the SHA.DIF.14k model, which were European models based on regı nal rather than global basis functions (Pavón-Carrasco et al., 2010). Few archaeomagnetic (a 'd v slcanic) data in the Southern Hemisphere highlight the importance of using sediment recol is f $\mathrm{Jm}$ the Southern Hemisphere to constrain the field in this region. Several other models $\ldots+$ scussed in detail here) mitigate the problem by including high resolution (mainly lacustrinc, sediment records (see Constable and Korte (2015) and Korte et al. (2019) for reviews o the e e).

\subsubsection{Major findings}

The main applications of purely " "chaeomagnetic models are for dating purposes and for the calibration of relative intensities cot uned from sediments. The advantage of models over regional reference curves for arch. eomidgnetic dating lies in that models can generate directional and intensity curves for any lo ^tı $\urcorner$ without the need for re-location of data. Pavón-Carrasco et al. (2011) presented a converianı Natlab tool to obtain age probability density functions from any combination of declina $i_{1}$, $\therefore$. clination and intensity data. Estimated age ranges tend to be smaller if more than one field c nponent is available. A range of published field models and reference curves are implemented in the published version of the tool, and additional ones can be incorporated by the user.

As absolute field strength cannot be retrieved from sediments, archaeological materials and volcanic rocks are the only sources available for obtaining palaeointensity. Based on our current compilation of archaeomagnetic data, both dipole moment reconstructions and global models show that the dipole moment was high around 2 to $3 \mathrm{ka}$ and greater than today's field (e.g., Constable and Korte, 2015). The Holocene maximum seems high compared to the preceding 40 kyr, as noted by Knudsen et al. (2008) and the long-term palaeomagnetic average (Tauxe, 2006; 
Yamamoto and Tsunakawa, 2005). Geomagnetic intensity spikes, on the other hand, might be linked to strong dipole moment variations (Korte and Constable, 2018; Hervé et al., 2021), but their origin is not fully understood.

Studies of global field characteristics, such as symmetry (e.g., Constable et al., 2016) or the field morphology at the CMB (Dumberry and Finlay, 2007; Nilsson et al., 2020), with relevance for the theoretical understanding of the geodynamo, are preferably based on models including sediment records, which provide improved data coverage, in particular for the Southern Hemisphere. Asymmetries seen in the modern field have been found to persist over at least $10 \mathrm{kyr}$ : the field is weaker, but more variable on average in the Southern Hu misphere compared with the Northern Hemisphere, and secular variation tends to be stronger, 7 th Atlantic and Indian Oceans compared with the Pacific (Constable et al., 2016). Although he I lagnetic flux morphology at the $\mathrm{CMB}$ changes notably with time, there are preferred $\mathrm{o}^{r}$ : $^{\mathrm{c}} \mathrm{c} \cdot \mathrm{rrent}$ long-term patterns evident in time-averaged models, in particular nearly symmetrical $p_{n}$ - nes of intense flux at high latitudes in both hemispheres (for more details see, e.g., Ami $\mathrm{e}^{t} \mathrm{c}^{1}$. (2011) and the review by Constable and Korte (2015)). Terra-Nova et al. (2017) mor _ - ec ntly found recurring positions, but no preferred direction of motion and some correlation ' ' flux evolution with lower mantle heterogeneities, supporting hypotheses of mantle conts on the geodynamo (Bloxham and Gubbins, 1987; Bloxham, 2002). Although both west v $r$ and eastward azimuthal flow motions seem to occur in the core over archaeomagnetic ti $\mathrm{i}_{1}$ es (Dumberry and Finlay, 2007; Wardinski and Korte, 2008), recent studies show a clear doı ina nce of westward drift, with rates between $0.07 \% \mathrm{yr}$ (Nilsson et al., 2014, 2020) and $0.25^{\circ} \mathrm{iy}$ : (1 iellio and Gillet, 2018; Nilsson et al., 2020).

The South Atlan ${ }^{i} \mathrm{c}$ inomaly (SAA) is an area stretching from southern Africa over the Atlantic to South Amtrica where the geomagnetic field intensity is notably lower than at comparable latitudes. It is known to have deepened and moved westward from about 1700 onwards from historical data (Mandea et al., 2007; Hartmann et al., 2009). It is linked to the growth of patches of reversed flux at the CMB in the Southern Hemisphere (Gubbins and Bloxham, 1987; Terra-Nova et al., 2016) and has been discussed as a trigger for geomagnetic field reversals (Gubbins and Bloxham, 1987; Tarduno et al., 2015). A unique connection to reversals is unclear as recent modelling of the field for times prior to the Holocene (Brown et al., 2018; Panovska et al., 2019) suggests that features similar to the SAA maybe recurrent and do not necessarily lead to reversals. It is of great interest to know the longevity of the SAA, and whether it 
is a recurrent feature of the field, as it may be linked to structures at the CMB that influence core flow and hence geomagnetic field generation (Tarduno et al., 2015; Tarduno, 2018). SHAWQ2k and other models indicate that reverse flux appeared in the Southern Hemisphere as early as 900 CE east of Africa and evolve into the SAA (Campuzano et al., 2019) (Fig. 14).

\section{Future challenges}

Challenges for the future include addressing current inadequacies in the GEOMAGIA50 database, how to improve the temporal and spatial distribution of archaeomagnetic data, and advances in geomagnetic field modelling.

\subsection{GEOMAGIA50}

In previous sections we outlined some of the iss es i using data from GEOMAGIA50 for modelling purposes; especially for data selection. One unalle.lge is to homogenize the definition of

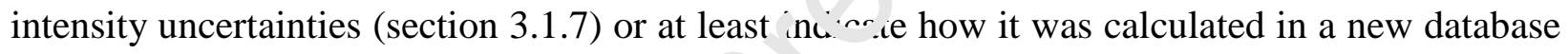
field. Furthermore, a large number of di ect onal entries are missing $k$ values and some are missing $\alpha_{95}$. All entries lacking these tata neud to be reassessed and the data added if missing; however, it is likely, especially for $k, t^{1}{ }^{+}+$the values were not given in the original publications.

A major deficiency in GECMM 'GIA50 is the treatment of chronological metadata and we outline these issues and possible olutions in section 5.1.1. The definition of numbers of samples and specimens also require g. $\bullet$ at $: r$ clarification, because they can differ for displaced and in-situ archaeological materi.'s, 'nd or lava flows (section 5.1.2).

Keeping the datal ase up-to-date and useful for the scientific community remains a challenge. Given limited resources, it is not feasible to release a new update of the database when each new archaeomagnetic study is published. Instead over coming years, we intend to release an update at the end of each year containing all the new studies published that year. We note, for example, that the recent studies of Shaar et al. (2020) and Troyano et al. (2020) have yet to be included in version 3.4. of the database, but will be available in the 2021 release.

\subsubsection{Archival of chronological data}

Section 3.2.3 highlighted how complex the estimation of age uncertainties can be. All 
methods have caveats and the reliability of the age information is intimately linked to knowledge of the archaeological context. It is a difficult task to develop a hierarchy of dating methods and deduce/calculate dates, while preserving the complexity of the dating process in the database. This may only be partly achievable in future revisions to the database. It requires more metadata which de facto increases the complexity of the database and its searchability. Ideally, additional fields could be added to GEOMAGIA50 giving more specific age information that could be used to sieve data for model or curve construction. However, owing to the range and complexity of dating methods, this is impractical. An alternative would be to add an accompanying text field to each entry describing the chronological controls, e.g. the cultural name $\mathrm{o}_{\mathrm{f}} \mathrm{p}$ ariod and a short description of the dating results (as is given in ArcheoInt database (Gener $y f_{i}$ al., 2008)). This approach would not allow automatic data selection and would require i nan al assessments of the quality of data prior to modelling. Such functionality is not $\mathrm{cu}^{r}{ } n_{\mathrm{t}_{2}}$, available and would require the assessment of all articles in GEOMAGIA50.

Although attempts at incorporating greater ra di ccarbon information were made in version 2 of the database, there are numerous comr"* ainns to successful implementation. Radiocarbon dates are currently entered in accordance $w_{*}$ " information provided in published articles, but not consistently and sometimes ambiguously. Ages maybe calibrated or not and calibrated dates can be reported with symmetrical or ssymmetrical bounds (reflecting the calibrated age's non-gaussian distribution) and at 58 ur $95 \%$ confidence. It is not always clear at what level uncertainty is reported.

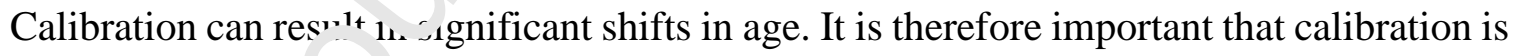
clearly documented. A. th ${ }_{1}$ atabase stands, there are still uncalibrated ages that are used for the date of an entry. An ir ${ }^{\circ+}{ }^{\circ}$ d goal will be to reexamine all the uncalibrated ages and, if there is enough information available, calibrate those ages. As noted in section 3.2, uncalibrated ages are just one of a number of methods that may have been used at a site, e.g., uncalibrated ages may have been combined with archaeological ages or relative stratigraphic ages. In these cases, the dates can not be simply recalibrated, as the radiocarbon ages may form only one aspect of the structural framework for the stratigraphy. This requires that every paper with radiocarbon ages is reexamined in detail to see what scope there is for age re-evaluation.

Documenting calibration of radiocarbon dates is also problematic. GEOMAGIA50 contains studies from the 1960s onwards and numerous improvements have been made in 
calibration methods since this time and new calibration curves are published every few years (e.g. Reimer et al., 2013, 2020) (section 3.2.2). Therefore, there are likely some differences in field variations that are not geomagnetic in origin, but rather they relate to changes in calibration curves. Although there is minimal revision for the past 10,000 years between the generations of calibration curves since 1998 (boundaries of the 95\% intervals of date are generally modified by 5-10 years at the most), calibrated ages can be shifted up to several centuries for older periods (Reimer et al., 2020). Even if changes are small, radiocarbon ages should be recalibrated to keep them mutually consistent and to remove differences in field variations that stem from non-geomagnetic origins. At a minimum, the experimental radiocarbon ages should be $1 t_{1}$ orted accompanied by the calibration method.

The uncertainties on calibrated ages are not treated id alls in the database. Currently only \pm uncertainties are given. Although this allows asymm $-a^{i c}$ ncertainties, i.e. the maximum and minimum ages at two standard deviations resulting from . ilbration, there is no way to record the full multi-modal probability distribution of a calit $a^{+} e r$ age. This is a significant limitation of the database, as it is important to take into ar . ' 'll : the irregular shape of the probability density function of calibrated radiocarbon dates in $\_$omagnetic modelling and regional secular variation curves (e.g., Hellio et al., 2014; Lano. 2004; Hervé and Lanos, 2018; Tema et al., 2017; Yutsis-Akimova et al., 2018a). Systır a ically storing uncalibrated ages (when available) and updating all radiocarbon ages and inctitainties after calibration is a major undertaking, but is an aim for the future.

\subsubsection{Clarification of ile .mple-specimen hierarchy}

Reporting of th. . uumber of samples and specimens used for directional and intensity analysis requires evaluation. The database aims to follow the standard palaeomagnetic hierarchy, whereby each entry in the database is considered to be a site, a group of data related to a geological unit or archaeological context that has a unique age. A sample is treated as part of the site that was removed for further analysis. A specimen is a subdivision of a sample and it is this that palaeomagnetic or archaeomagnetic measurements are made on. In palaeomagnetism, this hierarchy works well. A site would be, e.g., a lava flow; a sample, a palaeomagnetic core drilled out of the lava flow; and a specimen, the subdivision of the sample (core) that was measured and the directional or intensity data were obtained from. The number of samples and specimens maybe 
similar, e.g., if one specimen was taken from each sample or the number of specimens could be more if multiple specimens were measured from a sample. In this case, the specimen numbers are averaged to give a sample mean and it is always the sample mean and number of samples that are used to calculate the site mean direction.

In archaeointensity studies this may work differently. For example, a piece of pottery may be related to an instance in time, but might not belong to a context with other pieces of pottery of the same age (a context being a site, analogous, e.g., to a lava flow). In this case the piece of pottery could be treated as both a site or a sample. The piece of pottery can be further divided for measurement and these divisions could be considered to be eithe piece of pottery were treated as if it were to belong to a context $\mathrm{w}$ ith , lany other pieces of pottery, then it is just one sample of possibly many, therefore the nu $n b \in$ of samples would be one and there would be multiple specimens. If the piece of potte is reated as a site, then the number of samples would be multiple and equal to the number of sp imens.

In archaeomagnetic directional studies th it de "in situ" structures, i.e. ones that have remained in their original position since fi- $\mathrm{g}$, there is obviously no ambiguity; a site can be equated with the structure it derives from. ' $\mathrm{n}$ this case, and for directional determination, one should emphasize the importance of $w$ rking on several independently oriented samples for deriving a mean direction.

Both approaches have thei, advantages, depending on how the data are to be used or from a consistency point of view (riria 'ise of the site, sample, specimen hierarchy). For example, obtaining multiple measureme. ${ }^{\text {tr }}$ of intensity from a piece of pottery can provide an accurate mean intensity determination, $v_{a}{ }^{\prime \prime}{ }^{\prime}$.ble for secular variation or curve construction. This would require that the piece of potter, is treated as a site and that the number of specimens is treated as the number of samples. In the database, the number of archaeointensity measurements used for the mean value is therefore treated in the same way as the number of samples from, e.g., a lava flow: they would have equal value. However, this leads to a mismatch in how different archaeological entries may be treated in the database (e.g., an in-situ structure versus a piece of pottery) and between archaeological and palaeomagnetic hierarchies, e.g., a lava flow would no longer be equal to a context, if the piece of pottery becomes the site. Treating a single artefact as belonging to a single context, regardless of whether there are other artefacts maintains the logic of the hierarchy, but may result in data not being included in further analyses if the number of samples is listed as 
one, e.g., if the data are filtered by the number of samples.

The fact that there is no common system of hierarchy is a current weakness of the database. In the future, we propose (as in ArcheoInt) that $\mathrm{N}$ corresponds to the number of thermal units, i.e. the number of units that can be considered to have been magnetized at the same time. It is fixed to 1 for a lava flow, an archaeological in-situ structure and a single fragment of pottery, or is higher than 1 for a group of baked clay fragments. A second number, $n$, would be the number of individual values from which the average and its uncertainty are calculated. Because the averages are not calculated homogeneously between data entries, either at the sample level or the specimen level, this solution has the disadvantage to mix samples and specimıt.'s, but it would clearly make it easier for data selection.

\subsection{Improvements in data distribution}

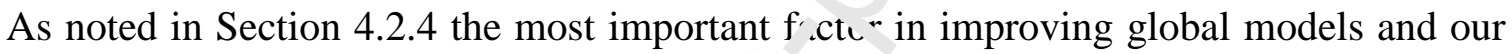
overall understanding of the global archaeomagnt $+\mathrm{j}$. $\mathrm{f}$ eld is more data from regions with sparse data distributions. With $\sim 50 \%$ of all data on in from Europe (Section 2.3), there is significant room for improving data coverage. Afric is a clear target given its large area and rich archaeological history. Studies on Burkin. Faso, Ivory Coast, Mali, Ethiopia, Kenya, Zimbabwe and South Africa over the past 10 vear have made significant steps in improving data coverage. However, an increased empharis should be placed on developing archaeomagnetic research projects in Africa. Similarly, su 'itı. America is well positioned to provide useful data. Data from both southern Africa and su 'th America will be key to unraveling the long term evolution of the South Atlantic Anoma, iie Indian subcontinent has a rich archaeological history and yet no archaeomagnetic directluılal data have been produced. Given its unique position, new directional data could aid in understanding of westward drift of the field across the Indian Ocean. Australia, New Zealand and Pacific islands also have the potential to provide further archaeomagnetic data. This would be especially valuable as it could improve our understanding of field variations in the Southern Hemisphere and the Pacific, which are greatly lacking in data. It would be interesting to investigate/confirm the persistence of lower field variability in the western Pacific (Constable et al., 2016). Finally, the large amount of Japanese directional data not in the database should be added. There are hundreds of entries in this data set and it will be of great interest to see how this influences our understanding of field evolution in eastern Asia. 
Acquiring data in regions with few data presents practical challenges. Access to in-situ structures is crucial for full vector studies. However, sampling must take place shortly after excavation and this is not always practical. In most countries archaeomagnetists are limited by several constraints (e.g., travel, time, funding, and export licences). This explains why the spatial distribution of directions is fairly close to palaeomagnetic laboratories, as is the case with Europe. A solution would be to develop local laboratories and/or networks of researchers trained in archaeomagnetic sampling, as well as to collaborate with and train local archaeologists. However, such efforts take time to implement, so we may only see a gradual increase in the amount of data from poorly represented areas.

Another aspect of improving the data distribution is to ex enc the database further back in time through the Iron Age, Bronze Age and the Neolithic. T rere is a tendency to focus on more dramatic field changes, e.g., spikes in intensity during th -911 ition from the Iron to Bronze age in the Levant and surrounding areas; however, all times (c. 'quiet times") are equally valuable to study, as all field variations relate to the under yj $₫$ geodynamo process. Furthermore, more detailed descriptions of field evolution thr $r_{0}$.ght time will allow for the development of more accurate archaeomagnetic dating curves.

A consideration of the types of a haeological materials used to extend our knowledge of field variations to older times is also 1 zr u1 ed. Baked clays are less frequent back through time, as are in situ structures, which are 1 . ore likely to suffer eventual post-displacements. The baking degree of older clay-based $\mathrm{ma}^{+} \mathrm{er}_{\mathrm{n}} \mathrm{l} \mathrm{l}$ s is also usually lower, resulting in a less stable mineralogy prone to alteration and the $\mathrm{f}_{\mathrm{O}_{1}} \cdot$ ess favourable for obtaining archaeointensity results. Increasing the success rate of arch. $e^{-i n t}$ nsity experiments on such materials is a major challenge that could be overcome in the next trade by new approaches, such as scanning magnetometry and computed tomography (de Groot et al., 2018). Furthermore, a better understanding of the magnetic mineralogy of archaeological materials will aid in this research (e.g., Lopez-Sanchez et al., 2020). To recover intensity variations in the early Holocene or even in the Pleistocene prior to apparition of ceramic production, an alternative to baked clays is the study of heated rock artefacts, such as burnt cherts (Kapper et al., 2014; Zeigen et al., 2019).

Beyond the acquisition of data for older periods and/or for regions that are still poorly documented, an important challenge in archaeomagnetism remains to better understand the issue of data dispersion. Dispersion is characteristic for many data sets and hinders our ability to finely 
trace geomagnetic field variations through time. Besides age uncertainty, the sources of dispersion are more numerous for intensity data (undetected alteration, MD effects, uncorrected TRM anisotropy and cooling rate) than for directions. One major issue is the cooling rate correction because its absence can potentially result in a systematic overestimation. One could think to apply a correction factor to uncorrected data. On average, the correction factor seems to be 5-10\% (Genevey et al., 2008). However, defining a suitable rate of correction is difficult, because it depends on the specific rock magnetic properties of a specimen and the equipment and protocols used in each laboratory.

Furthermore, what is the precision with which the dircc: on and/or intensity of the geomagnetic field can be retrieved? Does dispersion reflect ou current limitations in the acquisition of data? To better constrain these questions, one can ask whether there would be an interest in revisiting regions with a good data coverage 1 an active archaeological research, in order to acquire new precisely dated data, for examp: from the past few centuries where chronological constraints can be extremely tight. By limiting the influence of age uncertainties, this could help solve the above issues, ".hic: are crucial in using archaeomagnetism for archaeological purposes and for refining ou ' ' nowledge of the evolution of the geomagnetic field.

\subsection{Global geomagnetic field $n$ orielling}

From a field modellins, s nint of view, the above-mentioned improvements to the

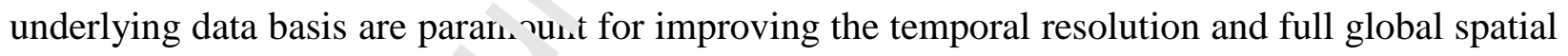
reliability of models. Bott i. ssu aspects are relevant when using field models to infer geodynamo processes in the core, or wirn using their predictions for regional reference curves. As noted in section 4.2.4, the lack oi archaeomagnetic data in the Southern Hemisphere and equatorial areas can be partly compensated for by using sediment data. Similarly, a recently renewed interest in speleothems may produce new high resolution time series for the Holocene in the coming years from locations where it is not possible to obtain archaeological or sediment data. Lascu and Feinberg (2011) give a detailed overview of the potential for speleothems to recover detailed field variations, with the study of Trindade et al. (2018) providing a detailed Holocene record from Brazil and other studies resolving other geomagnetically interesting times in great detail (e.g., Lascu et al., 2016; Chou et al., 2018).

Continuing the efforts to improve the treatment of data and dating errors and translating 
them into realistic model errors through methodological developments is also of interest for both these cases. Improved global archaeomagnetic field models may contribute to answering open questions about, e.g., the maximum possible rate of geomagnetic field change and the influences of lowermost mantle structure on the geodynamo (which is reflected in magnetic field morphology). They will also likely contribute to improved predictions of future geomagnetic field evolution by assimilation of data-based models into numerical simulations (e.g., Fournier et al., 2010; Tangborn and Kuang, 2018).

\section{Acknowledgments}

We thank the archaeomagnetic community for providind Elisabeth Schnepp, Patrick Arneitz and Mary Kovacheva. U e a lowledge Fabio Donadini, Kimo Korhonen and Lauri Pesonen for the development and resign of GEOMAGIA50. GH was supported by the Labex LsScArBx (Borderax Archaeological Sciences Labex, ANR-10-LABX-52). Development of GEOMAFL. ${ }^{\wedge} 50$ was supported by DFG SPP-1488. This is Institute for Rock Magnetism contribution 2003.

Conflict of interest

I declare no conflicts of interests or hel ə' $^{\prime}$ of all authors.

\section{References}

Aidona, E., Polymerir C. K ndopoulou, D., Spassov, S., Raptis, K., 2021. Archaeomagnetism and luminescence on Late Byzantine kilns in Thessaloniki (N. Greece): Implications for geomagnetic field variations during the last two millennia. Phys. Earth Planet. Inter. 316, 106709.

Aitken, M., Hawley, H., 1970. Archaeomagnetism: evidence for magnetic refraction in kiln structures. Archaeometry 13, 83-85.

Aitken, M. J., 1985. Thermoluminescence dating. Academic Press.

Aitken, M. J., 2014. Science-Based Dating in Archaeology. Longman Archaeology Series. Routlegde.

Aitken, M. J., Alcock, P. A., Bussel, G. D., Shaw, C. J., 1981. Archaeomagnetic determination of 
the past geomagnetic intensity using ancient ceramics: Allowance for anisotropy. Archaeometry 23 (1), 53-64.

Aitken, M. J., Allsop, A. L., Bussell, G. D., Winter, M. B., 1988. Determination of the intensity of the Earth's magnetic field during archaeological times: Reliability of the Thellier technique. Reviews of Geophysics 26 (1), 3-12.

Aitken, M. J., Allsop, A. L., Bussell, G. D., Winter, M. B., 1989. Geomagnetic intensity variation during the last 4000 years. Phys. Earth Planet. Inter. 56 (1), 49 - 58.

Aitken, M. J., Hawley, H. N., 1966. Magnetic dating-III: further archaeomagnetic measurements in Britain. Archaeometry 9, 187-199.

Aitken, M. J., Weaver, G. H., 1962. Magnetic dating: Some ar hae Jmagnetic measurements in Britain. Archaeometry 5 (1), 4-18.

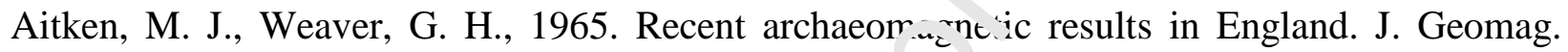
Geoelectr. 17, 391-394.

Alken, P., Thébault, E., Beggan, C. D., Amit, H., A ur ert, J., Baerenzung, J., Bondar, T. N., Brown, W., Califf, S., Chambodut, A., Chulliat _.., Tox, G., Finlay, C. C., Fournier, A., Gillet, N., Grayver, A., Hammer, M. D., Holschn` ‘er, M., Huder, L., Hulot, G., Jager, T., Kloss, C., Korte, M., Kuang, W., Kuvshinov, A., Langlais, B., Léger, J. M., Lesur, V., Livermore, P. W., Lowes, F. J., Macmillan, S., Mouı.d J. Z., Nair, M., Nakano, S., Olsen, N., Pavón-Carrasco, F. J., Petrov, V. G., Ropp, G., Rı her, M., Sabaka, T. J., Sanchez, S., Saturnino, D., Schnepf, N. R., Shen, X., Stolle, C., T. ngi orn, A., Tffner-Clausen, L., Toh, H., Torta, J. M., Varner, J., Vervelidou, F., Vignernn, ? Wardinski, I., Wicht, J., Woods, A., Yang, Y., Zeren, Z., Zhou,

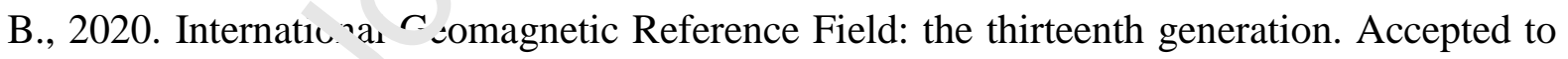
Earth Planets and $\mathrm{S}_{\mathrm{r}} \sim$ - e.

Amit, H., Korte, M., Aubert, J., Constable, C., Hulot, G., 2011. The time-dependence of intense archeomagnetic flux patches. J. Geophys. Res. 116, B12106.

Arneitz, P., Egli, R., Leonhardt, R., Fabian, K., 2019. A Bayesian iterative geomagnetic model with universal data input: Self-consistent spherical harmonic evolution for the geomagnetic field over the last 4000 years. Phys. Earth Planet. Inter. 290, 57-75.

Arneitz, P., Leonhardt, R., Schnepp, E., Heilig, B., Mayrhofer, F., Kovacs, P., Hejda, P., Valach, F., Vadasz, G., Hammerl, C., Egli, R., Fabian, K., Kompein, N., 2017. The HISTMAG database: combining historical, archaeomagnetic and volcanic data. Geophys. J. Int. 210 (3), 
1347-1359.

Athavale, R. N., 1966. Intensity of the geomagnetic field in India over the past 4000 years. Nature 210, 1310-1312.

Athavale, R. N., 1969. Intensity of the geomagnetic field in prehistoric Egypt. Earth Planet. Sci. Lett. 6, 221-224.

Basavaiah, N., Deenadayalan, K., Babu, J. M., Kanu, M., Kumar, K. N., Demudu, G., Rao, K. N., Mallikarjunarao, N., 2019. Last 3000 years of geomagnetic field intensity from India: New reference palaeointensity data from two east coast archaeological sites and archaeomagnetic dating insights. Journal of Archaeological Science: Reports 27, 171943.

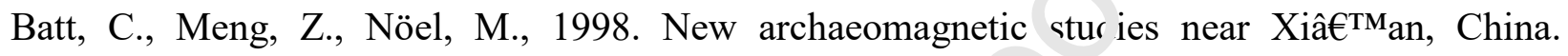
Archaeometry 40 (1), 169-175.

Batt, C. M., Brown, M. C., Clelland, S.-J., Korte, M., Li... archaeomagnetic dating in Britain: New data, new $a_{1}$, roaches and a new calibration curve. Journal of Archaeological Science 85, 66-82.

Belshé, J. C., Cook, K., Cook, R. M., 196乞. Sı me archaeomagnetic results from Greece. The Annual of the British School at Athens _ $\ulcorner$. 813.

Ben-Yosef, E., Millman, M., Shaar, I. Tauxe, L., Lipschits, O., 2017. Six centuries of geomagnetic intensity variations rec or ied by royal Judean stamped jar handles. Proceedings of the National Academy of Scie. ses i14 (9), 2160-2165.

Ben-Yosef, E., Tauxe, L., Lev, 1. E., Shaar, R., Ron, H., Najjar, M., 2009. Geomagnetic intensity spike recorded in high "asc' '.ion slag deposit in Southern Jordan. Earth Planet. Sci. Lett. 287 (3), 529-539.

Bloxham, J., 2002. Tim : :adependent and time-dependent behaviour of high-latitude flux bundles at the core-mantle boundary. Geophys. Res. Lett. 29, 1854.

Bloxham, J., Gubbins, D., 1985. The secular variation of Earth's magnetic field. Nature 317, $777-781$.

Bloxham, J., Gubbins, D., 1987. Thermal core-mantle interactions. Nature 325, 511-513.

Bloxham, J., Jackson, A., 1992. Time-dependant mapping of the magnetic field at the core-mantle boundary. J. Geophys. Res. 97, 19537-19563.

Bowen, P., Ranck, H., Scarlett, T., Drelich, J., 1971. Rehydration/rehydroxylation kinetics of a reheated XIX-Century Davenport (Utah) ceramic. J. Am. Ceram. Soc. 94, 2585-2591. 
Bowles, J., Gee, J., Hildebrand, J., Tauxe, L., 2002. Archaeomagnetic intensity results from California and Ecuador: evaluation of regional data. Earth Planet. Sci. Lett. 203 (3), 967-981.

Braginskiy, S. I., Burlatskaya, S. P., 1979. Spherical analysis of the geomagnetic field based on archaeomagnetic data. Izv. Earth Phys. 15, 891-895.

Bronk Ramsey, C., 2009. Bayesian analysis of radiocarbon dates. Radiocarbon 51, 337-360.

Brown, M., Korte, M., Holme, R., Wardinski, I., Gunnarson, S., 2018. Earth's magnetic field is probably not reversing. Proceedings of the National Academy of Sciences 115 (20), $5111-5116$.

Brown, M. C., Donadini, F., Frank, U., Panovska, S., Nilsson, A., I'vrhonen, K., Schuberth, M., Korte, M., Constable, C. G., 2015a. GEOMAGIA50.v3: 2. a new paleomagnetic database for lake and marine sediments. Earth Planets Space 67, 70.

Brown, M. C., Donadini, F., Korte, M., Nilsson, A., K hoven, K., Lodge, A., Lengyel, S. N., Constable, C. G., 2015b. GEOMAGIA50.v3: 1. gen al structure and modifications to the archeological and volcanic database. Earth Pla 1e's Space 67, 83.

Bucha, V., 1967. Intensity of the Ear+.. $\mathrm{n}_{\text {. }}$ gnetic field during archeological times in Czechoslovakia. Archaeometry 10, 12- ¿?

Bucur, I., 1994. The direction of the wrrestrial magnetic field in France, during the last 21 centuries. recent progress. Phys. La th Planet. Inter. 87 (1), 95-109.

Burakov, K. S., Nachasova, I. I . 1 185 . Correcting for chemical change during heating in archeomagnetic determina ${ }^{i}$ or of the ancient geomagnetic field intensity. Izvestiya, Phys. Solid Earth 21, 801-802

Burakov, K. S., Nacha' NV 1. E., 2013. Archaeomagnetic study and rehydroxylation dating of fired-clay ceramics. ' vestiya, Phys. Solid Earth 49, 105-112.

Burlatskaya, S., Nachasova, I., Didenko, E., Shelestun, N., 1986. Archeomagnetic determinations of geomagnetic field elements of the USSR Academy of Sciences. Soviet Geophysical Comittee of the USRR Academy of Sciences: Moskow, 168pp.

Burlatskaya, S. P., 1961. Archeomagnetic evidence for the Earth's magnetic field near Tiflis during the past. Geomagnetism and Aeronomy 1, 707-708.

Butler, R. F., 1992. Paleomagnetism: Magnetic domains to geologic terrains. Blackwell Science.

Cai, S., Chen, W., Tauxe, L., Deng, C., Qin, H., Pan, Y., Yi, L., Zhu, R., 2015. New constraints on the variation of the geomagnetic field during the late Neolithic period: Archaeointensity results 
from Sichuan, southwestern China. J. Geophys. Res. 120 (4), 2056-2069.

Cai, S., Tauxe, L., Paterson, G. A., Deng, C., Pan, Y., Qin, H., Zhu, R., 2017. Recent advances in Chinese archeomagnetism. Frontiers in Earth Science 5, 92.

Cai, S., Tauxe, L., Wang, W., Deng, C., Pan, Y., Yang, L., Qin, H., 2020. High-fidelity archeointensity results for the Late Neolithic Period from Central China. Geophys. Res. Lett. 47 (10), e2020GL087625.

Calvo-Rathert, M., Morales Contreras, J., Carrancho, A., Camps, P., Goguitchaichvili, A., Hill, M. J., 2019. Reproducibility of archaeointensity determinations with a multimethod approach on archaeological material reproductions. Geophys. J. Int. 218 (3), : 719-1738.

Campuzano, S., Gómez-Paccard, M., Pavón-Carrasco, F., Os `te, M., 2019. Emergence and evolution of the South Atlantic Anomaly revealed by th ne' $v$ paleomagnetic reconstruction SHAWQ2k. Earth Planet. Sci. Lett. 512, 17-26.

Capdepont, I., Sánchez Bettucci, L., Morales, J., Gogici ushvili, A., 2019. Archaeomagnetism applied to ceramics from coastal archaeologic: 1 ' 1 t's in Uruguay. In: Inda Ferrero, H., García Rodríguez, F. (Eds.), Advances in Cr «ta. Geoarchaeology in Latin America. Springer International Publishing, pp. 157-176.

Carrancho, A., Villalaín, J., Pavón-Carı ‘co, F., Osete, M., Straus, L., Vergès, J., Carretero, J., Angelucci, D., González Morale., M., Arsuaga, J., Bermúdez de Castro, J., Carbonell, E., 2013. First directional Eurow an palaeosecular variation curve for the Neolithic based on archaeomagnetic data. Ear.' $\mathrm{F}$ : 'anet. Sci. Lett. 380, 124-137.

Casas, L., Incoronato, A.. $\cap\urcorner^{7}$ Distribution analysis of errors due to relocation of geomagnetic data using the 'Cor. 'e ${ }^{-i}, n$ via Pole' (CVP) method: Implications on archaeomagnetic data. Geophysical Journa' 'T.ternational 169 (2), 448-454.

Cejudo, R., Goguitchaichvili, A., Montejo, F., Ruiz, R. G., lvaro Botiva, Morales, J., 2019. First archaeomagnetic results from Colombia (the Bogotá Savanna Pre-Hispanic sites): Implications for the Caribbean absolute geomagnetic intensity variation curve. Journal of Archaeological Science: Reports 26, 101898.

Chauvin, A., Garcia, Y., Lanos, P., Laubenheimer, F., 2000. Paleointensity of the geomagnetic field recovered on archaeomagnetic sites from France. Phys. Earth Planet. Inter. 120 (1-2), 111-136.

Chelidze, Z. A., 1965. Some results of a study of the past geomagnetic field in Georgian SSR by 
the archeomagnetic method. Geomagnetism and Aeronomy 5, 744-746.

Chiari, G., Lanza, R., 1997. Pictorial remanent magnetization as an indicator of secular variation of the Earth's magnetic field. Phys. Earth Planet. Inter. 101 (1), 79-83.

Chou, Y.-M., Jiang, X., Liu, Q., Hu, H.-M., Wu, C.-C., Liu, J., Jiang, Z., Lee, T.-Q., Wang, C.-C., Song, Y.-F., Chiang, C.-C., Tan, L., Lone, M. A., Pan, Y., Zhu, R., He, Y., Chou, Y.-C., Tan, A.-H., Roberts, A. P., Zhao, X., Shen, C.-C., 2018. Multidecadally resolved polarity oscillations during a geomagnetic excursion. Proceedings of the National Academy of Sciences 115 (36), 8913-8918.

Clark, A. J., Tarling, D. H., Noel, M., 1988. Developments in archa mmagnetic dating in Britain. Journal of Archaeological Science 15 (6), 645-667.

Coe, R. S., 1967. Paleo-intensities of the Earth's magnetic, fiels determined from Tertiary and Quaternary rocks. J. Geophys. Res. 72, 3247-3262.

Constable, C., Korte, M., 2015. Centennial- to millennia: cale geomagnetic field variations. In: Treatise on Geophysics, Second Edition. Elser re', Amsterdam, Netherlands.

Constable, C., Korte, M., Panovska, S., 20\% 1 rsistent high paleosecular variation activity in southern hemisphere for at least 10000 , ars. Earth Planet. Sci. Lett. 453, 78-86.

Constable, C. G., Johnson, C. L., Lund, s P., 2000. Global geomagnetic field models for the past

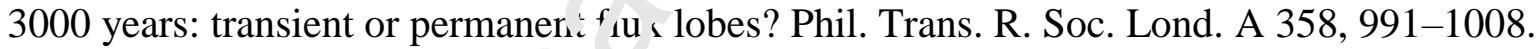

Cook, R., Belshé, J., 1958. ArchaŁ magnetism. A preliminary report on Britain. Antiquity 32, 167.

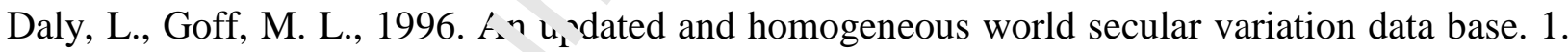
Smoothing of the archnon: " gnetic results. Phys. Earth Planet. Inter. 93 (3), 159 - 190.

Davies, C. J., Constat: ? G., 2017. Geomagnetic spikes on the core-mantle boundary. Nat. Commun. 8, 15593.

Day, R., Fuller, M., Schmidt, V. A., 1977. Hysteresis properties of titanomagnetites: grain size and compositional dependence. Phys. Earth Planet. Inter. 13, 260-267.

de Groot, L., Biggin, A., Dekkers, M., Langereis, C., Herrero-Bervera, E., 2013. Rapid regional perturbations to the recent global geomagnetic decay revealed by a new Hawaiian record. Nature Communications 4, 2727.

de Groot, L. V., Fabian, K., Béguin, A., Reith, P., Barnhoorn, A., Hilgenkamp, H., 2018. Determining individual particle magnetizations in assemblages of micrograins. Geophysical Research Letters 45 (7), 2995-3000. 
De Marco, E., Tema, E., Lanos, P., Kondopoulou, D., 2014. An updated catalogue of Greek archaeomagnetic data for the last 4500 years and a directional secular variation curve. Stud. Geophys. Geod. 58 (1), 121-147.

Deenadayalan, K., Gawali, P. B., Lakshmi, B. V., Rai, M., 2020. Rock-magnetic and archaeomagnetic investigations on archaeological artefacts from Maharashtra, India. Geological Society, London, Special Publications 497 (1), 9-26.

Dekkers, M. J., Böhnel, H. N., 2006. Reliable absolute palaeointensities independent of magnetic domain state. Earth Planet. Sci. Lett. 248, 508-517.

Deng, X. H., Li, D. J., 1965. The geomagnetic field in Peking rty: on and its secular variation during the last 2000 years. Acta Geophys. Sinica 14, 181-19

Domen, H., 1977. A single heating method of paleomagnetic 'ielc intensity determination applied to old roof tiles and rocks. Phys. Earth Planet. Inter. .2 (4), 315 - 318.

Donadini, F., Korte, M., Constable, C., 2009. Geomagne : field for 0-3 ka: 1. New data sets for global modeling. Geochem. Geophys. Geosyst 1'j, Q06007.

Donadini, F., Riisager, P., Korhonen, K., Pe , ทє. L., 2006. Database for Holocene geomagnetic intensity information. Eos Trans. AGU ¿ (14), 137-143.

Donadini, F., Serneels, V., Kapper, L., Eı Kateb, A., 2015. Directional changes of the geomagnetic field in West Africa: Insights fron t'ie ınetallurgical site of Korsimoro. Earth Planet. Sci. Lett. 430, 349-355.

Dumberry, M., Bloxham, J., 270c. Azimuthal flows in the Earth's core and changes in length of day at millennial timesnalt: Jeophys. J. Int. 165, 32-46.

Dumberry, M., Finlay, ? I , 2007. Eastward and westward drift of the Earth's magnetic field for the last three millen. ${ }_{2}$. Earth Planet. Sci. Lett. 254, 146-157.

Dunlop, D. J., 2002. Theory and application of the Day plot $\left(M_{r s} / M_{s}\right.$ versus $\left.H_{c r} / H_{c}\right) 1$. Theoretical curves and tests using titanomagnetite data. J. Geophys. Res. 107 (B3), 2056.

Dunlop, D. J., 2011. Physical basis of the Thellier-Thellier and related paleointensity methods. Phys. Earth Planet. Inter. 187, 118-138.

Ertepinar, P., Hammond, M. L., Hill, M. J., Biggin, A. J., Langereis, C. G., Herries, A. I. R., Yener, K. A., Akar, M., Gates, M.-H., Harrison, T., Greaves, A. M., Frankel, D., Webb, J., Ozgen, I., Yazicioglu, G. B., 2020. Extreme geomagnetic field variability indicated by Eastern Mediterranean full-vector archaeomagnetic records. Earth Planet. Sci. Lett. 531, 115979. 
Evans, M., Hoye, G., 2005. Archaeomagnetic results from southern Italy and their bearing on geomagnetic secular variation. Phys. Earth Planet. Inter. 151 (1), 155-162.

Evans, M. E., 1991. An archaeointensity investigation of a kiln at Pompeii. J. Geomag. Geoelectr. 43 (5), 357-361.

Fabian, K., Leonhardt, R., 2010. Multiple-specimen absolute paleointensity determination: An optimal protocol including pTRM normalization, domain-state correction, and alteration test. Earth Planet. Sci. Lett. 297, 84-94.

Fanjat, G., Camps, P., Alva Valdivia, L. M., Sougrati, M. T., Cuevas-Garcia, M., M.Perrin, 2013. First archeointensity determinations on Maya incense burners fro $\leadsto$ Palenque temples, Mexico: New data to constrain the Mesoamerica secular variation cu ve. Earth Planet. Sci. Lett. 363, $168-180$.

Fisher, R. A., 1953. Dispersion on a sphere. Proc. R. Sor. I o. d., A 217, 295-305.

Folgheraiter, G., 1899. Sur les variations séculaires de l'iı 'inaison magnétique dans l'antiquité. J. Phys. Theor. Appl. 8, 660-667.

Fournier, A., Hulot, G., Jault, D., Kuang, ' $\cdots$, Tangborn, A., Gillet, N., Canet, E., Aubert, J., Lhuillier, F., 2010. An introduction to $C$ ca assimilation and predictability in geomagnetism. Space Science Reviews 155, 247-29:

Fox, J. M. W., Aitken, M. J., 1980. C'c Jl ıg-rate dependency of thermoremanent magnetisation. Nature 283, 462-463.

Gallet, Y., D’Andrea, M., Fen 'vey, A., Pinnock, F., Le Goff, M., Matthiae, P., 2014. Archaeomagnetism at $\mathrm{Dh}_{1}$. (Tell Mardikh, Syria). new data on geomagnetic field intensity

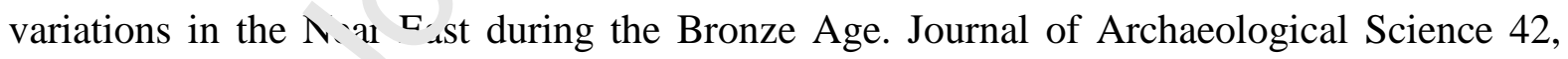
295-304.

Gallet, Y., Fortin, M., Fournier, A., Le Goff, M., Livermore, P., 2020. Analysis of geomagnetic field intensity variations in Mesopotamia during the third millennium $\mathrm{BC}$ with archeological implications. Earth Planet. Sci. Lett. 537, 116183.

Gallet, Y., Genevey, A., Courtillot, V., 2003. On the possible occurrence of archaeomagnetic jerks in the geomagnetic field over the past three millennia. Earth Planet. Sci. Lett. 214 (1), $237-242$.

Gallet, Y., Genevey, A., Fluteau, F., 2005. Does earth's magnetic field secular variation control centennial climate change? Earth Planet. Sci. Lett. 236 (1), 339-347. 
Gallet, Y., Genevey, A., Le Goff, M., 2002. Three millennia of directional variation of the Earth's magnetic field in western Europe as revealed by archeological artefacts. Phys. Earth Planet. Inter. $131(1), 81-89$.

Gallet, Y., Hulot, G., Chulliat, A., Genevey, A., 2009. Geomagnetic field hemispheric asymmetry and archeomagnetic jerks. Earth Planet. Sci. Lett. 284, 179-186.

Gallet, Y., Montaña, M. M., Genevey, A., García, X. C., Thébault, E., Bach, A. G., Goff, . M. L., Robert, B., Nachasova, I., 2015. New late neolithic (c. 7000-5000 BC) archeointensity data from Syria. Reconstructing 9000 years of archeomagnetic field intensity variations in the Middle East. Phys. Earth Planet. Inter. 238, 89-103.

Games, K. P., 1977. The magnitude of the paleomagnetic field: a $\mathrm{n}$ w non-thermal, non detrital method using sun-dried bricks. Geophys. J. R. astr. Soc <. \&, 315329.

Genevey, A., Gallet, Y., 2002. Intensity of the geomagn $:$ isld in western Europe over the past 2000 years: New data from ancient French pottery. I. .eophys. Res. 107, 2285.

Genevey, A., Gallet, Y., Constable, C. G., Korte, N.., Hulot, G., 2008. ArcheoInt: An upgraded compilation of geomagnetic field intens, da. for the past ten millennia and its application to the recovery of the past dipole moment. -eochem. Geophys. Geosyst. 9, Q04038.

Genevey, A., Gallet, Y., Jesset, S., Théb. •lt, E., Bouillon, J., Lefèvre, A., Le Goff, M., 2016. New archeointensity data from French. $\mathrm{La}$ ) iy Medieval pottery production (6-10th century AD). Tracing 1500 years of geoma netic field intensity variations in Western Europe. Phys. Earth Planet. Inter. 257, 205-21s

Genevey, A., Gallet, Y., ${ }^{\wedge} \mathbf{a}_{\Perp}$ w.eron, J.-C., 2003. Eight thousand years of geomagnetic field intensity variations in wo eastern Mediterranean. J. Geophys. Res. 108.

Genevey, A., Gallet, Y, Rosen, J., Le Goff, M., 2009. Evidence for rapid geomagnetic field intensity variations in Western europe over the past 800 years from new French archeointensity data. Earth Planet. Sci. Lett. 284 (1), 132-143.

Genevey, A., Gallet, Y., Thébault, E., Livermore, P., Fournier, A., Jesset, S., Lefèvre, A., Maé-Hourlier, N., Marot, E., Regnard, S., 2021. Archeomagnetic intensity investigations of French medieval ceramic workshops: Contribution to regional field modeling and archeointensity-based dating. Phys. Earth Planet. Inter. 318, 106750.

Genevey, A., Principe, C., Gallet, Y., Clemente, G., Le Goff, M., Fournier, A., Pallecchi, P., 2019. Refining the high-fidelity archaeointensity curve for Western Europe over the past 
millennium: analysis of Tuscan architectural bricks (Italy). Geol. Soc. Lond. Spec. Pub. 497 (1), 73-88.

Goguitchaichvili, A., Greco, C., Garcia Ruiz, R., Pereyra Domingorena, L., Cejudo, R., Morales, J., Gogorza, C., Scattolin, C., Tarrag, M., 2019. First archaeointensity reference paleosecular variation curve for South America and its implications for geomagnetism and archaeology. Quaternary Research 92 (1), 8197.

Goguitchaichvili, A., Greco, C., Morales, J., 2011. Geomagnetic field intensity behavior in South America between $400 \mathrm{AD}$ and 1800 AD: first archeointensity results from Argentina. Phys. Earth Planet. Inter. 186, 191-197.

Goguitchaichvili, A., Morales, J., Schavelzon, D., Vásquez, C G gorza, C. S., Loponte, D., Rapalini, A., 2015. Variation of the Earth's magnetic fie. 1 st ength in South America during the last two millennia: New results from historical bu ${ }^{: 1 .}{ }^{1} n_{\xi}$ s of Buenos Aires and re-evaluation of regional data. Phys. Earth Planet. Inter. 245, 15-7j.

Gómez-Paccard, M., Chauvin, A., Albeck, M. E., ‘ a a's rlín, M. A., Basso, D. M., Pavón-Carrasco, F. J., Osete, M. L., Campuzano, S. A., ^n1 s. New archeointensity data from NW Argentina (1300-1500 CE). Phys. Earth Planet. Inı.286, 92-100.

Gómez-Paccard, M., Chauvin, A., Lanos, P., Dufresne, P., Kovacheva, M., Hill, M. J., Beamud, E., Blain, S., Bouvier, A., Guiber, I., ¿012a. Improving our knowledge of rapid geomagnetic field intensity changes observ 1 in Europe between 200 and 1400 AD. Earth Planet. Sci. Lett. 355-356, 131-143.

Gómez-Paccard, M., McIn+rsı., S., Chauvin, A., Beamud, E., Pavón-Carrasco, F. J., Thiriot, J., 2012b. Archaeoma $n_{\epsilon_{i}}$ : $^{-}$and rock magnetic study of six kilns from North Africa (Tunisia and Morocco). Geophys. '. Int. 189 (1), 169-186.

Gubbins, D., Bloxham, J., 1987. Morphology of the geomagnetic field and implications for the geodynamo. Nature 325, 509-511.

Gunn, N. M., Murray, A. S., 08 1980. Geomagnetic field magnitude variations in Peru derived from archaeological ceramics dated by thermoluminescence. Geophys. J. Int. 62 (2), 345-366.

Hagstrum, J. T., Blinman, E., 2010. Archeomagnetic dating in western North America: An updated reference curve based on paleomagnetic and archeomagnetic data sets. Geochem. Geophys. Geosyst. 11, Q06009.

Hare, V. J., Tarduno, J. A., Huffman, T., Watkeys, M., Thebe, P. C., Manyanga, M., Bono, R. K., 
Cottrell, R. D., 2018. New archeomagnetic directional records from Iron Age Southern Africa (ca. 425-1550 CE) and implications for the South Atlantic Anomaly. Geophys. Res. Lett. 45 (3), 1361-1369.

Hartmann, G. A., Genevey, A., Gallet, Y., Trindade, R. I., Goff, M. L., Najjar, R., Etchevarne, C., Afonso, M. C., 2009. Time evolution of the South Atlantic magnetic anomaly. Anais da Academia Brasileira de Ciencias 81 (2), 243-255.

Hartmann, G. A., Genevey, A., Gallet, Y., Trindade, R. I., Goff, M. L., Najjar, R., Etchevarne, C., Afonso, M. C., 2011. New historical archeointensity data from Brazil: evidence for a large regional non-dipole field contribution over the past few centuries. Earth Planet. Sci. Lett. 306, 66-76.

Hartmann, G. A., Genevey, A., Gallet, Y., Trindade, R. I. F ^tch vvarne, C., Goff, M. L., Afonso, M., 2010. Archeointensity in Northeast Brazil over wist five centuries. Earth Planet. Sci. Lett. 296, 340-352.

Hartmann, G. A., Poletti, W., Trindade, R. I., Ffrreira, L. M., Sanches, P. L., 2019. New archeointensity data from South Brazil ... . he influence of the South Atlantic Anomaly in South America. Earth and Planetary Scl - ce Letters 512, 124 - 133.

Heaton, T. J., Köhler, P., Butzin, M., Båı ', E., Reimer, R. W., Austin, W. E. N., Bronk Ramsey, C., Grootes, P. M., Hughen, K. A., Ku umer, B., Reimer, P., Adkins, J., Burke, A., Cook, M., Olsen, J.and Skinner, L., 20乞า. Niarine20 - the marine radiocarbon age calibration curve (0-55,000 cal BP). Radioc.rbı 762 (4), 779820.

Hellio, G., Gillet, N., $20^{1 \mathrm{e}}$ : ne-correlation-based regression of the geomagnetic field from

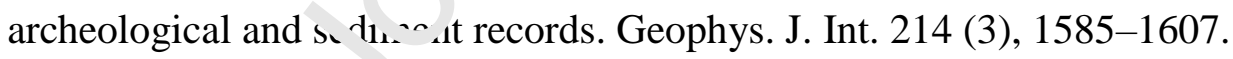

Hellio, G., Gillet, N., Souligand, C., Jault, D., 2014. Stochastic modelling of regional archaeomagnetic series. Geophys. J. Int. 199 (2), 931-943.

Henthorn, D. I., Parkington, J., Reid, R. C., Rüther, H., Fox, J. M. W., McFadden, P. L., 1979. An archaeomagnetic study of Mgungundlovu. Goodwin Series (3), 149-158.

Herrero-Bervera, E., Athens, S., Tema, E., Alva Valdivia, L. M., Camps, P., Trejo, A. R., 2020. First archaeointensity results from Ecuador with rock magnetic analyses and 14C dates to constrain the geomagnetic field evolution in South America: Enhancing the knowledge of geomagnetic field intensity. Journal of South American Earth Sciences 103, 102733.

Hervé, G., Chauvin, A., Lanos, P., 2013a. Geomagnetic field variations in Western Europe from 
1500BC to 200AD. Part I: Directional secular variation curve. Phys. Earth Planet. Inter. 218, $1-13$.

Hervé, G., Chauvin, A., Lanos, P., 2013b. Geomagnetic field variations in Western Europe from 1500BC to 200AD. Part II: New intensity secular variation curve. Phys. Earth Planet. Inter. $218,51-56$.

Hervé, G., Chauvin, A., Lanos, P., Lhuillier, F., Boulud-Gazo, S., Denti, M., Macario, R., 2021. How did the dipole axis vary during the first millennium BCE? New data from West Europe and analysis of the directional global database. Phys. Earth Planet. Inter. 315, 106712.

Hervé, G., Chauvin, A., Lanos, P., Rochette, P., Perrin, M., Perroı^ d’Arc, M., 2019a. Cooling rate effect on thermoremanent magnetization in archaeologi al $\mathrm{r}$ aked clays: an experimental study on modern bricks. Geophys. J. Int. 217 (2), 1413-1 124.

Hervé, G., Faßbinder, J., Gilder, S. A., Metzner-Nebelsi _.. C., Gallet, Y., Genevey, A., Schnepp, E., Geisweid, L., Pütz, A., Reuß, S., Wittenborn, F., F. -ıtas, A., Linke, R., Riedel, G., Walter, F., Westhausen, I., 2017. Fast geomagnetic fi $₫ l r$. intensity variations between 1400 and 400 BCE: New archaeointensity data from C_.. ma ๆy. Phys. Earth Planet. Inter. 270, 143-156.

Hervé, G., Lanos, P., 2018. Improvements 1. trchaeomagnetic dating in Western Europe from the Late Bronze to the Late Iron Agc. An alternative to the problem of the Hallstattian radiocarbon plateau. Archaeometi y d (4), 870-883.

Hervé, G., Perrin, M., Alva Valuivia, L., Tchibinda, B. M., Rodriguez-Trejo, A., Hernandez-Cardona, A., Teln M. C., Rodriguez, C. M., 2019b. Critical analysis of the Holocene palaeointencity ${ }^{\prime n}$ abase in Central America: Impact on geomagnetic modelling.

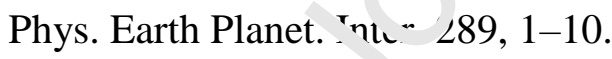

Hervé, G., Perrin, M., ‘lva-Valdivia, L. M., Rodríguez-Trejo, A., Hernández-Cardona, A., Córdova Tello, M., Meza Rodriguez, C., 2019 c . Secular variation of the intensity of the geomagnetic field in Mexico during the first millennium BCE. Geochem. Geophys. Geosyst. 20 (12), 6066-6077.

Hill, M. J., Shaw, J., 1999. Palaeointensity results for historic lavas from Mt Etna using microwave demagnetization/remagnetization in a modified Thellier-type experiment. Geophys. J. Int. 139, $583-590$.

Hill, M. J., Shaw, J., 2007. The use of the 'Kono perpendicular applied field method' in microwave palaeointensity experiments. Earth Planets Space 59, 711-716. 
Hogg, A. G., Heaton, T. J., Hua, Q., Palmer, J. G., Turney, C. S. M., Southon, J., Bayliss, A., Blackwell, P. G., Boswijk, G., Ramsey, C. B., Pearson, C., Petchey, F., Reimer, P., Reimer, R., Wacker, L., 2020. SHCal20 Southern Hemisphere calibration, 0-55,000 years cal BP. Radiocarbon 62 (4), 759-778.

Hongre, L., Hulot, G., Khokhlov, A., 1998. An analysis of the geomagnetic field over the past 2000 years. Phys. Earth Planet. Inter. 106, 311-335.

Hueda-Tanabe, Y., Soler-Arechalde, A., Urrutia-Fucugauchi, J., Barba, L., Manzanilla, L., Rebolledo-Vieyra, M., Goguitchaichvili, A., 2004. Archaeomagnetic studies in central Mexico-dating of Mesoamerican lime-plasters. Phys. Earth Plan`t. Inter. 147 (2), 269-283.

Hus, J., Geeraerts, R., Plumier, J., 2004. On the suitability of re ract sry bricks from a mediaeval brass melting and working site near Dinant (Belgium) q ger magnetic field recorders. Phys. Earth Planet. Inter. 147 (2), 103-116.

Jackson, A., Jonkers, A. R. T., Walker, M. R., 2000 _ vur centuries of geomagnetic secular variation from historical records. Phil. Trans. I. 'sc c. Lond. A 358, 957-990.

Jones, S. A., Tauxe, L., Blinman, E., Genf. 'y, 4., 2020. Archeointensity of the Four Corners Region of the American Southwest. Gec ıem. Geophys. Geosyst. 21 (3), e2018GC007509.

Kapper, K. L., Donadini, F., Mauvilly, M., Panovska, S., Hirt, A. M., 2014. New directional archaeomagnetic data of burned $\mathrm{c} \mathrm{N}$, sediments from Switzerland and geomagnetic field variations in Central Europe. C eopıys. J. Int. 198, 1208-1221.

Kapper, L., Donadini, F., Se nec's, V., Tema, E., Goguitchaichvili, A., Morales, J. J., 2017. Reconstructing the germiar atic field in West Africa: First absolute intensity results from Burkina Faso. Scie. $+i_{1}-r$.eports 7 (45225).

Kapper, L., Serneels, V., I anovska, S., Ruiz, R. G., Hellio, G., de Groot, L., Goguitchaichvili, A., Morales, J., Ruiz, R. C., 2020. Novel insights on the geomagnetic field in West Africa from a new reference curve (0-2000 AD). Scientific Reports 10 (1121).

Kawai, N., Hirooka, K., 1967. Wobbling motion of the geomagnetic dipole field in historic time during these 2000 years. J. Geomag. Geoelectr. 19 (3), 217-227.

Kawai, N., Hirooka, K., Nakajima, T., Tokieda, K., Tosi, M., 1972. Archaeomagnetism in Iran. Nature 236, 223-225.

Kitahara, Y., Nishiyama, D., Ohno, M., Yamamoto, Y., Kuwahara, Y., Hatakeyama, T., 2020. Construction of new archaeointensity reference curve for East Asia from $2000 \mathrm{CE}$ to $1100 \mathrm{CE}$. 
Phys. Earth Planet. Inter., 106596.

Kitahara, Y., Yamamoto, Y., Ohno, M., Kuwahara, Y., Kameda, S., Hatakeyama, T., 2018. Archeointensity estimates of a tenth-century kiln: first application of the Tsunakawa-Shaw paleointensity method to archeological relics. Earth Planets Space 70, 79.

Kitazawa, K., 1970. Intensity , of the geomagnetic field in Japan for the past 10,000 years. J. Geophys. Res. 75 (35), 7403-7411.

Kitazawa, K., Kobayashi, K., 1968. Intensity variation of the geomagnetic field during the past 4000 years in South America. J. Geomag. Geoelectr. 20, 7-19.

Knudsen, M. F., Riisager, P., Donadini, F., Snowball, I., Muscheler, ' ' Korhonen, K., Pesonen, L. J., 2008. Variations in the geomagnetic dipole moment duri.g $t$ l e Holocene and the past 50 kyr. Earth Planet. Sci. Lett. 272, 319-329.

Kondopoulou, D., Aidona, E., Ioannidis, N., Polymeris. $~$ Isolakis, S., 2015. Archaeomagnetic study and thermoluminescence dating of Protobyzani • kilns (Megali Kypsa, North Greece). Journal of Archaeological Science: Reports 2, 15, 168.

Kono, M., 1978. Reliability of palaeointen $\therefore$. ethods using alternating field demagnetization and anhysteretic remanence. Geophys. J. ‘. astr. Soc. 54, 241-261.

Korhonen, K., Donadini, F., Riisager, P., ? Pesonen, L. J., 2008. GEOMAGIA50: an archeointensity database with PHP and MySQL. Ur oc uem., Geophys., Geosyst. 9, Q04029.

Korte, M., Brown, M. C., Gunnars n, S. R., Nilsson, A., Panovska, S., Wardinski, I., Constable, C. G., 2019. Refining Holo`nc geochronologies using palaeomagnetic records. Quaternary Geochronology 50, 47. 74.

Korte, M., Constable, $\neg, \Omega^{\prime} 3$. Continuous global geomagnetic field models for the past 3000 years. Phys. Earth P' int. Inter. 140, 73-89.

Korte, M., Constable, C., 2018. Archeomagnetic intensity spikes: global or regional geomagnetic field features? Frontiers in Earth Science 6, 17.

Korte, M., Constable, C. G., 2005. Continuous geomagnetic field models for the past 7 millenia: 2. CALS7K. Geochem. Geophys. Geosyst. 6, Q02H16.

Korte, M., Donadini, F., Constable, C. G., 2009. Geomagnetic field for 0-3 ka: 2. a new series of time-varying global models. Geochem. Geophys. Geosyst. 10, Q06008.

Kostadinova-Avramova, M., Jordanova, N., 2019. Study of cooling rate effect on baked clay materials and its importance for archaeointensity determinations. Phys. Earth Planet. Inter. 
288, 9-25.

Kostadinova-Avramova, M., Kovacheva, M., Boyadzhiev, Y., 2014. Contribution of stratigraphic constraints of Bulgarian prehistoric multilevel tells and a comparison with archaeomagnetic observations. J. Arch. Sci. 43, 227-238.

Kostadinova-Avramova, Kovacheva, Boyadzhiev, and Hervà Kostadinova-Avramova, M., Kovacheva, M., Boyadzhiev, Y., Hervé, G., 2020. Archaeomagnetic knowledge of the Neolithic in Bulgaria with emphasis on intensity changes. Geological Society, London, Special Publications 497 (1), 89-111.

Kovacheva, M., 1969. Inclination of the Earth's magnetic field u.ring the last 2000 years in Bulgaria. J. Geomag. Geoelectr. 21 (3), 573-578.

Kovacheva, M., 1997. Archaeomagnetic database from Bulg, ria: the last 8000 years. Phys. Earth Planet. Inter. 102 (3), 145-151.

Kovacheva, M., Boyadziev, Y., Kostadinova-Avramova, : .., Jordanova, N., Donadini, F., 2009a. Updated archeomagnetic data set of the past $\varepsilon \mathrm{m}_{\boldsymbol{l}} \mathrm{l}^{\prime}$ ennia from the Sofia laboratory, Bulgaria. Geochem. Geophys. Geosyst. $10(5), \mathrm{Q}^{2} \sim \mathrm{O}_{2}$

Kovacheva, M., Chauvin, A., Jordanova, ' ' . Lanos, P., Karloukovski, V., 2009b. Remanence anisotropy effect on the palaeointensı.: results obtained from various archaeological materials, excluding pottery. Earth Planets Sp ct j1, 711-732.

Kovacheva, M., Kostadinova-Av`'mova, M., Jordanova, N., Lanos, P., Boyadzhiev, Y., 2014. Extended and revised arcl 'ec nagnetic database and secular variation curves from Bulgaria for the last eight millernia. D.lys. Earth Planet. Inter. 236, 79-94.

Krása, D., Heunemanı, C., I_eonhardt, R., Petersen, N., 2003. Experimental procedure to detect multidomain remai ace during Thellier-Thellier experiments. Phys. Chem. Earth 28, 681-687.

Lanos, P., 1987. The effects of demagnetizing fields on thermoremanent magnetization acquired by parallel-sided baked clay blocks. Geophys. J. Int. 91 (3), 985-1012.

Lanos, P., 2004. Bayesian Inference of Calibration Curves: Application to Archaeomagnetism. Springer London, London, pp. 43-82.

Lanos, P., Le Goff, M., Kovacheva, M., Schnepp, E., 2005. Hierarchical modelling of archaeomagnetic data and curve estimation by moving average technique. Geophys. J. Int. 160 (2), 440-476. 
Lanos, P., Philippe, A., 2018. Event date model: a robust Bayesian tool for chronology building. Communications for Statistical Applications and Methods 25 (2), 131-157.

Lascu, I., Feinberg, J. M., 2011. Speleothem magnetism. Quaternary Science Reviews 30 (23), 3306-3320.

Lascu, I., Feinberg, J. M., Dorale, J. A., Cheng, H., Edwards, R. L., 2016. Age of the Laschamp excursion determined by U-Th dating of a speleothem geomagnetic record from North America. Geology 44 (2), 139-142.

Latham, A., Schwarcz, H., Ford, D., 1986. The paleomagnetism and U-Th dating of Mexican stalagmite, DAS2. Earth Planet. Sci. Lett. 79 (1), 195-207.

Le Goff, M., Daly, L., Dunlop, D. J., Papusoi, C., 2006. Emile 1 hell er (1904-1987), a pioneer in studies of the "fossil" Earth's magnetic field. Historic. 1 er ents and people in aeronomy, geomagnetism and solar-terrestrial physics, 98-112.

Le Goff, M., Gallet, Y., 2004. A new three-axis vibrat $\iota_{\iota_{c}}$ sample magnetometer for continuous high-temperature magnetization measuremen s: a pplications to paleo- and archeo-intensity determinations. Earth Planet. Sci. Lett. ??, $1-43$.

Le Goff, M., Gallet, Y., 2014. Evaluation c: che rehydroxylation dating method: Insights from a new measurement device. Quaternary Geochronology 20, 89-98.

Le Goff, M., Gallet, Y., 2015. Experiı nt « variability in kinetics of moisture expansion and mass gain in ceramics. J. Am. Ceraı. Soi. 98, 398-401.

Le Goff, M., Gallet, Y., Warr. ‘́, ' ' , Genevey, A., 2020. An updated archeomagnetic directional variation curve for Franne $\cdots$ er the past two millennia, following 25 years of additional data acquisition. Phys. $\mathbf{L}\urcorner r_{1}$ D ${ }_{\text {anet. Inter. 309, } 106592 .}$

Le Goff, M., Henry, B., Jaly, L., 1992. Practical method for drawing a VGP path. Phys. Earth Planet. Inter. 70 (3), 201-204.

Lengyel, S. N., Eighmy, J. L., 2002. A revision to the U.S. Southwest archaeomagnetic master curve. J. Arch. Sci. 29 (12), 1423-1433.

Leonhardt, R., Krása, D., Coe, R. S., 2004. Multidomain behavior during Thellier paleointensity experiments: a phenomenological model. Phys. Earth Planet. Inter. 147, 127-140.

Leonhardt, R., Matzka, J., Nichols, A. R. L., Dingwell, D. B., 2006. Cooling rate correction of paleointensity determination for volcanic glasses by relaxation geospeedometry. Earth Planet. Sci. Lett. 243, 282-292. 
Levi, S., 1977. The effect of magnetite particle size on paleointensity determinations of the geomagnetic field. Phys. Earth Planet. Inter. 13, 245-259.

Licht, A., Hulot, G., Gallet, Y., Thébault, E., 2013. Ensembles of low degree archeomagnetic field models for the past three millennia. Phys. Earth Planet. Inter. 224, 38-67.

Liritzis, L., Lagios, E., 1993. A global archaeomagnetic intensity data bank. Eos Trans. AGU 74 (27), 303-306.

Liritzis, Y., Thomas, R., 1980. Palaeointensity and thermoluminescence measurements on Cretan kilns from 1300 to $2000 \mathrm{BC}$. Nature 283, 54-55.

Livermore, P. W., Fournier, A., Gallet, Y., 2014. Core-fic v constraints on extreme archeomagnetic intensity changes. Earth Planet. Sci. Lett. $38^{7} .1<5-156$.

Livermore, P. W., Fournier, A., Gallet, Y., Bodin, T., 09 2 118 . Transdimensional inference of archeomagnetic intensity change. Geophys. J. Int. 21 ₹ (3, 2008-2034.

Livermore, P. W., Gallet, Y., Fournier, A., 2021. Archeo . dgnetic intensity variations during the era of geomagnetic spikes in the Levant. $\mathrm{Ph}_{\mathrm{s}} \mathrm{si} / \mathrm{s}$ of the Earth and Planetary Interiors 312, 106657.

Lodge, A., Holme, R., 2009. Towards a new .pproach to archaeomagnetic dating in Europe using geomagnetic field modelling. Archat -metry 51, 309-322.

Lopez-Sanchez, J., Palencia-Ortas, 1.. del Campo, A., McIntosh, G., Kovacheva, M., Martin-Hernandez, F., Carmo. ๆ, ․, Rodriguez De la Fuente, O., Marin, P., Molina-Cardin, A., Osete, M., 2020. Occui - n` of epsilon iron oxide in archeological materials: Effect on the natural remanent magnetizition. Phys. Earth Planet. Inter. 307, 106554.

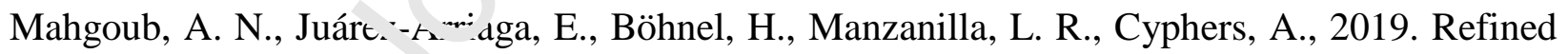
3600 years palaeoin - sity curve for Mexico. Phys. Earth Planet. Inter. 296, 106328.

Mandea, Korte, Mozzoni, and Kotzà Mandea, M., Korte, M., Mozzoni, D., Kotzé, P., 2007. The magnetic field changing over the southern African continent: a unique behaviour. South African Journal of Geology 110, 193-202.

Mandea, M., Olsen, N., 2009. Geomagnetic and archeomagnetic jerks: where do we stand? Eos, Transactions American Geophysical Union 90 (24), 208.

Márton, P., 1970. Secular variation of the geomagnetic virtual dipole field during the last $2000 \mathrm{yr}$ as inferred from the spherical harmonic analysis of the available archeomagnetic data. Pure and Applied Geophysics 81, 163-176. 
Márton, P., 2003. Recent achievements in archaeomagnetism in Hungary. Geophys. J. Int. 153 (3), 675-690.

Márton, P., 2010. Two thousand years of geomagnetic field direction over central Europe revealed by indirect measurements. Geophys. J. Int. 181, 261-268.

Mauerberger, S., Schanner, M., Korte, M., Holschneider, M., 2020. Correlation based snapshot models of the archeomagnetic field. Geophys. J. Int. 223, 648-665.

McElhinny, M. W., Senanayake, W. E., 1982. Variations in the geomagnetic dipole: I. The past 50 000 years. J. Geomag. Geoelectr. 34, 39-51.

Merrill, R. T., McElhinny, M. W., McFadden, P. L., 1996. The '^agnetic Field of the Earth: Palaeomagnetism, the core, and the deep mantle. Vol. 63 of 'nte national Geophysics Series. Academic Press.

Mitra, R., Tauxe, L., McIntosh, S. K., 2013. Two thou years of archeointensity from West Africa. Earth Planet. Sci. Lett. 364, 123-133.

Molina-Cardín, A., Campuzano, S. A., Osete, M. _. Pivero-Montero, M., Pavón-Carrasco, F. J., Palencia-Ortas, A., Martín-Hernández, F., Tu.nez-Paccard, M., Chauvin, A., Guerrero-Suárez, S., Pérez-Fuentes, J. C., McIntosh, G., ' atanzariti, G., Sastre Blanco, J. C., Larrazabal, J., Fernández Martínez, V. M., Álvarez sananchís, J. R., Rodríguez-Hernández, J., Martín Viso, I., Garcia i Rubert, D., 2018. Upc.ateo Iberian archeomagnetic catalogue: New full vector paleosecular variation curve $f_{\mathcal{L}}$ - the iast three millennia. Geochem. Geophys. Geosyst. 19 (10), $3637-3656$.

Morales, J., Goguitchai ${ }^{h_{v}}$ : : A., Acosta, G., Gonzalez-Moran, T., Alva-Valdivia, L., Robles-Camacho, $\therefore$ d, 1 Sol Hernandez-Bernal, M., 2009. Magnetic properties and archeointensity dete - ination on Pre-Columbian pottery from Chiapas, Mesoamerica. Earth Planets Space 61, 83-91.

Morales, J., Goguitchaichvili, A., Aguilar-Reyes, B., Pineda-Duran, M., Camps, P., Carvallo, C., Calvo-Rathert, M., 2011. Are ceramics and bricks reliable absolute geomagnetic intensity carriers? Phys. Earth Planet. Inter. 187 (3), 310-321.

Nachasova, I. E., Burakov, K. S., 1995. Archaeointensity of the geomagnetic field in the 5th millennium B.C. in northern Mesopotamia. Geomagnetism and Aeronomy 35 (3), 398-402.

Nachasova, I. E., Burakov, K. S., 1998. Geomagnetic variations in the VI-V millenia B.C. Geomagnetism and Aeronomy 38 (4), 502-505. 
Nachasova, I. E., Burakov, K. S., 2012. Variations in geomagnetic intensity and temperature in the second millennium B.C. in Spain. Izvestiya, Phys. Solid Earth 48, 434-440.

Nachasova, I. E., Burakov, K. S., Bernabeu, J., 2002. Geomagnetic field intensity variation in Spain. Izvestiya, Phys. Solid Earth 38 (5), 371-376.

Nachasova, I. E., Burakov, K. S., Molina, F., C]ámara, J. A., 2007. Archaeomagnetic study of ceramics from the Neolithic Los Castillejos multilayer monument (Montefrio, Spain). Izvestiya, Phys. Solid Earth 42, 170-176.

Nagata, T., Arai, Y., Momose, K., 1963. Secular varaition of the geomagnetic force during the last 5000 years. J. Geophys. Res. 68, 5277-5281.

Nagata, T., Kobayashi, K., Schwarz, E. J., 1965. Archeomagnei ic ir tensity studies of South and Central America. J. Geomag. Geoelectr. 17, 399-405.

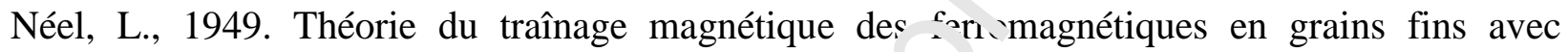
applications aux terre cuites. Ann. Géophys. 5, 99-1 3

Neukirch, L. P., Tarduno, J. A., Huffman, T. N., V/a'K ys, M. K., Scribner, C. A., Cottrell, R. D., 2012. An archeomagnetic analysis of J.rn. grain bin floors from ca. 1200 to 1250 AD Iron-Age South Africa. Phys. Earth Plaı . Inter. 190-191, 71-79.

Nilsson, A., Holme, R., Korte, M., 'r'ttie, N., Hill, M., 2014. Reconstructing Holocene geomagnetic field variation: new r se iods, models and implications. Geophys. J. Int. 198, 229-248.

Nilsson, A., Suttie, N., Korte, M. Holme, R., Hill, M., 2020. Persistent westward drift of the geomagnetic field at th $\mathrm{cl} \cdots$-mantle boundary linked to recurrent high-latitude weak/reverse flux patches. Geopı.:'s. I int. 222 (2), 1423-1432.

Noel, M., Batt, C. M., 990. A method for correcting geographically separated remanence directions for the purpose of archaeomagnetic dating. Geophys. J. Int. 102 (3), 753-756.

Osete, M. L., Catanzariti, G., Chauvin, A., Pavón-Carrasco, F. J., Roperch, P., Fernández, V. M., 2015. First archaeomagnetic field intensity data from Ethiopia, Africa (1615 \pm 12 AD). Phys. Earth Planet. Inter. 242, 24-35.

Palencia-Ortas, A., Molina-Cardín, A., Osete, M. L., Gómez-Paccard, M., Martín-Hernández, F., Chauvin, A., Roperch, P., 2021. Inclination flattening effect inhighly anisotropic archaeological structures from Iberia. Influence on archaeomagnetic dating. Phys. Earth Planet. Inter., 106762. 
Palencia-Ortas, A., Osete, M., Campuzano, S., McIntosh, G., Larrazabal, J., Sastre, J., Rodriguez-Aranda, J., 2017. New archaeomagnetic directions from Portugal and evolution of the geomagnetic field in Iberia from Late Bronze Age to Roman Times. Phys. Earth Planet. Inter. 270, 183-194.

Panovska, S., Korte, M., Constable, C. G., 2019. One hundred thousand years of geomagnetic field evolution. Reviews of Geophysics 57 (4), 1289-1337.

Paterson, G. A., Tauxe, L., Biggin, A. J., Shaar, R., Jonestrask, L. C., 2014. On improving the selection of Thellier-type paleointensity data. Geochem. Geophys. Geosyst. 15 (4), 1180-1192.

Pavón-Carrasco, F., Osete, M., Torta, J., Gaya-Piqué, L., Lanc s, P, 2008. Initial SCHA.DI.00 regional archaeomagnetic model for Europe for the last 2.00 ) years. Phys. Chem. Earth 33, 596-608.

Pavón-Carrasco, F. J., Osete, M. L., Torta, J. M., 2010. ?egional modeling of the geomagnetic field in Europe from 6000 to 1000 B.C. Geoch ər.. Geophys. Geosyst. 11, Q11008.

Pavón-Carrasco, F. J., Osete, M. L., Torta, I : 1., De Santis, A., 2014. A geomagnetic field model for the Holocene based on archaeomag - ic and lava flow data. Earth Planet. Sci. Lett. 388, 98-109.

Pavón-Carrasco, F. J., Osete, M. L., I urta, J. M., Gaya-Piqu’ e, L. R., 2009. A regional archeomagnetic model for $\mathrm{Fu}_{\mathrm{L}}$ ope for the last 3000 years, SCHA.DIF.3K: Applications to

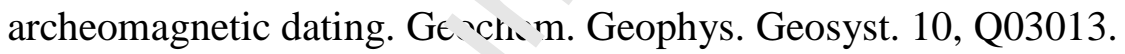

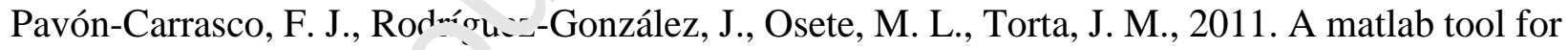
archaeomagnetic $d_{a}{ }^{i n} n_{0}$ 'ournal of Archaeological Science 38 (2), 408-419.

Poletti, W., Hartmann, C A., Hill, M. J., Biggin, A. J., Trindade, R. I. F., 2013. The cooling-rate effect on microwave archeointensity estimates. Geophys. Res. Lett. 40 (15), 3847-3852.

Poletti, W., Trindade, R. I., Hartmann, G. A., Damiani, N., Rech, R. M., 2016. Archeomagnetism of Jesuit Missions in South Brazil (1657-1706 AD) and assessment of the South American database. Earth Planet. Sci. Lett. 445, 36-47.

Reimer, P., Austin, W., Bard, E., Bayliss, A., Blackwell, P., Ramsey, C., Butzin, M., Cheng, H., Edwards, R., Friedrich, M., Grootes, P., Guilderson, T., Hajdas, I., Heaton, T., Hogg, A., Hughen, K., Kromer, B., Manning, S., Muscheler, R., Palmer, J., Pearson, C., van der Plicht, J., Reimer, R., Richards, D., Scott, E., Southon, J., Turney, C., Wacker, L., Adolphi, F., Büntgen, 
U., Capano, M., Fahrni, S., Fogtmann-Schulz, A., Friedrich, R., Köhler, P., Kudsk, S., Miyake, F., Olsen, J., Reinig, F., Sakamoto, M., Sookdeo, A., Talamo, S., 2020. The IntCal20 Northern Hemisphere radiocarbon age calibration curve (0-55 Cal kBP). Radiocarbon 62, 725-757.

Reimer, P. J., Bard, E., Bayliss, A., Beck, J. W., Blackwell, P. G., Bronk Ramsey, C., Buck, C. E., Cheng, H., Edwards, R. L., Friedrich, M., Grootes, P. M., Guilderson, T. P., Haflidason, H., Hajdas, I., Hatté, C., Heaton, T. J., Hoffmann, D. L., Hogg, A. G., Hughen, K. A., Kaiser, K. F., Kromer, B., Manning, S. W., Niu, M., Reimer, R. W., Richards, D. A., Scott, E. M., Southon, J. R., Staff, R. A., Turney, C. S. M., van der Plicht, J., 2013. IntCal13 and Marine13 radiocarbon age calibration age curves 0-50,000 years cal BP. Ku tiocarbon 55, 1869-1887.

Riisager, P., Riisager, J., 2001. Detecting multidomain magnetic ‘rai $s$ in Thellier palaeointensity experiments. Phys. Earth Planet. Inter. 125, 111-117.

Rivero-Montero, M., Gómez-Paccard, M., Pavón-Carra _. `., Cau-Ontiveros, M., Fantuzzi, L., Martín-Hernández, F., Palencia-Ortas, A., Aidona, F., ``ma, E., Kondopoulou, D., Mas-Florit, C., Ramon-Torres, J., 2021. Refining geomag et ic field intensity changes in Europe between 200CE and 1800 CE. New data from the : "el terranean region. Phys. Earth Planet. Inter. 317, 106749.

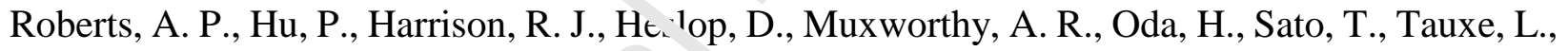
Zhao, X., 2019. Domain state 'ia Łnosis in rock magnetism: Evaluation of potential alternatives to the Day diao, ${ }_{1} \cdot m$. Journal of Geophysical Research: Solid Earth 124 (6), 5286-5314.

Roberts, R., Jacobs, Z., I i, D., Jankowski, N., Cunningham, A., 2015. Optical dating in archaeology: thirty : "ec- in retrospect and grand challenges for the future. J. Arch. Sci. 56, $41-60$.

Rogers, J., Fox, J., Aitken, M. J., 1979. Magnetic anisotropy in ancient pottery. Nature 277, 644-646.

Rolph, T. C., Shaw, J., 1985. A new method of paleofield magnitude correction for thermally altered samples and its application to Lower Carboniferous lavas. Geophys. J. R. astr. Soc. 80, 773-781.

Roperch, P., Chauvin, A., Lara, L. E., Moreno, H., 2015. Secular variation of the earth's magnetic field and application to paleomagnetic dating of historical lava flows in chile. Phys. Earth Planet. Inter. 242, 65-78. 
Sakai, H., 1980. Variation of geomagnetic field deduced from analysis of remanent magnetization of archaeological objects. Ph.D. thesis, Osaka University.

Sakai, H., Hirooka, K., 1986. Archaeointensity determinations from Western Japan. J. Geomag. Geoelectr. 38 (12), 1323-1329.

Salnaia, N., Gallet, Y., O.N., G., Gavryshukin, D., 2017. New archeointensity results on a baked-clay tile collection from the New Jerusalem Monastery (Moscow region, Russia). Geophysical Research 18, 83-94.

Sanchez, S., Fournier, A., Aubert, J., Cosme, E., Gallet, Y., 2016. Modelling the archaeomagnetic field under spatial constraints from dynamo simulations: a resc'ition analysis. Geophysical Journal International 207 (2), 983-1002.

Sasajima, S., 1965. Geomagnetic secular variation revealed in the saked earths in West Japan. Part 2 Change of the field intensity. J. Geomag. Geoelect $\%$ " , 413-416.

Schnepp, E., Lanos, P., 2005. Archaeomagnetic secular va :ation in Germany during the past 2500 years. Geophys. J. Int. 163 (2), 479-490.

Schnepp, E., Leonhardt, R., Korte, M., Klett Zre hsel, J., 2016. Validity of archaeomagnetic field recording: an experimental pottery kiln - Coppengrave, Germany. Geophys. J. Int. 205 (1), $622-635$.

Schnepp, E., Pucher, R., Goedicke, C., M ınzano, A., Müller, U., Lanos, P., 2003. Paleomagnetic directions and thermolumine ence dating from a bread oven-floor sequence in Lübeck (germany): A record of 45C ve. "s of geomagnetic secular variation. J. Geophys. Res. 108 (B2).

Schnepp, E., Thallner, I , * eitz, P., Leonhardt, R., 2020a. New archeomagnetic secular variation data from $\mathrm{Te}_{\mathrm{i}}+\mathrm{al}_{\mathrm{l}}$ Europe, II: Intensities. Phys. Earth Planet. Inter. 309, 106605.

Schnepp, E., Thallner, ₹ Arneitz, P., Mauritsch, H., Scholger, R., Rolf, C., Leonhardt, R., 10 2020b. New archaeomagnetic secular variation data from Central Europe. I: directions. Geophys. J. Int. 220 (2), 1023-1044.

Schwarz, E. J., Christie, K. W., 1967. Original remanent magnetization of Ontario potsherds. J. Geophys. Res. 72, 3263-3269.

Selkin, P. A., Tauxe, L., 2000. Long-term varations in palaeointensity. Philos. Trans. R. Soc. Lond. A 358, 1065-1088.

Shaar, R., Bechar, S., Finkelstein, I., Gallet, Y., Martin, M. A. S., Ebert, Y., Keinan, J., Gonen, L., 2020. Synchronizing geomagnetic field intensity records in the Levant between the 23rd and 
15th Centuries BCE: Chronological and methodological implications. Geochem. Geophys. Geosyst. 21 (12), e2020GC009251.

Shaar, R., Ben-Yosef, E., Ron, H., Tauxe, L., Agnon, A., Kessel, R., 2011. Geomagnetic field intensity: How high can it get? How fast can it change? Constraints from Iron Age copper slag. Earth Planet. Sci. Lett. 301, 297-306.

Shaar, R., Hassul, E., Raphael, K., Ebert, Y., Segal, Y., Eden, I., Vaknin, Y., Marco, S., Nowaczyk, N. R., Chauvin, A., Agnon, A., 2018. The first catalog of archaeomagnetic directions from Israel with 4,000 years of geomagnetic secular variations. Frontiers in Earth Science 6, 164.

Shaar, R., Ron, H., Tauxe, L., Kessel, R., Agnon, A., Ben-Yosef, 7., F zinberg, J. M., 2010. Testing the accuracy of absolute intensity estimates of the ancient geo nagnetic field using copper slag material. Earth Planet. Sci. Lett. 290 (1), 201-213.

Shaar, R., Tauxe, L., Ben-Yosef, E., Kassianidou, V., L oı .tzen, B., Feinberg, J. M., Levy, T. E., 2015. Decadal-scale variations in geomagn $\mathrm{ir}$ field intensity from ancient Cypriot slag mounds. Geochem. Geophys. Geosyst. 1' ' 1, 195-214.

Shaar, R., Tauxe, L., Ron, H., Ebert, Y., Zı kerman, S., Finkelstein, I., Agnon, A., 2016. Large geomagnetic field anomalies reveale.' in Bronze to Iron Age archeomagnetic data from Tel Megiddo and Tel Hazor, Israel. E.r'^ $n$ ianet. Sci. Lett. 442, 173-185.

Shaw, J., 1974. A new methor of cetermining the magnitude of the palaeomagnetic field. Application to five historic 'av.s and five archaeological samples. Geophys. J. R. astr. Soc. 39, 133-141.

Shaw, J., Yang, S., Ro ${ }_{1}{ }^{h}$, ${ }^{2}$ C., Sun, F. Y., 1999. A comparison of archaeointensity results from Chinese ceramics us: $\mathrm{g}$ microwave and convential Thellier's and Shaw's methods. Geophys. J. Int. 136, 714-718.

Shaw, J., Yang, S., Wei, Q. Y., 1995. Archaeointensity variations for the past 7,500 years evaluated from ancient Chinese ceramics. J. Geomag. Geoelectr. 47 (1), 59-70.

Shuey, R. T., Cole, E. R., Mikulich, M. J., 1970. Geographic correction of archeomagnetic data. J. Geomag. Geoelectr. 22 (4), 485-489.

Simon, Q., Thouveny, N., Bourlès, D. L., Valet, J.-P., Bassinot, F., Ménabréaz, L., Guillou, V., Choy, S., Beaufort, L., 2016. Authigenic ${ }^{10} \mathrm{Be} /{ }^{9} \mathrm{Be}$ ratio signatures of the cosmogenic nuclide production linked to geomagnetic dipole moment variation since the Brunhes/Matuyama 
boundary. Journal of Geophysical Research: Solid Earth 121 (11), 7716-7741.

Smith, P. J., 1967. Ancient geomagnetic field intensities-I Historic and archaeological data: Sets H1-H9. Geophys. J. R. astr. Soc. 13, 417-419.

Soler Arechalde, A., Caballero Miranda, C., Osete López, M., López Delgado, V., Goguitchaichvili, A., Barrera Huerta, A., Urrutia Fucugauchi, J., 2019. An updated catalog of pre-hispanic archaeomagnetic data for north and central Mesoamerica: Implications for the regional paleosecular variation reference curve. Boletín de la Sociedad Geológica Mexicana 71 (2), 497-518.

Stark, F., Cassidy, J., Hill, M. J., Shaw, J., Sheppard, P., 2010. Estalı-hing a first archaeointensity record for the SW Pacific. Earth Planet. Sci. Lett. 298, 113-1?4.

Sternberg, R. S., 1989a. Archaeomagnetic paleointensity in he Imerican Southwest during the past 2000 years. Phys. Earth Planet. Inter. 56 (1), 1-1?

Sternberg, R. S., 1989b. Secular variation of archat -1agnetic direction in the American Southwest, A.D. 750-1425. J. Geophys. Res. Sol d Earth 94 (B1), 527-546.

Stillinger, M. D., Feinberg, J. M., Frahm, E. 2ר1- Refining the archaeomagnetic dating curve for the Near East: new intensity data from $\perp$ onze Age ceramics at Tell Mozan, Syria. Journal of Archaeological Science 53, 345-355.

Tangborn, A., Kuang, W., 2018. In.p $x$ of archeomagnetic field model data on modern era geomagnetic forecasts. Phys. I arth Planet. Inter. 276, 2-9.

Tarduno, J. A., 2018. Subtc raı an clues to the future of our planetary magnetic shield. Proceedings of the Natin $a^{\prime}$ icademy of Sciences 115 (52), 13154-13156.

Tarduno, J. A., Watke, s. ^ K., Huffman, T. H., Cottrell, R. D., Blackman, E. G., Wendt, A., Scribner, C. A., Wa $a_{i}^{-n}$ rr, C. L., 2015. Antiquity of the South Atlantic Anomaly and evidence for top-down control on the geodynamo. Nature Communications 6, 7865.

Tarling, D. H., 1989. Geomagnetic secular variation in Britain during the last 2000 years. Kluwer Academic Publishers, Dordrecht, pp. 55-62.

Tauxe, L., 2006. Long-term trends in paleointensity: The contribution of DSDP/ODP submarine basaltic glass collections. Phys. Earth Planet. Inter. 156, 223-241.

Tauxe, L., Banerjee, S., Butler, R., van der Voo, R., 2018. Essentials of Paleomagnetism, 5th Web Edition.

Tauxe, L., Shaar, R., Jonestrask, L., Swanson-Hysell, N. L., Minnett, R., Koppers, A. A. P., 
Constable, C. G., Jarboe, N., Gaastra, K., Fairchild, L., 2016. PmagPy: Software package for paleomagnetic data analysis and a bridge to the Magnetics Information Consortium (MagIC) Database. Geochem. Geophys. Geosyst. 17 (6), 2450-2463.

Tauxe, L., Yamazaki, T., 2015. 5.13 - Paleointensities. In: Schubert, G. (Ed.), Treatise on Geophysics (Second Edition). Elsevier, Oxford, pp. 461-509.

Tchibinda Madingou, B., Hervé, G., Perrin, M., M’Mbogori, F. N., Guemona, D., Mathé, P.-E., Rochette, P., Williamson, D., Mourre, V., Robion-Brunner, C., 2020. First archeomagnetic data from Kenya and Chad: Analysis of iron furnaces from Mount Kenya and Guéra Massif. Phys. Earth Planet. Inter. 309, 106588.

Tema, E., Hedley, I., Lanos, P., 2006. Archaeomagnetism in Italy a c smpilation of data including new results and a preliminary Italian reference curve. Ge nhy ;. J. Int. 167, 1160-1171.

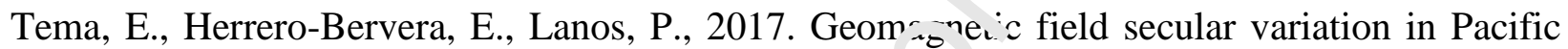
Ocean: A Bayesian reference curve based on Holocen ? : 1awaiian lava flows. Earth Planet. Sci. Lett. 478, 58-65.

Tema, E., Lanos, P., 2020. New Italian direr '. ' ' na.' and intensity archaeomagnetic reference curves for the past 3000 years: Insights $c$ secular variation and implications on dating. Archaeometry.

Terra-Nova, F., Amit, H., Hartmann, J ,'j indade, R., 2016. Using archaeomagnetic field models to constrain the physics of $i$ e cure: robustness and preferred locations of reversed flux patches. Geophys. J. Int. 2^5 (2), 1890-1913.

Terra-Nova, F., Amit, H. L.a.tann, G., Trindade, R., Pinheiro, K., 2017. Relating the South Atlantic Anomaly a.d z omagnetic flux patches. Phys. Earth Planet. Inter. 266, 39-53.

Thébault, E., Gallet, Y 2010. A bootstrap algorithm for deriving the archeomagnetic field intensity variation curve in the Middle East over the past 4 millennia BC. Geophys. Res. Lett. 37, L22303.

Thellier, E., 1938. Sur l'aimantation des terres cuites et ses applications geophysiques. Ann. Inst. Globe Univ. Paris 16, 157-302.

Thellier, E., 1941. Sur les propriétés de l'aimantation thermorémanente des terres cuites. C. R. Acad. Sci. Paris 213, 1019-1022.

Thellier, E., 1946. Sur l'intensité du champ magnétique terrestre, en France, à l'époque gallo-romaine. C. R. Acad. Sci. Paris 222, 905-907. 
Thellier, E., 1977. Early research on the intensity of the ancient geomagnetic field. Phys. Earth Planet. Inter. 13, 241-244.

Thellier, E., 1981. Sur la direction du champ magnetique terrestre, en France, durant les deux derniers millenaires. Phys. Earth Planet. Inter. 24 (2), 89-132.

Thellier, E., Thellier, O., 1959. Sur l'intensité du champ magnétique terrestre dans le passé historique et géologique. Ann. Géophys. 15, 285-376.

Trindade, R. I. F., Jaqueto, P., Terra-Nova, F., Brandt, D., Hartmann, G. A., Feinberg, J. M., Strauss, B. E., Novello, V. F., Cruz, F. W., Karmann, I., Cheng, H., Edwards, R. L., 2018. Speleothem record of geomagnetic South Atlantic Anomaly 1e 'irrence. Proceedings of the National Academy of Sciences 115 (52), 13198-13203.

Troyano, M., Gallet, Y., Genevey, A., Pavlov, V., Fournier, 4., Jiyazova, M., Mirzaakhmedov, D., 2020. Constraining the axial dipole moment var... ${ }^{i}$ os during the historical period from new archeointensity results obtained in Bukhara (c vekistan, Central Asia). Phys. Earth Planet. Inter. 309, TBD.

Tsunakawa, H., Shaw, J., 1994. The Shar. mothod of palaeointensity determinations and its application to recent volcanic rocks. Geı: nys. J. Int. 118, 781-787.

Turner, G. M., Kinger, R., McFadgen, L . Gevers, M., 2020. The first archaeointensity records from New Zealand: evidence for a il wenth century AD archaeomagnetic 'spike' in the SW Pacific Region? Geological Sc iety, London, Special Publications 497.

Usoskin, I. G., Gallet, Y., Lop`s, ₹ , Kovaltsov, G. A., Hulot, G., 2016. Solar activity during the Holocene: the Hallstat ${ }^{\sim} V_{c}{ }^{1}$ and its consequence for grand minima and maxima. Astronomy and Astrophysics 5?7, 1150.

Usoskin, I. G., Korte, M. Movaltsov, G. A., 2008. Role of centennial geomagnetic changes in local atmospheric ionization. Geophys. Res. Lett. 35, L05811.

Usoskin, I. G., Mironova, I. A., Korte, M., Kovaltsov, G. A., 2010. Regional millennial trend in the cosmic ray induced ionization of the troposphere. J. Atmos. Sol. Terr. Phys. 72, 19-25.

Usoskin, I. G., Solanki, S. K., Korte, M., 2006. Solar activity reconstructed over the last 7000 years: The influence of geomagnetic field changes. Geophys. Res. Lett. 33, L08103.

Valet, J.-P., Herrero-Bervera, E., LeMoüel, J.-L., Plenier, G., 2008. Secular variation of the geomagnetic dipole during the past 2000 years. Geochem. Geophys. Geosyst. 9, Q01008.

Veitch, R., Hedley, I., Wagner, J., 1984. An investigation of the intensity of the geomagnetic field 
during Roman times using magnetically anisotropic bricks and tiles. Arch. Sci. Genève 37, 359-373.

Walton, D., 1977. Archaeomagnetic intensity measurements using a SQUID magnetometer. Archaeometry 19 (2), 192-200.

Walton, D., Snape, S., Rolph, T., Shaw, J., Share, J., 1996. Application of ferrimagnetic resonance heating to palaeointensity determinations. Phys. Earth Planet. Inter. 94 (3), 183-186.

Wardinski, I., Korte, M., 2008. The evolution of the core-surface flow over the last seven thousands years. J. Geophys. Res. 113, B05101.

Watanabe, N., 1958. Secular variation in the direction of geomagne: $\mathrm{sm}$ as the standard scale for geomagnetochronology in Japan. Nature 182 (3-4), 383-384.

Watanabe, N., Dubois, R. L., 1965. Some results of an archae magnetic study on the secular variation in the southwest of North America. J. Geor .... T. Seoelectr. 17 (3-4), 395-397.

Wei, Q. Y., Li, D. J., Cao, G. Y., Zhang, W. S., Wang. S. '., 1982. Intensity of the geomagnetic field near Loyang, China between 500 BC and A'J 1900. Nature 296, 728-729.

Wei, Q. Y., Li, D. J., Cao, G. Y., Zhan , W. X., Wei, S. F., 1986. The total intensity of geomagnetic field in southern China for "1e period from 4500 B.C. to A.D. 1500. J. Geomag. Geoelectr. 38, 1311-1322.

Wilson, M. A., Carter, M. A., Hall, C., H if, W. D., Ince, C., Savage, S. D., Mckay, B., Betts, I. M., 2009. Dating fired-clay c ramics using long-term power law rehydroxylation kinetics. Proceedings of the Royal s in ty of London A 465 (2108), 2407-2415.

Wilson, R. L., 1961. Palermą ${ }^{n}$ tism in Northen Ireland, Part I, The thermal demagnetization of natural magnetic $m_{\longleftarrow} m_{\iota^{n+}}$ s in rocks. Geophys. J. R. astr. Soc. 5, 45-58.

Yamamoto, Y., Tsuna- Na, H., 2005. Geomagnetic field intensity during the last 5 Myr: LTD-DHT Shaw palaeointensities from volcanic rocks of the Society Islands, French Polynesia. Geophys. J. Int. 162, 79-114.

Yamamoto, Y., Tsunakawa, H., Shibuya, H., 2003. Palaeointensity study of the Hawaiian 1960 lava: implications for possible causes of erroneously high intensities. Geophys. J. Int. 153, 263-276.

Yang, S., Odah, H., Shaw, J., 2000. Variations in the geomagnetic dipole moment over the last 12000 years. Geophys. J. Int. 140, 158-162.

Yang, T., Shaw, J., Wei, Q. Y., 1993. A comparison of archaeointensity results from Chinese 
ceramics using Thellier's and Shaw's palaeointensity methods. Geophys. J. Int. 113, 499-508.

Yu, Y., Tauxe, L., Genevey, A., 2004. Toward an optimal geomagnetic field intensity determination technique. Geochem. Geophys. Geosyst. 5, Q02H07.

Yutsis-Akimova, S., Gallet, Y., Amirov, S., 2018a. Rapid geomagnetic field intensity variations in the Near East during the 6th millennium BC: New archeointensity data from Halafian site Yarim Tepe II (northern Iraq). Earth Planet. Sci. Lett. 482, 201-212.

Yutsis-Akimova, S., Gallet, Y., Petrova, N., Nowak, S., Le Goff, M., 2018b. Geomagnetic field in the Near East at the beginning of the 6th millennium BC: Evidence for alternating weak and strong intensity variations. Phys. Earth Planet. Inter. 282, 49-5\%.

Zanella, E., Gurioli, L., Chiari, G., Ciarallo, A., Cioni, R., L a C ırolis, E., Lanza, R., 2000. Archaeomagnetic results from mural paintings and, 'vro lastic rocks in Pompeii and Herculaneum. Phys. Earth Planet. Inter. 118 (3), 227 2

Zeigen, C., Shaar, R., Ebert, Y., Hovers, E., 2019. Archa . nagnetism of burnt cherts and hearths from Middle Palaeolithic Amud Cave, Israel: T or is for reconstructing site formation processes and occupation history. Journal of Arch _ - $\mathrm{lo}_{\varepsilon}$-ical Science 107, 71-86.

\section{Highlights}

- Review of all global archaeomagne+ ic uata;

- Overview of different types of dal and their number;

- Discussion on archaeomagnc tic a nd dating methods;

- verview of geomagnetic fic: 1 n odels for the Holocene;

- Future challenges for archier magnetism. 


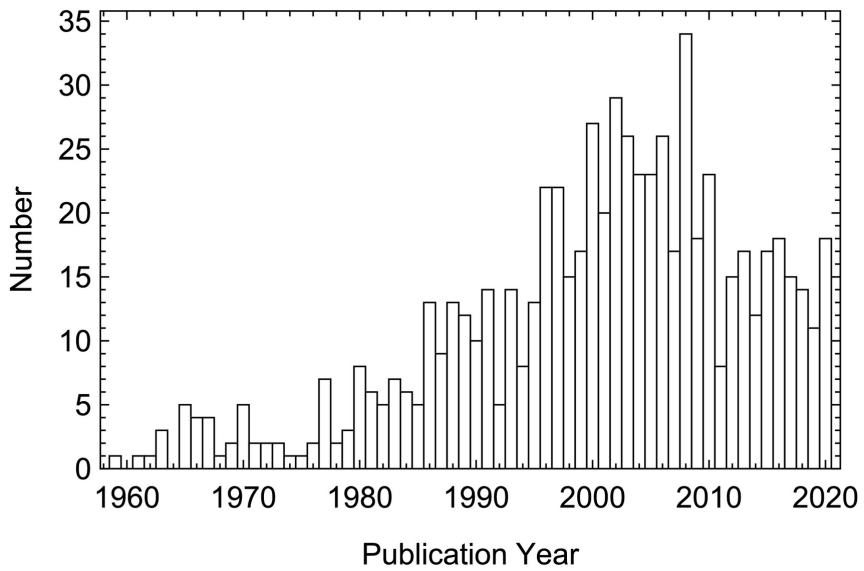

Figure 1 


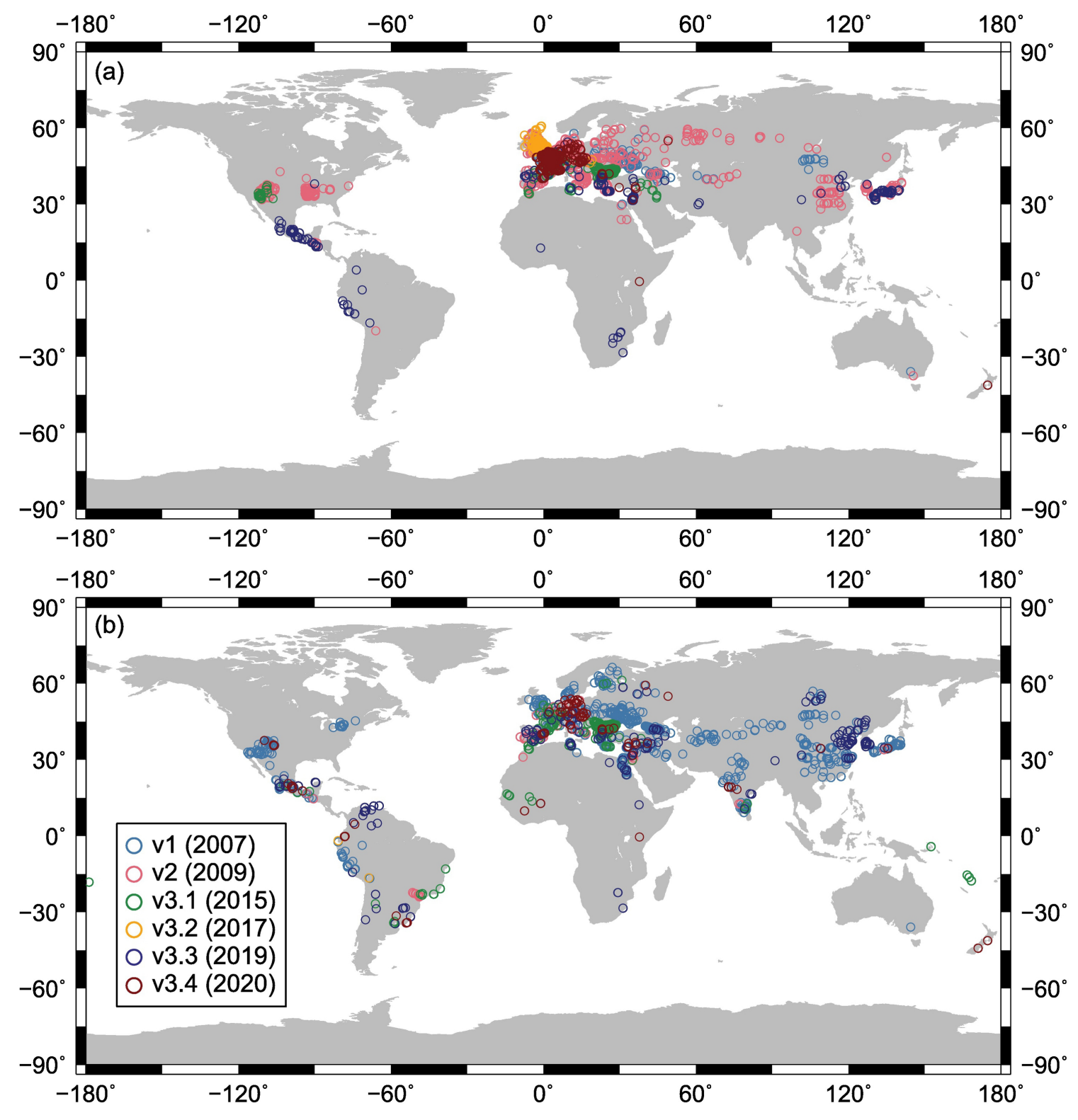

Figure 2 


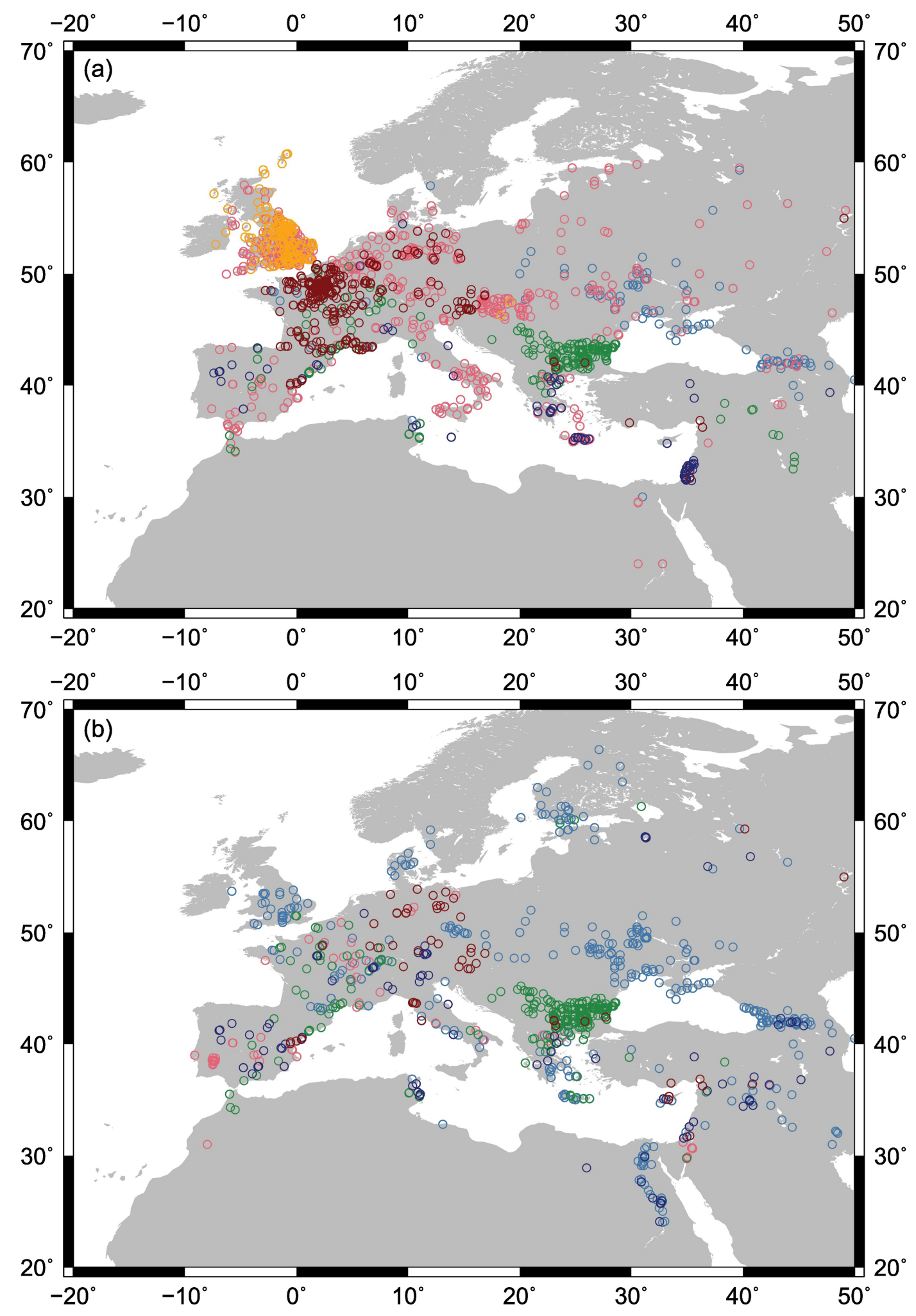

Figure 3 
(a)

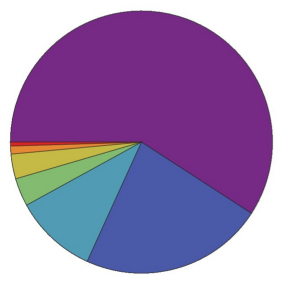

(d)

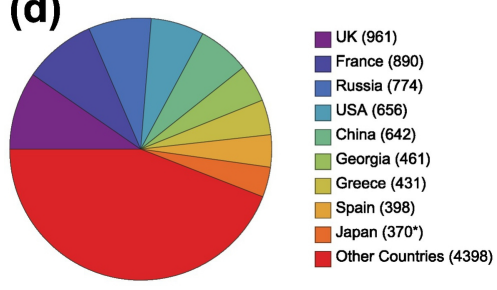

(b)

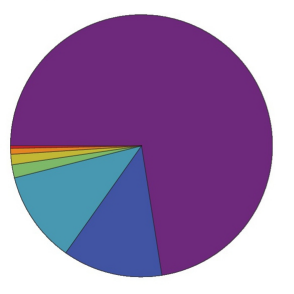

(e)

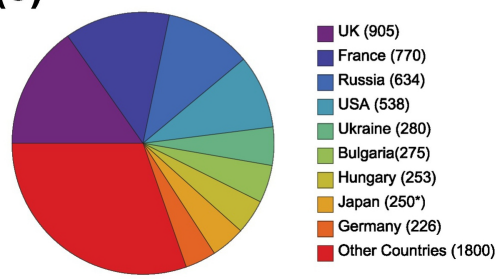

Europe (4301)

Asia (729)

$\square$ North America (668)

$\square$ Africa (96)

$\square$ Central America (76)

$\square$ South America (43)

$\square$ Oceania/Pacific (18) (c)

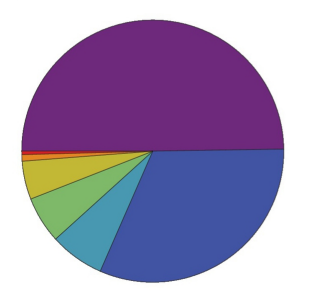

Europe (2603)

Asia (1664)

$\square$ North America (352)

South America (301)

$\square$ Africa (247)

$\square$ Oceania/Pacific (42)

Central America (22)

(f)

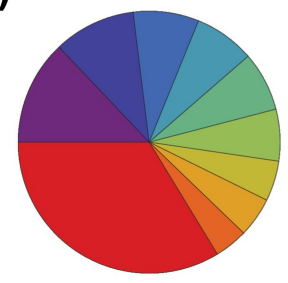

China (547)

Georgia (428)

Greece (343)

Bulgaria (316)

Spain (310)

$\square$ Russia (270)

$\square$ Mexico (210)

$\square$ Iraq (207)

Ukraine (174)

$\square$ Other Countries (2426)

Figure 4 
(a)

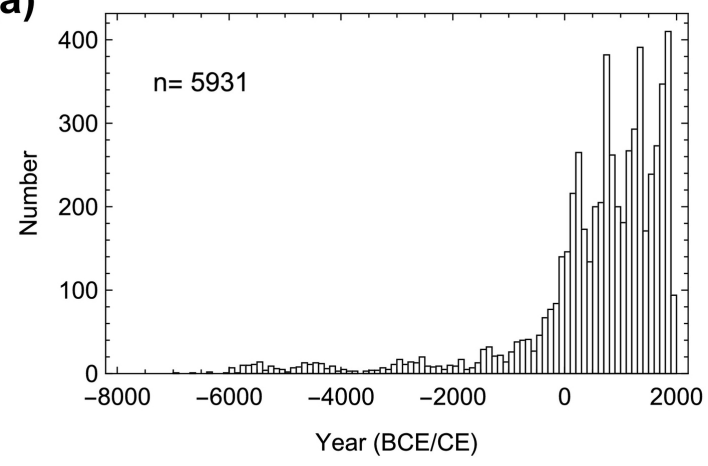

(c)

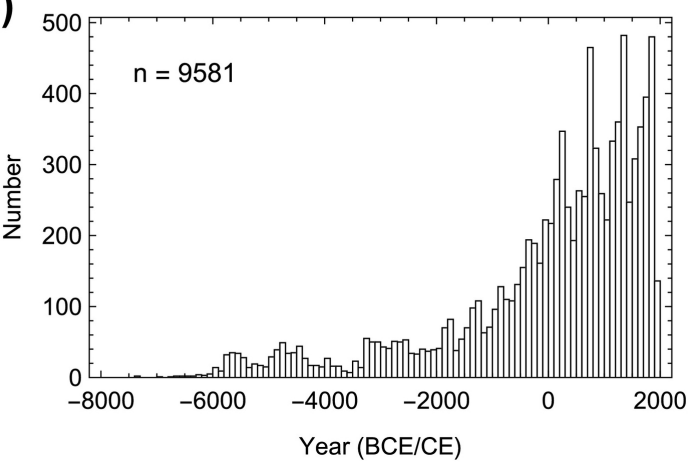

(b)

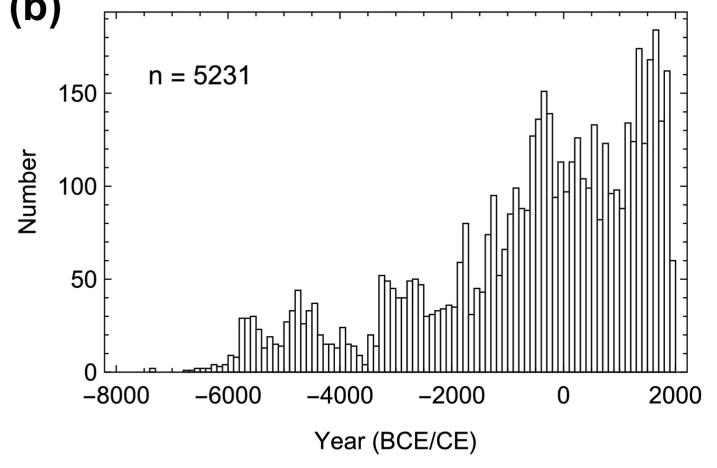

(d)

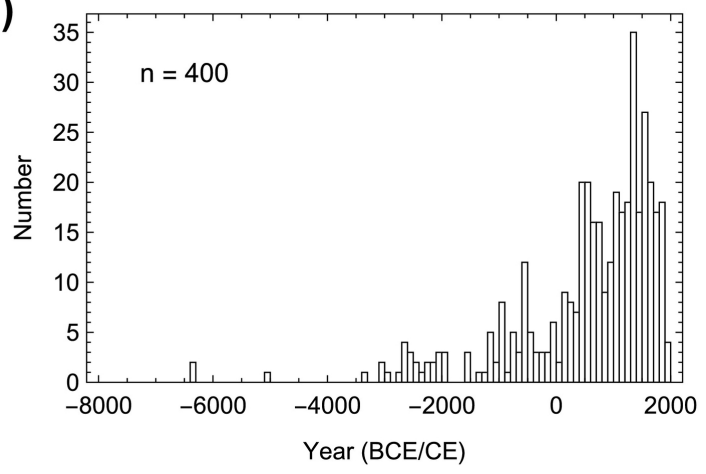

Figure 5 

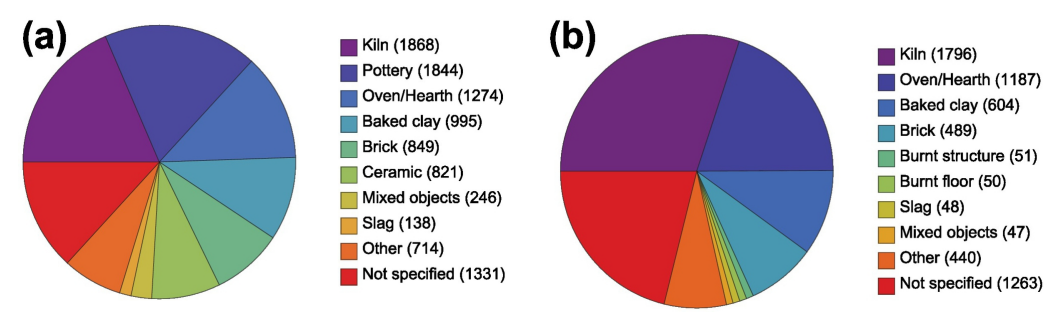

(c)

Figure 6
Pottery (1840)

Ceramic (818)

Brick (804)

Baked clay (604)

Kiln (399)

Oven/Hearth (234)

$\square$ Mixed objects (202)

$\square$ Slag (98)

Other (263)

Not specified (79) 


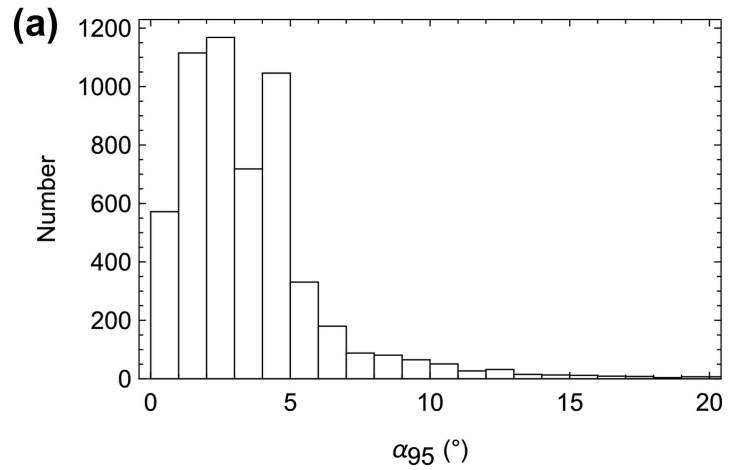

(b)

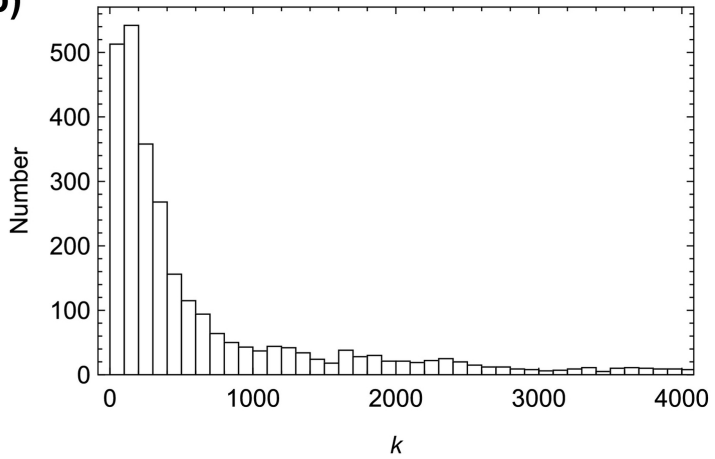

(c)

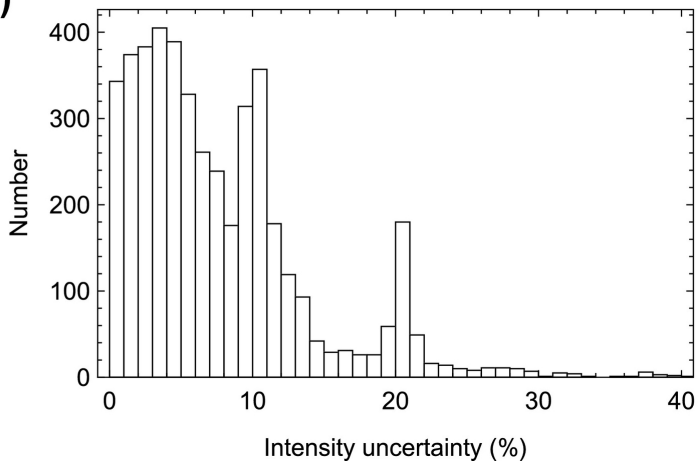

Figure 7 


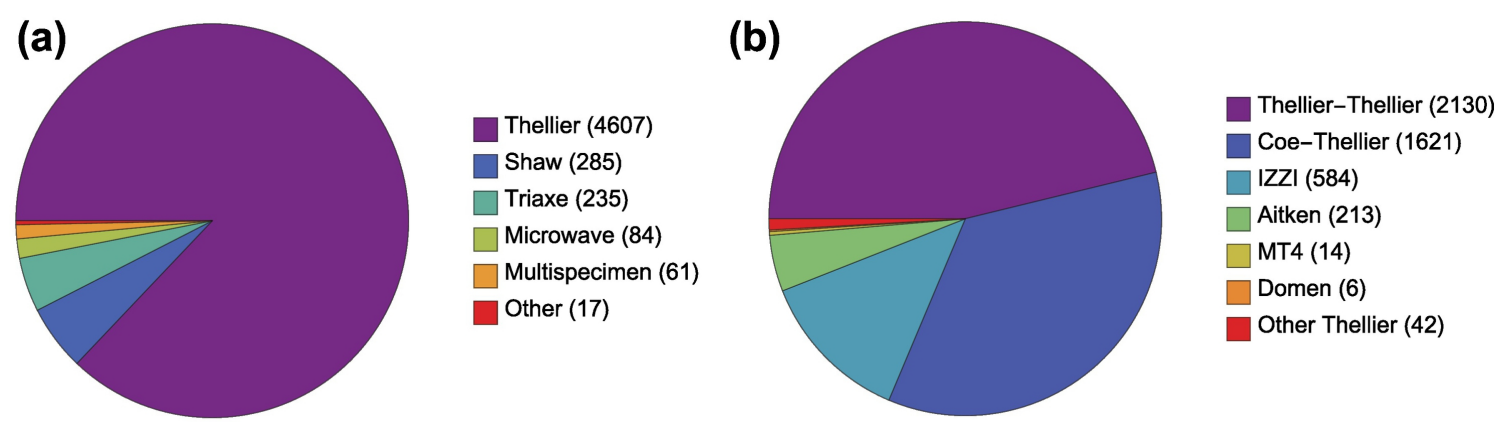

Figure 8 

(a)
(b)

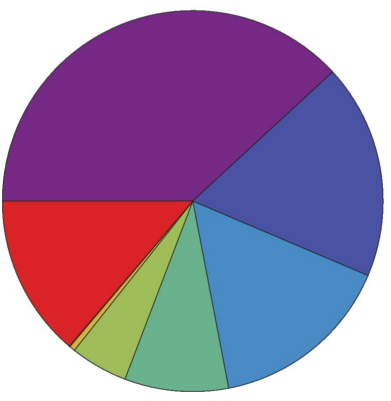

No correction (2046)

TRM tensor (979)

NRM $B_{\text {lab }}$ parallel (836)

Susceptibility tensor (473)

ARM tensor (262)

IRM tensor (26)

Correction not applied (4)

$\square$ Other correction (738)

Figure 9

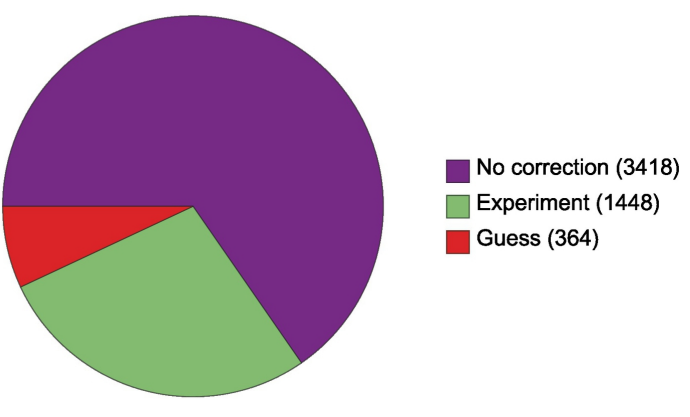




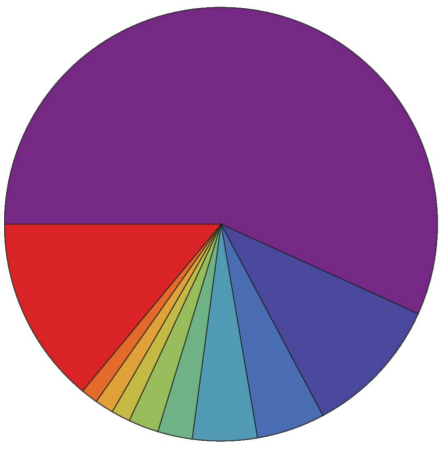

Archaeological (6718)

Calibrated ${ }^{14} \mathrm{C}$ (1233)

Historical (604)

Stratigraphic (571)

$\square$ Uncalibrated ${ }^{14} \mathrm{C}(306)$

Thermoluminescence (266)

$\square$ Relative Chronology (167)

$\square$ Dendrochronology (165)

$\square$ Other (150)

Not specified (1652)

Figure 10 

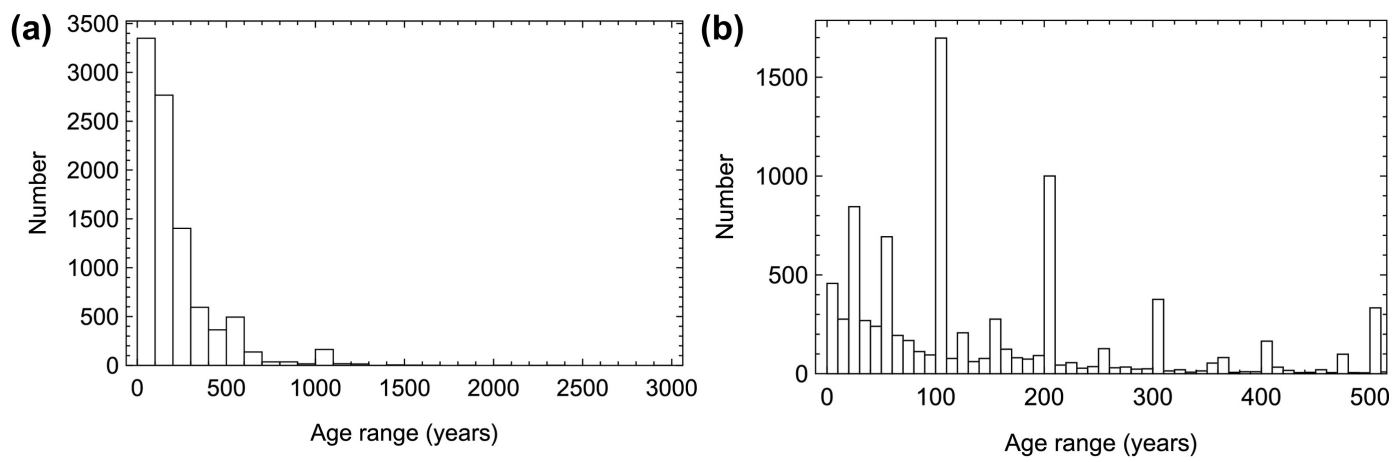

Figure 11 

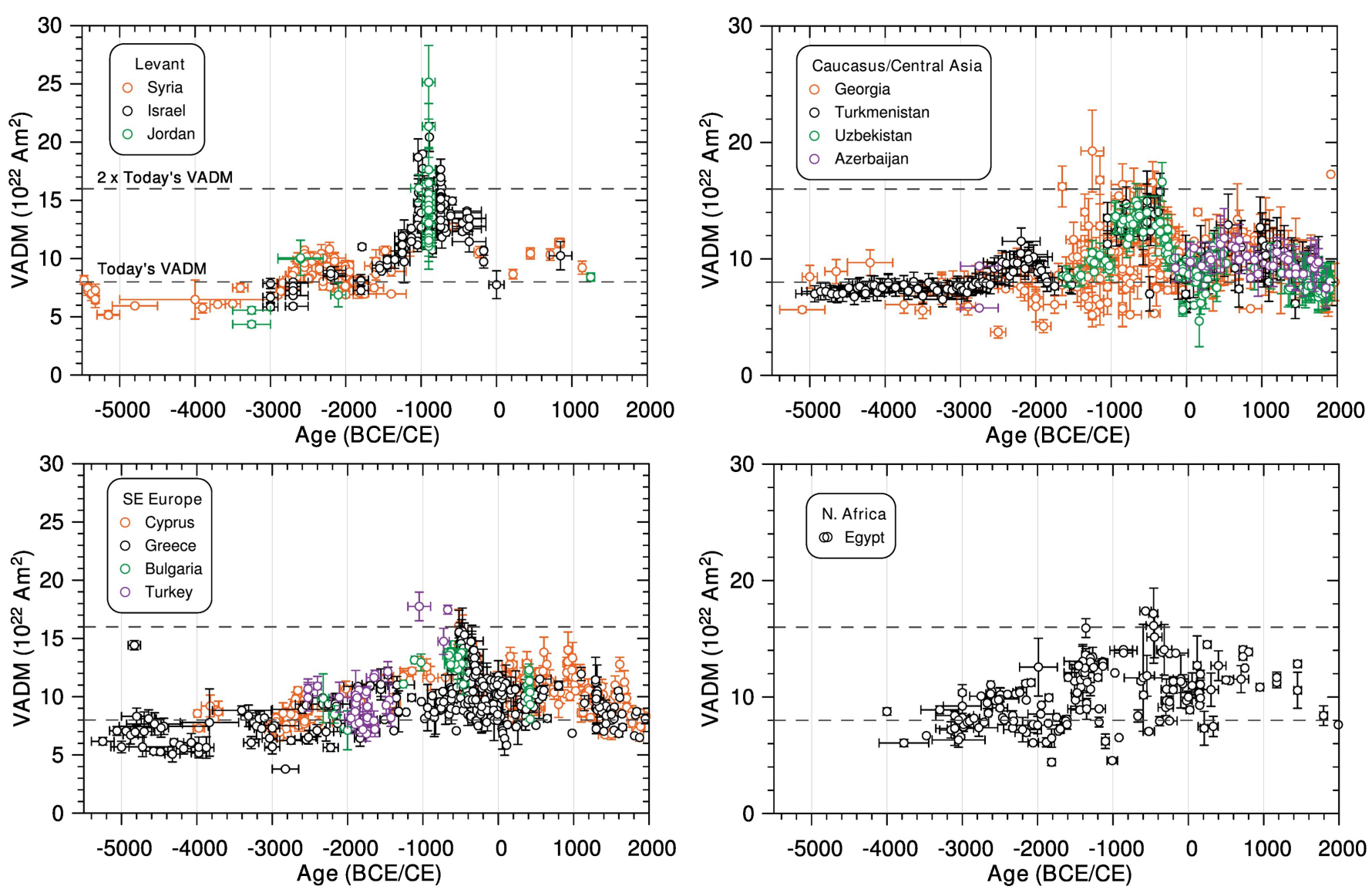

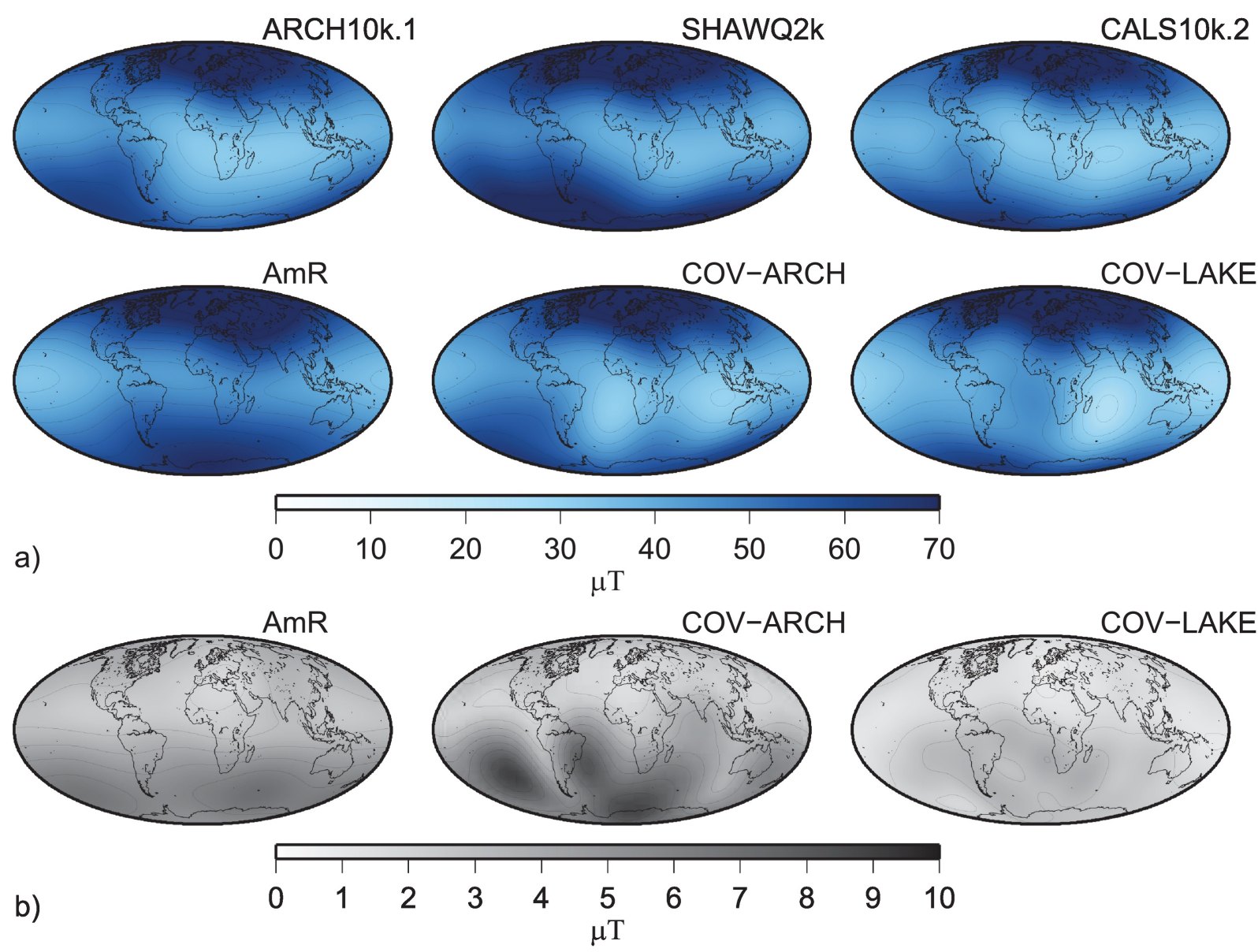
ARCH10k.1
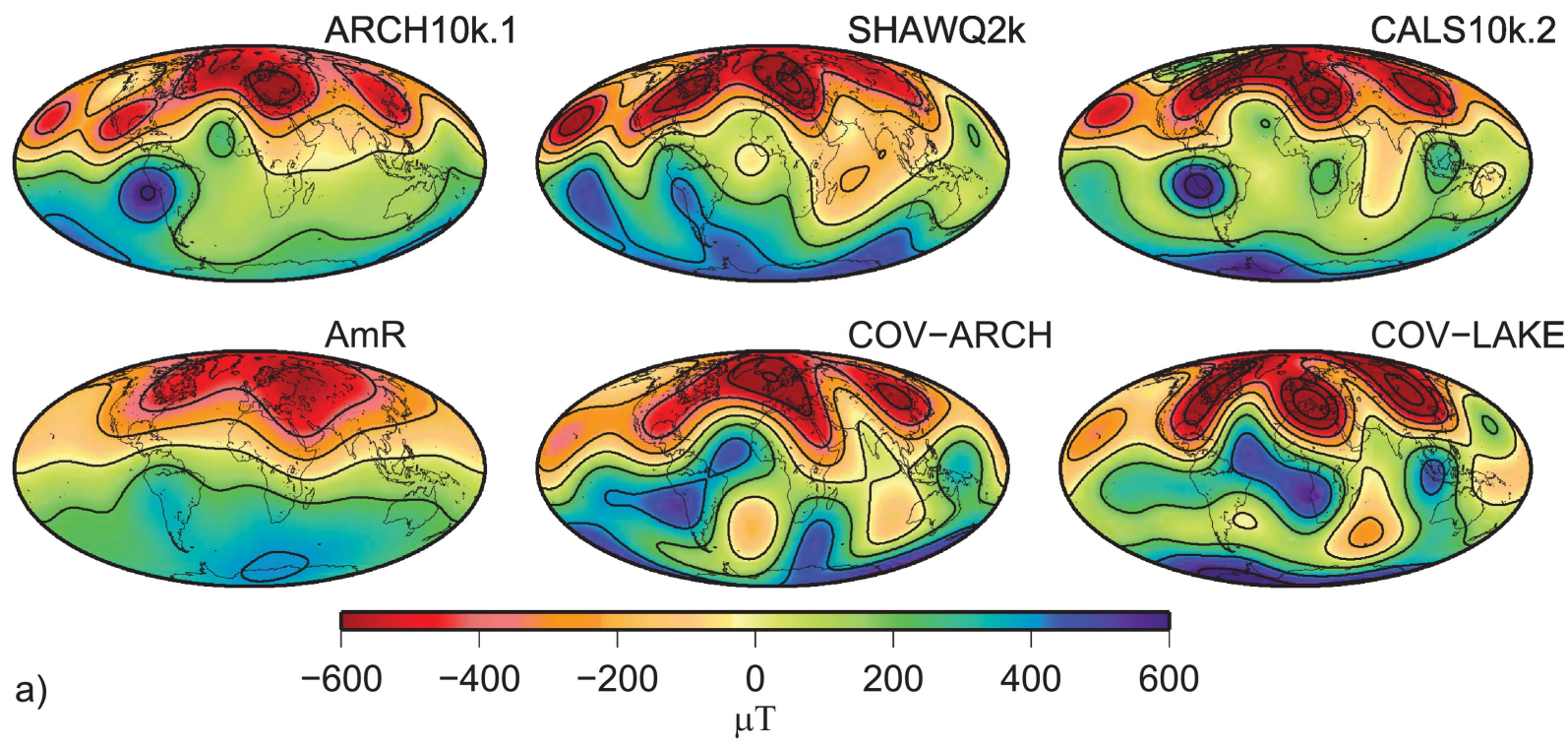

a)
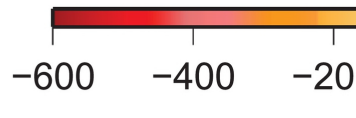

AmR
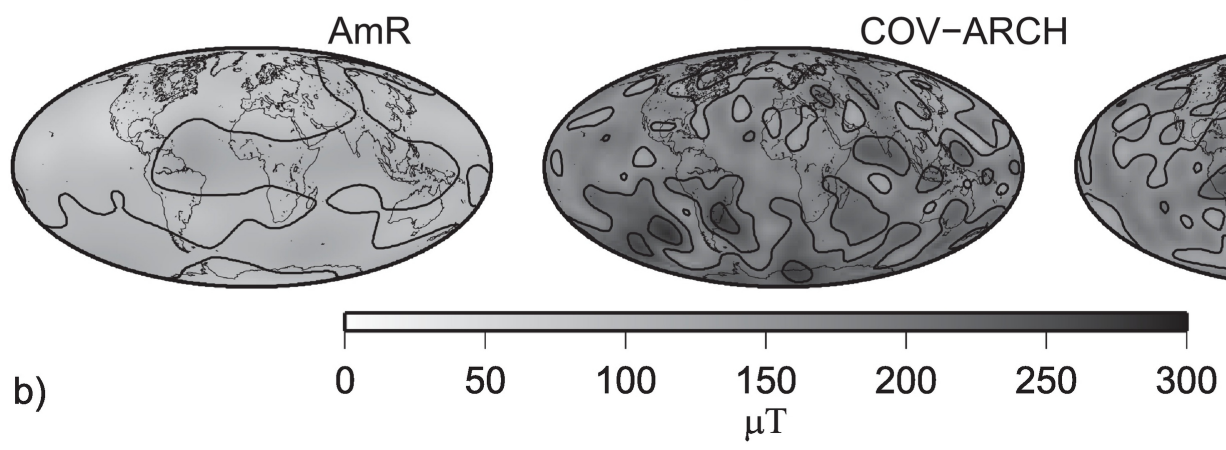

Figure 14 
Paris (48.86 N, 2.35 E)

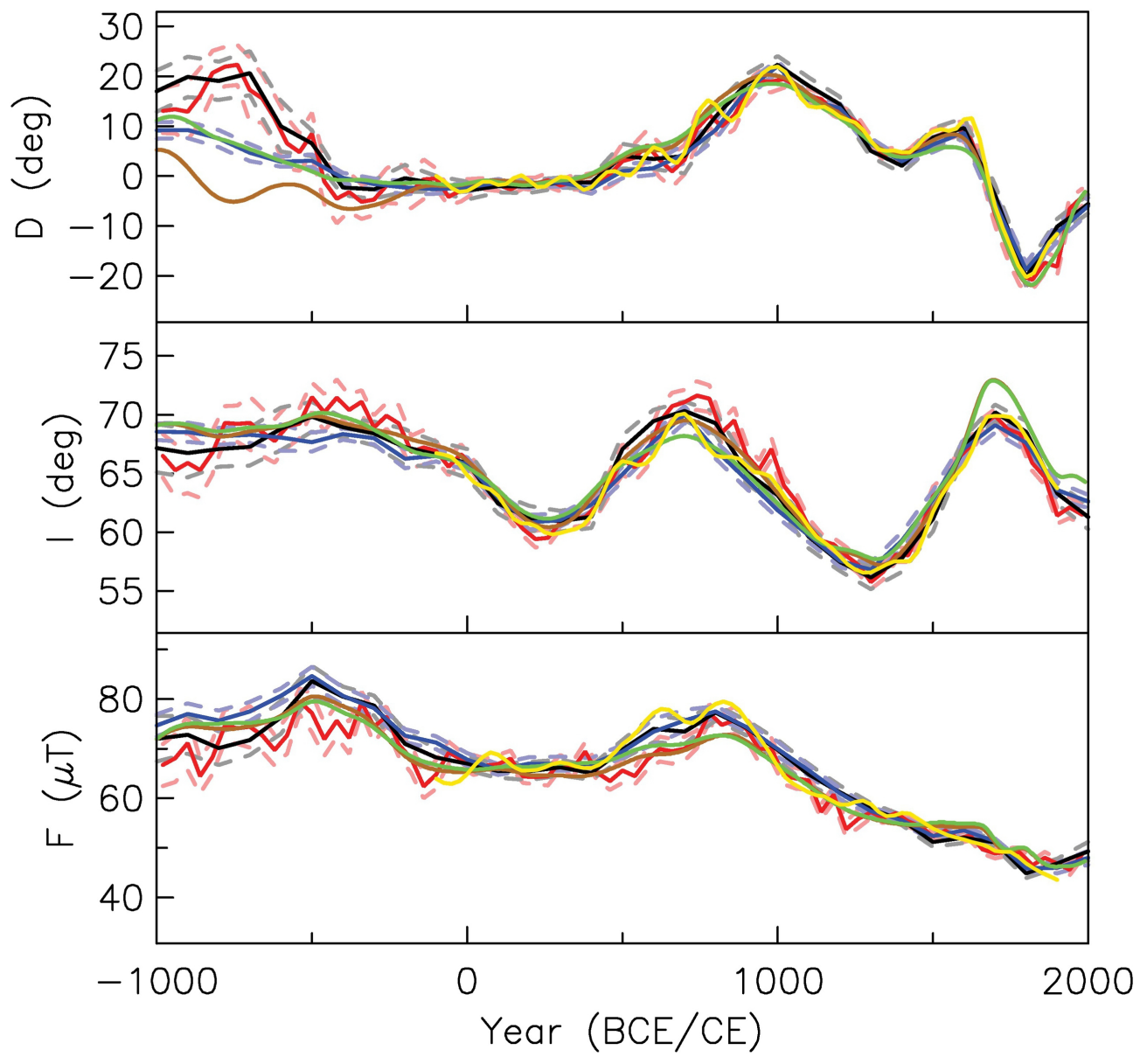

Figure 15 